


\section{Prof. Alfred Hetschko Teschen}

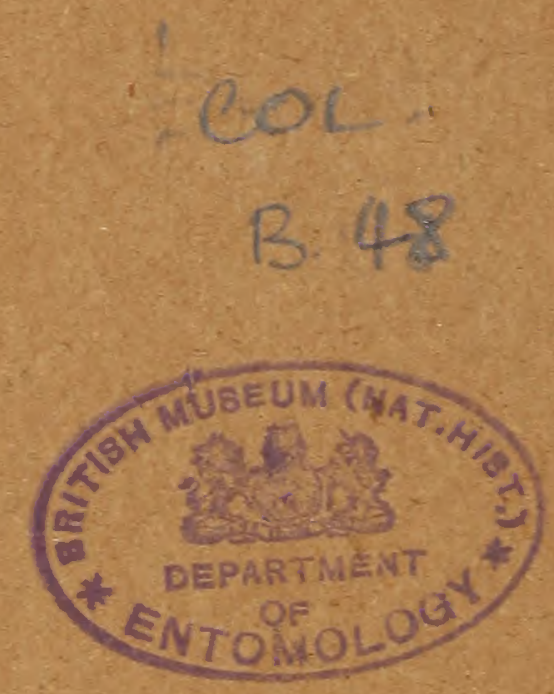

Natural History Museum Library ||||||||||||||||||||||||||||||||| 000013932 




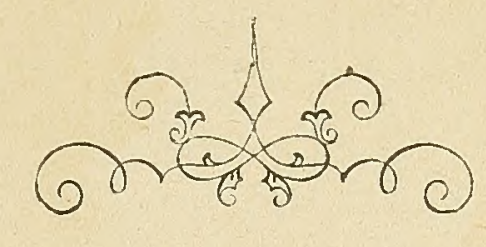

DIE

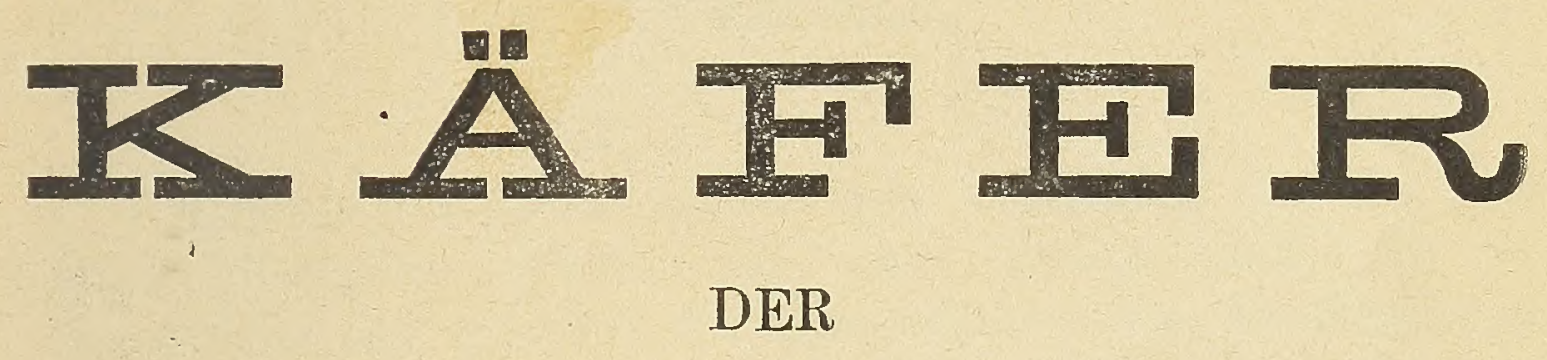

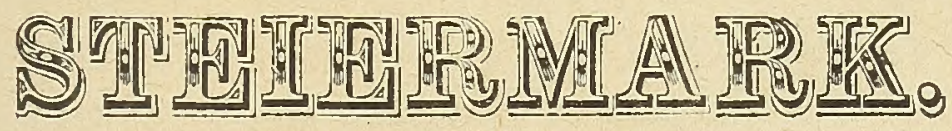

\title{
SYSTEMATISCH ZUSAMMENGESTELLT
}

\author{
VON \\ Carl Prancsik.
}

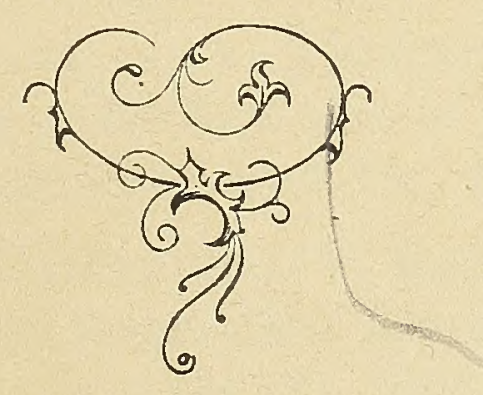

\author{
C R A 18 , $18 \%$.
}

DRUCK VON AUGUST WEPNER. - VERLAG VON PAUL CIESLAR. 


$$
p P \cdot[1 v]+114
$$




\section{Vorrede.}

Indem ich diese Arbeit den Freunden der Entomologie iibergebe, glaube ich eine kleine Liicke in der Kenntniss des grossen Faunengebietes von Deutschland, wenn auch nicht ganz, so doch theilweise ausgefiillt zu haben. Soviel mir bekannt, ist iiber die an entomologischen Schätzen so reiche Steiermark bisher noch keine eingehende Fauna erschienen, wenn ich Grimmers sehr mangellaften Katalog nicht dafuir halten soll.

Werthvollere Anhaltspunkte lieferte mir die von Hochw. Cölestin Kodermann, Stifts-Capitular in St.Lambrecht, in den Heften des naturwissenschaftlichen Vereines für Steiermark veröffentlichten „Käfer der St. Lambrechter Gegend".

Vieles Interessante enthiclten die Aufzeichnungen von Hocliw. Gabr. Stroblüber die Käfer der Umgegend des Stiftes Admont; von hohem Werthe waren inir die die Notizen des Herrn Univ. Prof. Dr. L e it g e b. über das Vorkommen von Coleopteren in der Umgegend von Cilli.

Werthvolle Beiträge liessen mir zukommen die Herren: Tschappek, k. k. Hauptmann-Auditor, Dirnböck, k. k. Verpflegs-Obercommissär in Pension, G. Dorfmeister, k. k. Ingenieur und Dr. Ullrich.

Die reichen Erfahrungen V. Kahrs, des trotz hohem Alter unermiddicken Sammlers, konnte ich nur theilweise einschalten, werde sie aber im Nachtrage, als werthvolles Material verwenden.

Ausgezeichnete Daten gab mir die Einsicht in die reichen Sammlungen, der, um die Kenntniss der Fauna höchst verdienten Herren: F. Gatterer, k. k. Major in 
Pension und J. N. Spitzy, von denen Ersterer besonders die nördliche Steiermark, Letzterer die weite Umgebung St. Leonhards bei Marburg ihrer eingehenden Untersuchung unterzogen.

Von Literatur stand mir nur das ausgezeichnete Werk der Insecten Deutschlands, begonnen von Dr. W. F. Erichson, fortgesetzt von Dr. Schaum, Dr. Kratz und H. von Kiesenwetter zur Verfügung, und ich getenke die Ergebnisse bei Durchsicht der übrigen einschlägigen Literatur im Nachtrage zusammenzufassen.

Meinen grössten Dank allen Denen, die mich durch freundliches Entgegenkommen in meiner Arbeit unterstiutzt haben, sowie auch den ausgezeichneten Entomologen Herrn L. Miller und Hern Dr. G. Kraatz, die mir in der Bestimmung schwieriger Partien hilfreiche Haind boten.

Graz, Mai 1871.

\section{Karl Brancsik.}

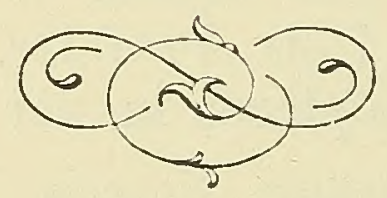




\section{Carabicidae.}

Cicindela. I.

C. campestris. L. Auf sonnigen Waldwegen häufig.

C. hybrida. L. Auf sounigen Waldwegen häufig.

v. riparia Dej. Am Sande der Murufer nicht selten.

C. sylvicola. Dej. Auf sonnigen Waldabhängen nicht häufig.

C. literata v. sinuatu. Fabr. Am Mursande bei Graz. (Gr. Sp.)

C. germanica. L. Auf Feldern nicht selten.

\section{Omophron. Latr.}

O. limbatus. Fabr. Aeusserst selten am Ufer des Holzerteiches bei St. Lambrecht (Kod.), häufiger im Mursande bei Graz.

\section{Notiophilus. Drum.}

N. aquaticus. $L$. Unter Steinen und Moos häufig.

N. palustris. Duft. An feuchten Stellen unter Moos und Laub.

N. biguttatus. Fabr. Mit Vorigen in Gemeinschaft.

N. punctulatus. Wesm. Von Kahr in Steiermark gefunden.

Elaphrus. Fabr.

E. uliginosus. Fabr. Auf sandigen Ufern bei St. Leonhard, (Sp.), an Pfützen um Cilli (Ltgb.)

E: cupreus. Duft. An Teichufern bai Admont (Strb.), an Utern der Sann (Ltgb.)

E. Ultrichii. Redt. Auf sandigen Ufern der Enns und Mur.

E. riparius. $L$. Am Sande der Mur oft häufig.

E. aurens. Milll. An der Inur bei Graz(Br.), bei St. Lambrecht (Kod.)

\section{Blethisa. Bon.}

B. multipunctata. L. Am Ufer der Hungerlache bei Mariahof selten (Kod.), häufiger in ausgetrockneten Sümpfen bei St. Leonhard (Sp.)

\section{Cychrus. Fabr.}

C. angustatus. Hop. Unter Steinen um St. Lambrecht sehr selten (Kod.), auf feuchten Wiesen um Graz (Gr.)

C. rostratus $L$. Im Gebirge unter Steinen häıfig. $v$. elongatus. Hop. Unter Steinen am Schöckl (Gr.), Neuberg (Drbk.)

C. attenuatus. Fubr. In Gebirge unter Steinen häıfig. 


\section{Procerus. Dej.}

P. gigas. Creutz. Bei St. Leonhard selten (Sp.', häufiger um Cilli $(\mathrm{Ltg} \cdot \mathrm{b}$.

\section{Carabus. L.}

C. coriaceus. L. Im Gebirge unter Steinen und Holzstiicken.

C. nodulous. Creutz. An nassen sumpfigen Stellen im Gebirge.

C. intricatus. $L$. In schattigen Wäldern unter Steinen.

C. Fabricii. Panz. Unter Steinen auf höheren Alpen Nord-Steielmarks.

C. Creutzeri. Fabr. Am Bacher bei Marburg in morschen Holzstöcken selten (Sp.)

C. ivegularis. Fabr. Im Gebirge unter Steinen.

C. auronitens. Fabr. Im Gebirge unter Steinen nicht häufig.

C. clathratus. $L$. An einer sumpfigen Stelle auf der Kleinalpe (Drfmster.)

C. Ullrichii. Germ. Auf Feldwegen um St. Lambrecht häufig (Kod.), seltener um Graz.

C. cancellatus. Fabr. Auf Feldern häufig.

$v$. emarginatus, Duft. Am Nikolaiberge bei Cilli (Ltgb.) granulatus. L. Auf Feldern häufig. v. interstitialis. Duft. Auf Feldern bei Karlau (Tpk.) arvensis. Fabr. In schattigen Wäldern unter Steinen.

C. catenatus, Panz. Bei St. Lambrecht 1 Exempl. (Kod.), häufig um Cilli (Ltgb.)

catenulatus. Scop. Unter Steinen im Gebirge.

C. nemoralis. Ill. Unter Steinen im Gebirge.

C. convexus. Fab. In Wäldern unter Laub und Steinen.

C. hortensis. L. Unter Steinen und Holzstiicken.

C. Linnei. Panz. Unter Steinen bei Neuberg. (Dirbk.)

C. sylvestris. Fabr. Im Gebirge nicht häıfig.

$v$. alpestris. Sturm. Auf höheren Alpen unter Steinen häufig.

v. Hoppii. Germ. Bei St. Lambrecht (Kod.)

v. alpinus. Dej. Am Hochschwab (Sp.)

C. scabriusculus. L. In Wäldern bei St. Leonhard (Sp.)

C. Scheidleri. Fabr. Am Buchkogel bei Graz (Mglch.)

C. glabratus. Payk. In Wäldern unter Steimen.

C.violaceus. L. Wie Voriger.

v. purpurascens. Fabr. Bei St. Lambrecht (Kod.)

v. Germari. Sturm. Nach Dejean in Steiormark.

\section{Calosoma. Web.}

C. inquisitor. L, Um St. Leonhard auf Eichen häufig (Sp.)

C. sycophanta. L. In Gärten immer nur einzeln und selten.

\section{Nebria. Latr.}

C. picicornis. Fahr. An dor Mur häufig.

N. brevicollis. Fabr. Unter Steinen und Laub nicht hänfig.

N. Jokischii. Sturm. Auf Alpen im nördlichen Steiermark nicht selten. 
1. Gyllenhalii. Schh. An den Ufern der Miirz häufig. (Gat.)

N. Dahlii. Duft. In den Steiner-Alpen (Gob.), und den angrenzenden steierischen Gebirgen.

N. fasciatopunctata. Mill. Auf höheren Alpen unter Steinen, an Quellen und kleinen Bächen.

N. Jlellurigii. Panz. An Quellen und Bächen auf den Alpen NordSteiermarks.

v. stigmula. Dej. An Alpenbächen selten. (Kod.), 'Teichalpe (Gr.)

$N$, Dejeanii. Dej. Von Miller und Kahr in den steierischen Alpen gesammelt.

N. castanea. Bon. An Quellen unter Steinen auf höheren Alpen Nord-Steiermarks.

v. brumea. Duft. Auf der Zirbis-Alpe (Kod.) Schneealpe (Drnk.)

N. angustata. Dej. In den Steineralpen von Goban's gefunden worden, wahrscheinlich auch im angrenzenden steirischen Gebirge vorkommend.

\section{Leistus. Fröhl.}

L. nitidus. Duft. Unter Steinen in Gebirge nicht häufig.

L. rufomarginatus. Duft. In Wäldern unter Laub und Steinen.

L. ferruginens. L. An Baumstämmen bei Eggenberg (Gat.)

L. rufescens. Fabr. Unter Laub und Steinen bei St. Leonhard (Sp.) bei Admont (Stbl).

L. piceus. Fröhl. Im Gewirge, im Moder alter Baumstämme.

Clivina. Latr.

C. fossor. L. Auf sandigen Ufern unter Steinen häufig.

\section{Dyschipius. Bon.}

D. rotundipennis. Chand. Unter schimmligem Moos am Bacher bei Marburg selten (Sp. Br.)

D. rufipes. Dej. An sandigen Stellen bei St. Leonhard (Sp).

D. globosus. Herbst. Unter Moos im Gebirge häufig.

D. laevinsculus Putz. Ain Mursande bei Graz selten (Gat.)

D. pussillus. Dej. An sandigen Stellen bei St. Leonhard (Sp.)

D. substriatus. Duft. Am Mursande bei Graz (Br.), St. Lambrecht (Kod.)

D. nitidns. Dej. An Sande der Dran bei Marburg (Sp.)

D. politus. Dej. Am Mursande häufig.

D. digitatus. Dej. Nach Erichs. Ins. Dentschlands in Steiermark vorkommend.

D. thoracicus. Rossi. Am Mursande selten.

D. aeneus Dej. An sandigen Stellen bei St. Leonhard (Sp.)

\section{Aptinus. Bon.}

A. mutilatus. Fahr. Auf Alpen im nördlichen Steiermark häufig unter Steinen.

\section{Brachinus. Web.}

B. srepitans. L. Unter Steinen häufig.

B. explodens. Duft. Unter Steinen sehr häufig. v. glabratus. Dej. 


\section{Drypta. Fabr.}

D. dentata. Rossi. Unter Steinen und Moos; Ulriclisbrunn bei Graz ('Tpk.), Voitsberg (Ulrch.), St. Leonhard (Sp.)

\section{Odacantha. Payk.}

O. melanura. L. Auf Schilf im Thal-T'eich bei Graz (Gr.), bei St. Leonhard (Sp.)

\section{Aëtophorus. Schm.-Goebl.}

A. imperialis. Germ. Nach Angabe Grimmers am Schöckl?

Demetrias. Bon.

D. atricapillus L. An 'Teichufern bei St. Leonhard (Sp.), am F'usse des Bacher bei Marburg von Erlen geklopft (Br.)

D. unipunctatus Germ. Mit Vorigem in Gesellschaft (Sp.)

\section{Dromilus. Bon.}

D. longiceps. Dej. Nach Erichs. Ins. Deutschlands in Steiermark vorkommend.

D. linearis. Ol. Unter Moos an Baumstämmen.

D. agilis Fabr. Unter Baumrinden nicht selten.

D. fenestratus Fabr. Unter Moos, auf diurrem Holze, unter Rinden im Gebirge nicht selten.

D. quadrimaculatus $L$. Unter Moos, an Baumstämmen häufiğ.

D. quadrinotatus. Panz. Unter Moos an Baumstämmen (Gr. Sp.)

D. quadrisignatus. Dej. Unter Hoos an Bammstämmen (Gat.)

D. nigriventris. Thoms. Unter Baumrinden suhr häufig (Kod. Sp.)

D. sigma Rossi. Unter Moos bei St. Leonhard (Sp.)

Blechrus. Schmidt-Goebl.

B. glabratus. Duft. Unter Moos an Baumstïmmen (Gat.)

B. maurus. Stum. Unter Moos (Gr.)

\section{Metabletus. Schmilt-Gocbl.}

11. obscuroguttutus. Duft. Unter Moos auf feuchten Wiesen bei St. Leonhard (Sp.)

I. pallipes. Dej. Unter Moos bei St. Leonhard (Sp.)

M. truncatellus. L. Unter Moos und Steinen hïufig.

1I. punctatelius. Duff. Unter Moos und Steinen häufigs. Aprostus. Chamd.

A. quadrillum. Duft. Au sandigen Ufern niclit selten.

sLebia. Latr.

L. cyanocephala. I. Unter Steinen.

L. chlorocephala. Ent. Heft. Unter Steinen.

L. crux minor. I. Anf biiinonden Sträuchern. unter Steinen.

L. haemorhoidalis. Fabr. Wie Vorige.

L. humeralis. Sturm. Auf blïhenden Sträuchern, unter Nloos im siidlichen Steiermark selten.

\section{Cymindis. Latr.}

C. humeralis, Eabr. 1n Wäldern unter Steinen. 
C. cingulatu. Dej. Unter Steinen im Gebirge sulten; Zirbisalpe (Korl.), Schöekl (Gat.)

C. axillaris. Fabn. Unter Steinen imGebirge nicht solten.

C. coadunata. Dej. Bei 'St. Lambrecht (Kod.)

C. angularis. Gyll. Auf der Grebenze sehr selten (Kod.)

C. vaporariorum. L. Auf Alpen selten (Kod. Gat.)

\section{Loricera. Latr.}

L. pilicornis. Fabr. An Pfiitzen nicht häufig.

Panagaeus. Latr.

$P$. crux major. L. Unter Steinen nicht häufig.

P. quadripustulutus. Sturm. Unter Steinen und Liub.

\section{Callistus. Bon.}

C. lunatus. F'abr. Unter Steinen.

\section{Chlaenins. Bon.}

Ch. spoliatus. Rossi. Häufig an Teichufern bei St. Leonhard (Sp.)

Ch. vestitus. Payl. Unter Steinen nicht häufig.

Ch. Schrankii. Duft. Unter Laub und Steinen.

Ch tibialis. Dej. Unter Steinen um Graz (Gat.), am Ufer der Enns (Stbl.)

Ch. nigricornis. Fabr. Unter Steinen.

Ch. holosericeus. Fabr. An Teichufern; im Thal bei Graz (Gat.) häufig um St. Leonhard (Sp.)

Ch. arureus. Duft. Auf Feldern bei St. Leonhard (Sp.)

\section{Dodes. Bonl.}

O. helopivides. Fabn. Unter angeschwemmtem Reisig an der Ënns (Stbl.), häufiger an Teichufern bei St. Leonhard (Sp.)

\section{Licinus. Latr.}

L. aernatus, Dej. Nach Angabe Spitzy's bei St. Leonlard.

L. cussideus. Fubr. An trockenen Stellen bei St. Leonhard (Sp.)

L. depressus. Payli. Unter Stēinen.

L. Iloffmannseggü. Pan:. Im Gebirge unter Steinen häufig.

\section{Badister. Clair.}

B. unipustulatus. Bon. Bei St. Leonhard (Sp.)

B. bipustulatus. Fabr. Unter Steinen nicht selten.

B. lumeralis. Bon. Unter Steinen selten (Gr. Sp.)

B. peltatus. Pans. An T'eichen 1 m St. Leonhard (Sp.)

Broscus. Panz.

B. cepluculotes. L. Unter Steinen im südlichen Steiermark.

Pogonus. Dej.

P. luridipennis. Germ. An der Kainach bei Voitsberg (Ulrich.) P. riparius. Dej. Im Sande an Bächen bei St. Lambrecht. (Kod.)

\section{Patrobus. Dej.}

Pexcavatus. Payk. Unter Steinen nicht häufig. 


\section{Sphodrus. Gair.}

S. leucophlhalnus L. Bei St. I.eonhar! (Sp.)

Calathus. Bon.

C. cisteloides. Ill. Unter Steinen häufig.

C. fulvipes Gyll. Anf Alpen unter Steinen.

C. fuscus. Fabr. Unter Steinen häufig.

C. mollis. Marsh. Auf der Kuhalpe unter Steinen selteu (Kod.)

C. melanocephalus. Duft. Unter Steinen sehr häufig. $v$. alpinus. Dej. Auf Alpen.

C. micropterus. Duft. Auf Alpen unter Steinen liäufig.

Taphria. Bon.

T. nivalis. Panz. Unter Steinen selten, bei Graz ('Tpk.), St. Leonhard (Sp.)

\section{Dolichns. Bon.}

D. flaviconis. Fabr. Unter Steinen nicht eben läufig.

Anchomenus. Er.

A. scrobiculatus. Fabr. In Gebirge unter Steinen an Quellen.

A. angusticollis. Fabr. Unter Steinen an Bächen und Flissen.

A. prasinus. Thunh, Unter Steinen selsr gemein.

A. albipes. Faln. An der Mur sehr liänfig.

A. oblongus. Hebr. An sandigan Stellen; bei Graz (Gat.), St. Leunhard (Sp.)

A. marginatus. L. Unter Steinen nicht selten.

A. impressus. Panz. Unter angeschwemmtem Reisig an Bächen und Fliissen.

A. sexpunctatus Fubr. Unter Steinen im Gebirge.

A. parampunctatus. Fabr. Unter Steinen lıäufig.

A. elongatus. Dej. Am Mursande bei Graz (Gr.)

A. austriacus. Fruln. An sandigen Ufern bei Graz (Mglch.), St. Leonhard (Sp.)

A. viduris. Parz. An sandigen Uferm häufig. v. moestus. Duft. Mit dem Vorig'en.

A. versutus. Sturn. Unter Laub in Mariahof selten (Kod.), häufig an 'Teichen bei St. Leonhard (Sp.)

A. subaeneus. Dej. An Teichen bei. St. Leonhard (Sp.)

A. micans. Nicol. Am 'T'eiche in Thal bei Graz (Gat.)

A picipes. Fabr. Unter Laub in Mariahof (Kod.)

A. gracilis. Stum. An 'T'eichufern um St. Leonhard (Sp.)

A. fuliginosus. Panz. An Pfiitzen und T'eichen bei Arlmont (Stbl.), St. Lambrecht (Kod.), Cilli (Ltgb.)

A. pusllus. Dej. Unter angeschwemmtem Reisig bei Admont (Stbl.)

Clisthopus. Dej.

O. rotundatus. Payl. Im Bachergebirge unter Steinen (Sp.)

O. glabricollis. Germ. Unter Steinen (Sp.)

Stomis. Clair.

St. pumicatus. Pans. Unter Steinen nicht häufig. 
St. rostratus. Sturm. Nach Erichs, Ins. Dentschlands in Steiermark vorkommend.

\section{Platylerus. Steph.}

P. rufus. Duft Am Schöckl (Ulrich, Gat.)

Feronia. Iatr.

F. cuprea. L. Auf Feldern, unter "Steinen häufig.

F. Koyi. Germ. Am Feldwege unterm Rainerkogel bei Graz (Br.)

F. lepida. Fabr. Unter Steinen liäufig.

F. subcoerulea. Schi. Auf Feldwegen, in der Göstinger-Au (Gat. Sp.)

F. vernalis. Panz. Unter Steinen und Holzstiicken.

F. aterrima. Payk. Bei St. Leonhard nnter Steinen selten (Sp.) häufiger am Schlossberge bei Cilli (Ltgb.)

F. inaequalis. Payk. Unter Steinen am Bacher (Sp.)

F. elongata. Duft. An 'Teichufern bei St. Leonhard (Sp.)

F. nigra. Schall. Unter Steinen im Gebirge.

$F$. melanario. Ill. Unter Steinen häufig.

$F$. nigrita. Fabr. Unter Steinen läufig.

$F$. anthracina. Ill. In Gebirge unter Steinen.

F. gracilis. Dej. Unter Steinen bei St. Leonhard (Sp.)

F. minor. Gyll. Unter Steinen bei Admont (Stbl.)

F. erudita. Dej. Unter Steinen im Gebirge (Gr. Gat.)

F. stremua. Parz. In Gebirge unter Steinen nicht lï̈nfig.

F. nivalis. Bris. Im nördlichen Steiermark auf Alpen (Gat.)

F. negligens. St Am Ufer der Bäche bei St. Lambrecht selten (Kod.)

F. oblongopunctata. Fabr. In Gebirge läufig unter Steinen.

F. angustata. Duft. Bei St. Lambrecht sehr selten (Kod.), häıfiger auf der Teichalpe unter Steinen (Gat. Br.)

Fr. aethiops. P'anz. Unter Steinen auf Alpen selten.

F. Illigeri. Punz. Im nördalichen Steiermark unter Steinen sehr liäufig.

F. melas. Crentz. Unter Steinen, bei Graz (Gat.), bei St. Leonhard (Sp.)

F. Kolieilii. Mill. Nach Erichs. Ins. Deutschlands in Steiermark vorkommend.

F. maura. Duft. Im nördlichen Steiermark auf höheren Alpen nicht selten.

F. Jurinei. Panz. In Gebirge unter Steinen häufig.

F. Welensii. Dej. Nach Erichs. Ins. Deutschlands in Steiermark vorkommend, von Gobanz in den angrenzenden Steineralpen häufig gefunden worden.

F. Selmanni. Duft. Auf der Teichalpe nnter Steinen und Holzstiicken liäufig, anch anf der Zirbisalpe aber səlten (Kod.)

F. fasciatopunctata. Creutz. Im Gebirge nicht selten.

F. Justusii. Redt. Am Bachergebirge unter Steinen (Sp. Gat.), auch auf der Choralpe gefunden worden.

F'. Ziegleri. Duft. Anf Alpen $n$ m Admont (Sthl), St. Lambrecht (Koil.) 
F. lineatnpunctata. Mill. Nach Erichs. Ins. Deutschlands in Steiermark vorkommend.

F. Panzeri. Panz. Im nördlichen Steiermark auf Alpen nicht selten.

F. Mühlfeldi. Duft. Nach Erichs. Ins. Dentschlands in Steiermark vorkommend, von Gobanz in den angrenzenden Steiner-Alpen gefunden worden.

F. metallica. Fals. Im Gebirge unter Steinen häufig:

F. transversalis. Duft. Im Gebirge nicht häufig.

F. unctulata. Duft. Im Gebirge sehr häufig unter Steinen.

F. subsinuata. Dej. Unter Steinen im Gebirge (Gr.) (?)

F. pusilla. Dej. Auf höheren Alpen im nördlichen Steiermark (Gat.)

F. striola. Fabr. Unter Steinen im Gebirge häufig.

v. parallelopipeda. Dej. Bei St. Leonhard selten (Sp.)

F. carinata. Duft. Unter Steinen selten.

F. ovalis. Duft. Im Gebirge unter Steinen.

F. parallela. Duft. Im Gebirge unter Steinen

F. striolata Falr. Bei St. Lambrecht 1 Ex. gefangen (Kod.)

E. elata. Fabr. In schattigen Wäldern unter Steinen.

F. terricola. Fabr. In Wäldern unter Steinen und Lanb.

\section{Amara. Boil.}

A. rufipes. Dej. An trockenen Feldwegen im siidlichen Steirrmark, St. Leonhard (Sp.), Cilli (Ltgb.).

A. similata. Gyll. Auf den Alpen bei St. Lambrecht selten (Kod.)

A. obsoleta. Dej. Auf Feldern sehr häufig.

A. montivaga. Stum. Unter Stainen bei St. Lambrecht selten (Korl.)

A. nitida. Sturm. Auf Feldwegen häufig.

A. communis. Panz. Auf Feldwegen häufig.

A. curta. Dej. Unter Steinen bei Graz selten (Gat)

A. spreta. Dej. Gibt Kodermann als bei St. Lambrecht gefangen an.

A. trivialis. Gyll. Auf Feldwegen sehr häufig.

A. acaminata. Payk. Auf Feldern.

A. familiaris. Duft. Auf Feldern unter Steinen.

A. lucida. Duft. Auf Feldwegen sehr häufig.

A. municipalis. Duft. Auf Feldwegen bei St. Lambrecht (Kod.)

A. erratica. Duft. Auf den Alpen des nördlichen Steiermark am schmelzenden Schnee nicht selter.

A. rufocinata. Schlb. Auf trockenen Grasplätzen bei St. Lambrecht selten (Kod.)

A. dalmatina. Dej. An den Ufern der Mur bei Graz 2 Exempl. (Miller.)

A. nobilis. Duft. Auf der Schneealpa bei Neuberg' oft sehr häufig unter Steinen (Gat.)

A. cuniculina. Dej. Auf Alpen um Admont sehr selten- nuter Steinen (Stbl.)

A. alpicola. Dej. Nach Erichs. Ins. Dentschlands in Steiermark vorkommenil. 
A. mlico. Pans. Unter Laub und Steinen bei Admont (Stbl.), St. Lambrecht (Kod.)

A. consularis. Duft. Bei St. Lambrecht unter Steinen sehr selten (Kod.)

A. fulva de Geer. Unter Steinen an Flüssen und Bächen.

A. apricavia. Payk. Auf Aeckern sehr häufig.

A. patricia. Duft. Bei St. Lambrecht auf Feldern (Korl.)

\section{Zabrus. Clair.}

Z. giblus. Fabr. Auf Feldern, unter Steinen häufig.

Diachromris. Er.

D. germanus. L. Bei St. Leonhard unter Steinen häıfig (Sp.)

Anisodactylus. Dej.

A. signatus. Panz. Unter Steinen vereinzelt.

A. Binotatus. Fabr. Unter Steinen und Laub nicht hänfig.

A. nemorivagus. Duft. Unter Steinen im Gebirge.

\section{Harpalus. Latr.}

H. sabulicola. Panz. Um St. Leonlard unter Steinen selten. (Sp.)

H. obscurus. Fabr. Um St. Leonhard häufig (Sp.)

H. punctulatus. Duft. Um Admont einigemal gefangen (Stbl.)

H. azureus. Fabr. Auf Feldern, unter Steinen häufig.

H. puncticollis. Payk. Unter Steinen (Gat.)

H. Brevicollis. Dej. Bei St. Lambrecht sehr selten (Kod.)

H. maculicornis. Duft. Auf Disteln häufig bei St Lambrecht (Kod.)

H. signaticomis. Duft. Unter Steinen bei St. Lambrecht. (Kod.)

H. ruficornis. Fabr. Unter Steinen, auf Feldern häufig.

H. grisens. Panz. Bei St. Lambrecht nicht häutig (Kod.)

H. calceatus. Duft. Unter Steinen bei St. Leonhard (Sp.)

H. ferrugineus. Fabr. Bei St. Lambrecht sehr häufig (Kod.)

H. Hortentotta. Duft. Unter Steinen nicht eben häufig.

H. laevicollis. Duft. In Gebirge unter Steinen häufig.

11. Tonestus. Duft. Unter Steinen (Gat.)

II. distinguendus. Duft. Unter Steinen nicht häufig.

H. aeneus. Fabr. Unter Steinen, auf Aeckern häufig.

H. discoidens. Fabr. Unter Steinen häufig.

H. rubripes. Duft. Unter Steinen häufig.

H. latus, L. Unter Steinen im Gebirge Nord-Steiermarks.

II. quadripustulatus. Dej. Unter Steinen im Gebirge.

II. flavicornis. Dej. Bei St. Lambrecht sahr selten (Kod.)

II. serripes. Schh. Unter Steinen häufig.

H. hivtipes. Pan. Bei St. Leonhard hä̉ufig nnter Steinen (Sp.)

H. semiviolaceus. Dej. Im nördlichen Steiermark häufig unter Steinen.

H. impiger. Duft. Auf Alpen bei St. Lambrecht nicht selten. (Kod.)

H. servus. Duft. Bei St. Leonhard (Sp.)

H. auxius. Duft. Unter Steinen bei St. Leonhard (Sp.)

H. picipenuis. Duft. Sehr selten unter Steinen bei St. Lambrecht (Koi.) 


\section{Stenolophis. Dej.}

St. vaporariorum. Fabr. Unter Steinen nicht lıäufig.

St. Slorimshiranus. Steph. An Teichufern bei St. Lcunhard oft sehr häufig (Sp.)

St. Aiscophoms. Fisch. Von Grimmer angegeben. (?)

St. vespertinus. Punz. An Teichufern um St. Leonhard häufig. (Sp.)

St. elegans. Dej. An 'Teichufern um St. Leonhard (Sp.)

St. flaricollis. Sturm. An der Enns bei Admont (Stbl.), unter Laub bei St. Lambrecht (Kod.)

St. brunnipes. Sturm. In Wäldern unter Steinen (Gr.)

St. suturalis. Dej. Unter Steinen (Gat.)

St. meridianus. I. Unter Steinen häufig.

Bradycellus. Er.

B. collaris. Payl. Unter Steinen (Gat.)

B. similis. Dej. Bei St. Lambrecht selten unter Holzstucken (Kod.)

Trechus. Clair.

T. discus Fabr. An Ufern der Bäche bei St. Lambrecht (Kod.), St. Leonhard (Sp.)

T. longicornis. Sturm. An Teichufern bei St. Leonhard (Sp.)

T. exaratus. Schaum. An einer Quelle am Bacher bei Marburg in Mehrzahl (Sp. Gat.)

T. mbens. Fabr. Unter 'Steinen $u$ Admont (Stbl.), St. Lambrecht (Kod.)

T. minutus: Fabr. Unter Moos und Steinen selur liäufig.

T. obtusus. Er. Nach Erichs. Ins. Dentschlands in Steiermark vorkommend.

T. nigrinus. Putz. Unter Steinen und Moos im Gebirge selten.

T. palpalis. Dej. Im nördlichen Steiermark häufig unter Steinen (Kod, Gat.)

T. micaus. Schaum. Auf höheren Alpen im nördlichen Steiermark (Miller, Gat.)

T. montanus. Putz. Auf der Zirbisalpe (Kod.)

T. striatulus. Putz. Auf Alpen bei St. Lambrecht (Kod.)

T. ochreatus. Dej. Im nördlichen Steiermark auf löheren Alpen (Kod. Gat.)

T. ovatus. Putz. Auf höleren Alpen im nördlichen Steiermark.

T. elegans. Putz. Nach Erichs. Ins. Deutchlands in Steicrmark vorkommend.

7. laevipennis. Heer. Im nördlichen Steiermark auf höheren Alpen (Gat.)

T. 'rotundatus. Dej. Auf Alpen selten; sehr häufig am Bacher im Moose *)

T. limacodes. Dej. Auf höheren Alpen selten, sehr häufig am Bachergebirge bei Marburg (Br.)

T. lithophilus. Putz. Auf hölieren Alpen selten.

T. rotundipennis. Duft. Auf hölıeren Alpen nicht selten im Moòse.

*) Irih verschickte einen Trechus, den ich fur rotumiatus halte, den aluer no Clemens Hampe füu neu hält und als styviacus versandte. 
T. constrictus. Schaum. Auf höheren Alpen (Miller).

T. latus. Put:. Auf der Choralpe (Hiller).

T. secalis. Payk. Unter Moos, bei Eggerberg (Gat.), bei St. Leonhard (Sp.)

\section{Perileptus. Schanm.}

I. areolatus Creutz. An sandigen Stellen bei St. Leonhard nicht selten (Sp.)

\section{Tachys. Schaum.}

T. Fockii. Humm. Nach Erichs. Ins. Deutschlands in Steiermark vorkommend.

T. quadrisignatus. Duft. Auf sandigen Ufern häufig.

T. sexstriatus. Duft. Am Sande der Mur bei Graz (Gat.)

T. parvulus Dej. Am Murufer bei Graz (Gr.)

T. nanns. Gyli. Auf sandigen Ufern.

T. bistriutus. Duft. Auf sandigen Ufern häufig.

Bembidium. Latr.

b. prmilio. Duft. Am Sande der Mur bei Graz (Gat.)

B. obtusum. Sturm. Auf sandigen Ufern.

B. guthla. Fabr. Am Mursande bei Graz (Gr.), St. Leonhard (Sp.)

[3. lignttatum. Fabr: An Mursande bei Graz (Gr.), St. Leonhard (Sp.)

b. assimile. Gyll. An sandigen Stellen bei St. Leonhard (Sp.)

b. fumigatume. Duft. Am Hursande bei Graz (Gat.)

B. lamerale. Stu'm. Nach Erichs. Ins. Dentschlands in Stciermark vorkonmend.

13. quadrinaculatum. L. Auf sandigen Ufern.

li. quadripustulatum. Dej. Am Mursande bei Graz ('T'pk.)

13. quadriguttatum. Fah. Auf sandigen Ufern häufig.

B. articilatum. Pans. Anf sandigen Ufern häufig.

13. Stimmii. Panz. Auf sandigen Stellen bei St. Leonhard (Sp.)

B. Sctriippelii. Dej. Am Sande der Enns (Stbl.)

B. Doris. Panz. Auf sandigen Ufern, bei Graz (Gat.), bei St. Leonhard (Sp.)

B. tenellum. Er. Auf sandigen Ufern häufig.

B. celere. Fabr. Auf sandigen Ufern sshr häufig. $v$ velox. Er. Bei St. Lambrecht an Bächen nicht selten (Kod,)

B. glaciale. Heer. Auf Alpen im nördlichen Steiermark anı schmelzenden Sclınee häufig.

B. bipunctatum. I. Auf Alpen am schmelzenden.Schnee häufig".

B. modestum. Fatr. Am Mursande häufig.

B. decorum. Punz. Auf sardigen Stellen bei St. Leonhard (Sp.)

B. monticola. Sturn. An Bachufern bei Admont (Stbl.), an Mursande bei Graz häufig (Br.)

B. nitidulum. Marsh. Am Mursande bei Graz (Gr.)

B. fasciolatum. Duft. Auf sandigen Ufern.

B. tibiale. Duft. Auf Ufersand bäufig.

B. tricolor. Fabr. Auf sandigen Ufern nicht häufig.

$B$, eques. Sturn. Nach Erichs. Ins. Deutschlands in Steiermark vorkommend. 
B. obsoletum. Dej. Am Mursande häufig.

B. Andrcae. Faln. Auf sandigen Ufern ler Fliisse und Bäche.

13. buxelleus?. Wesm? An Teichufern bei Adnont (Stbl.)

B. littorale. Ol. Auf sandigen Ufern; bei Graz (Br.), bei St. Leonhard (Sp.)

B. fluviatile. Dej. Am Lehme abgelassener 'Teiche bei Admont (Stbl.)

B. lunatum. Duft. An der Mur (Gat. Br.)

B. ruficorne. Sturm. Auf der Kühalpe (Kod.), unter Steinen bei Admont (Stbl.)

B. stomoides. Dej. An sandigen Stellen bei Admont (Stbl.), bei St. Leonhard (Sp.)

B. elongatum. Dej. Nach Erichs. Ins. Deutschlands in Steier mark vorkommend.

B. albipes. Dej. Auf sandigen Ufern; bei A(lmont (Stbl.), bei Graz (Br.)

B. pygmaeum. Fabr. Anf sandigen Ufern; bei Ardmont (Stbl.), bei Graz (Br.)

B. fammulatum. C'lair. Auf sandigen Ufern.

$B$. varium. Ol. Auf sandigen Ufern.

B. fumigatum. Dej. Am Mursande bei Graz (Gat. Br.)

B. prasinum. Duft. Anf sandigen Ufern, bei Graz (Gat.), St. Leonliard (Sp.)

B. punctulatum. Drap. An sandigen Stellen bei St. Leonhard (Sp.)

B. laticolle. Duft. An Teichnfern bei st. Leonhard selten (Sp.)

B. striatum. Fabr. Anf sandigen Ufern häutig.

B. foraminosum. Sturm. Auf sandigen Stellin ('irr.)

B. impressum. P'unz. Anf' sandigen Ufern (Gart.)

B. paludosum. Panz. Am Mursande häufig”.

Tachypus. Iac.

T. caraboides. Schrnk. Auf sandigen Stellen bei St. Leonlatrd (Sp.), an der Enns (Stbl.)

T. pallipes. Duft. Ain MLursande (Gat.)

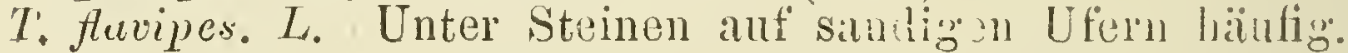

\section{Dytiscidae.}

Cnemidotus. Ill.

C. caesus. Duft. In stehondem Wasser selten.

Haliplus. Latr.

H. obliquus, Fabr. In Teichen nicht selten.

H. lineatus. Aubé. In 'T'eichen nnd Pfiitzen.

1. variegcutus. S'tum. In Teichen nicht hïutig.

H. fulvus. Fabr. In 'T'eichen' (Gr.) 
H. Anviatilis. Aubé. Im Anerlingteiche niclit selten (Kod.)

H. Aluicollis. Sturm. In 'Teichen.

II. cinereus. Aubé. In 'Teichen (Gat.)

-H. ruficollis de Geer. In Teichen nicht selten.

H. fulricollis. Hr. In 'Teichen nieht selten (Kod.)

11. lineatocollis. March. In Teichen nicht selten.

\section{Brychius. Thoms.}

B. elevatus. Panz. In T'eichen selten (Gr. Sp.)

\section{Hyphydrus. Ill.}

H. avalus. L. In T'eichen und Tümpeln selten.

\section{Oxynoptilus. Kiesw.}

O. cuspidatus. Kmmze. In Pfüitzen selten (Gat.)

\section{Hydroporus, Clair.}

II. reticulatus. Falr. In Pfiitzen und Teichen.

II. inaequalis. Fabr. In Pfützen und 'Teichen.

H. parallelogrunmus. Ahrs. In Pfützen (Gr. Gat.)

H. confluens. Fabr. In Pfïtzen (Gat.)

H. picipes. Fatr. In Pfützen und Tümpeln nicht selten.

H. geminus. Fabr. In Pfiitzen und 'Tümpeln häıfig.

H. mistriatus. Schrnk. In kleinen Bächen selten (Kod.)

II. pumilus. Aub. In stehendem Wasser selten (Kod. Gat.)

II. pictus. Fulsr. In Tiimpeln bei Admont (Stbl.). St. Lambrecht (Kod.)

H. Sanmarkii. Sahlb. In 'T'ümpeln selten (Gat.)

II. alpinus. Duft. In Alpentiimpeln (Gr.)

H. platynotu.. Germ. In 'Tiimpeln selten (Gat.)

1\%. depressus. Eabr. In Timpeln und Pfïtzen (Gr. Gat.)

II. assimilis. Payk. Leopoldsteiner See (IIampe.)

II. Hulensis. Fubr. In Pfützen (Gr. Sp.)

II. memnonius. Nic. In Quellen auf Alpen sehr selten (Kod.)

H. I'ictor. Aubé. In schlammigen Bächlein um Graz (Gat. 'T'pk.)

II. erythrocephalus. L. In T'impeln.

H. marginatus. Duft. In Pfützen und Teichen.

H. planus. Fabr. In 'T'ümpeln.

H. nigrita. Fabr. In Tümpeln selten (Kod. Stlb.)

H. nivalis. Heer. In 'Tümpeln sehr selten. (Gat. Sp.)

H. tristis. Payk. In 'T'impein $\mathrm{mm}$ Admont (Stbl.)

H. palustris. L. In Pfïitzen und 'T'iumpeln sehr' häutig.

11. angustatus. Stum. In Pfiitzen um Admont (Stbl.)

II. lineatus, F'abr. In 'Tiimpeln häufig.

H. styriacus. Hampe in lit. Im Leopoldsteiner See (Hampe.)

\section{Noteris. Clair.}

N. crassicornis. Fabr. In T'ümpeln nicht selten.

N. sparsus. Warsh. In der Hungerlache bei St. Lambrecht. (Kod.)

Laceophilus. Leach.

L. minutus. Gyll. In T'ümpeln und Teichen nicht häufig. 
L. luyclinus. Er. In 'T'ümpeln und 'T'eichen selten.

L. variegatus. Sturn. In Gesellschaft der Vorigen.

\section{Colymbetes. Clair.}

C. fuscus. L. In Teichen.

C. purerosus Sturm. In TümpeIn und Teichen häufign.

C. notatus. Fuln: In Teichen (Gr. Gat.)

C. adspersus. Fabr. In Teichen nicht häufig'.

C. collaris. Payk. In Pfützen nicht selten.

C. Grapii. Gyll. In Timpeln und Tejchen (Gr. Gat.)

Ilybius. Er.

I. fenestratus. Fabr. In Teichen nicht solten.

I. subceneus. Er. Im Auerling un l Markt-T'eiche (Kod.)

I. fuliginosus. Fabn'. In 'Timpehn und 'T'eichen häufig.

I. ater de Geer. In 'T'eichen nicht häufig (Kod. Gat.)

I. guttiger. Gyll. In Quellwasser nicht selten.

Liopteris. Esch.

L. agilis. Fabr. In 'T'umpeln in der Fischerau bei Graz (Gr.)

Agabus. Leach.

A serviconis. Puyk. In Teichen um St. Leonharil (Sp.)

A. congener. Payl. In Quellen auf der Bacheralpe. (Stbl.)

A. femoralis. Puyk. Im Quellwasser der Alpen sehr selten. (Kod.)

A. Sturmii. Gyll. In Teichen (Gr. Stbl.)

A. chalconotus. Panz. In 'Teichen (Gr.)

A. nigroceneus. Er. In (Quellen auf deŕ Kiihalpe nicht selten. (Koul.)

A. maculatus. L. Im Quellwasser nicht solten.

$v$. inaequalis. Panz. Im Leopoldsteiner-See (Hampe).

A. abbreviatns. Fabr. In Teichen und 'T'impeln selten.

A. didymus. Ol. In Teichen, bei Admont (Stbl.), St. Leonlard (Sp.)

A. bipunctatns. Futr. In 'Teichen (Gr.)

A. guttatus. Payk. In kleinen Bächlein häufiğ.

A. Dignitatus. Ol. In 'Teichen (Gr.)

A. bipustulatus. L. In Teichen und Pfitzen häufigg.

A. Solieri. Aub. In Teichen (Stbl. Gat.)

\section{Dytiscus. I.}

D. marginalis. L. In Teichen häufig'.

D. circumcinctus. Aler. In Teichen.

I. cireumfexus. Fabr. In Teichen um St. Leonhard (Sp.)

D. punctulatus. Eabr. In 'Teichen um St. Leonbard (Sp.)

D. dimidiatus. Bergstr. In Teichen um St, Leonhard (Sp.)

Acilius. Leach.

A. sulcatus. L. In Teichen und Timpehn.

Hydaticus. Leach.

H. zonatus. Ill. In T'eichen (Gr, Gat.) 
IT. cinerens. L. In Teichen und 'Tiimpeln nicht seiten.

H. Hybneri. Fain. In T'eichen (Gr. Sp.)

IT. transversalis. Fally. In Teichen (Gr.)

\section{Gyrinidae.}

Gypinus. Geoff.

G. minutus. Fabr. In der Hungerlache bei St. Lambrecht sehr häufig' (Kod,) in 'T'iimpeln an dem Bahndamme bei Cilli (Ltgb)

A. mergus. Ahr. In Teichen und Lachen häufig. v. nitator. All. Mit dem Vorigen.

G. Jicolor: Payk. In Teichen $u$ Im St. Leonhard (Sp.)

G. marinus. Gyll. Im Furt-Teiche bei St. Lambrecht sehr häufig (Kod.)

G. opacus. Suffr. In stehenden Wässern, bei St. Lambrecht (Kod.), bei Cilli (Ltgb.)

\section{Orectochilus. Lac.}

O. villosus Fubr. In 'T'eichen (Gr.)

\section{Hydrophilidae.}

Hyoipophilus. Geoff.

H. piceus, L. In Teichen selten.

Hydrous. Brillé.

H. caraboides. L. In Teichen nicht selten.

II. fluvipes. Stev. In T'eichen um St. Leonhard (Sp.)

Hydrobius. Leach.

Ir. fuscipes. L. In Pfüitzen häufig.

H. oblongurs. Hrbst. In Pfützen (Gr.)

II. globulus. Payk, In Lachen nicht selten (Stbl. Kod:)

\section{Philhydrus. Sol.}

Ph. testaceus, Fabr. In Pfützen nicht selten.

Ph. melanocephalus. Fabr. In Pfützen. (Br.)

Ph. marginellus. Falr. In stehendem Wasser.

Helochares. Huls.

H. lividus. Forst. In Pfiitzen nicht selten.

Laccobins. Fr.

L. mimutns. T. In Pfiitzen läufig. 


\section{Berosus. Leach.}

B. spinosus. Stev. In Pfiitzen (Gr.)

B. aericeps. Curt. In 'T'eichen und Pfiitzen selten.

Limmebits. Leach.

L. truncatellus. Thunb. In Pfützen und Teichen liäıfig.

L. papposus. Muls. In Pfützen selten.

L. atomus. Duft. In Pfützen (Br.)

Cyllidium. Er.

C. seminulum. Payk. In Pfützen und Teichen häufig.

\section{Helophorus. Fabr.}

H. mubilus. Faln. An Pfützen und Teichufern.

H. grandis. Ill. Am Ufer von Pfüitzen und Teichen.

H. granularis. L. Wie Vorige.

H. griseus. Hrbst, Wie Vorige.

H. nivalis. Thoms. In Pfuitzen auf Alpen. (Gat. Stbl.)

\section{Ochthebins. Leach.}

O. exculptus. Germ. In Pfützen und Teichen. (Gat.)

O. giblosus. Germ. In Pfützen. (Gr.)

O. margipallens. Latr. In Pfützen. (Gat.)

O. pygmaeus. Fabr. In Pfiitzen. (Gat.)

\section{Hydraena. King.}

H. palustris. Er. In einem Gebirgsbächlein am Bacher bei Marburg. (Br.)

H. riparia. Kug. An Steinen in Bächen lıäufig.

H. gracilis. Germ. Unter Steinen in Bächen häufig.

H. flavipes. Sturn. An Steinen in Bächen um St. Lambrecht sehr selten (Kod.)

H. pulchella. Germ. In Muschelschalen einigemal boi St. Lambrecht gefangen. (Kod.)

Cyclonotum. Er.

C. orbiculare. Fabr: An T'eichufern hä̈ufig.

\section{Sphaeridium. Fabr.}

Sph. scarabaeoides. L. In Diinger sehr häufigg.

Sph. bipunctatum. Fabr. Im Diinger häufig. v. marginatum. Scril. (Gr.)

\section{Cercyon. Leach.}

C. obsoletum. Gyll. Im Diinger. (Gr. Stbl.)

C. haenorrhoidaie. Fabr. Im Diinger nicht selten.

C. haemorrhoum. Gyll. Im Dünger hänfig:

C. aquaticum. Muls, Bei faulenden Vegetabilien. (Gat.)

C. flaciper. Ful,r. Im Diinger sehr häufig. 
C. Iittorate. Gyll. Bei faulenden Vegetabilien. (Gat.)

C. mipunctatum. L. Im Dïnger häufig.

' U. quisquilium. I. Im Dïnger håufig.

C. melanocephatum. L. Bei faulenden Vegetabilien selten. (Stbl. Kod.)

C. pygmaeum. Ill. Bei faulenden Vegetabilien.

C. nigripes. Marsh. Bei faulenden Vegetabilien.

C. minutum. Fabr. Bei faulenden Vegetabilien.

C. anale. Payk. Bei faulenden Vegetabilien häufig.

C. granarium. $E r$. Bei faulenden Vegetabilien.

\section{Megasternum. Muls.}

M. polithophagım. Er. Bei faulenden Vegetabilien nicht selten.

Cryptopleurim. Muls.

C. atomarinm. Fabr. Im Dünger häufig.

\section{Staphylinidae.}

Antalia. Steph.

A. impressa. Ol. An Baumschwämmen, nicht häufig. (Kod. Br.) A. rivularis. Grax. An Baumschwämmen bei Admont. (Stbl.)

Falagria. Steph.

F. thoracica. Curt. Unter Laub am Plabutsch bei Graz. (Gat.)

F. sulcata. Payk. Unter Laub und Moos sehr häufig.

F. sulcatula. Grav. Nach Angabe Grimmers unter Geniste.

F. obscurc. Curt. Unter Laub und Moos liäufig.

F. nigra. Grav. Bei faulenden Vegetabilien, im Ausspuilicht der Bäche und Fliisse.

\section{Bolitochara. Mann.}

B. Iucida. Grav. Auf Baumschwämmen und Blätterspitzen. (Kod. Gat.)

B. lumulata. Payk. Auf faulen Baumschwämmen lıäufig.

P. bella. Märlcl. Auf einem Baumschwamme am Bacher ein Exemplar. (Br.)

B. obliqua. Er. Auf Blätterpitzen sehr selten. (Kod. Stbl.)

Silusa. Er.

S. rubiginosa. Er. An ausfliessendem Safte. (Gat. Br.)

Ocalea. Er.

O. castanea. Heer. Unter Moos. (Gat.)

O. badia. Er. Unter Moos und Laub. (Gat.) 


\section{Stenoglossa. Kr.}

St. semimfa. Ex. Unter den von Grimmer in Steiermark gesammelten unbestimmten Käfern gefunden.

\section{Ischnoglossa. Kr.}

I. prolixa. Grav. Unter Rinden, selten. (Gat.)

1. rufopicea. Kr. Unter Rinden, selten. (Gat.)

I. corticina. Er. Wie die Vorigen, jedoch häufiger. (Br.)

\section{Leptusa. Kr.}

I. analis. Gyll. Unter Noos selten. (Br.)

L. fumida. Er. Unter Rinden selten. (Gat.)

L. ruficollis. Er. Unter Moos an Bacher 2 Exemplare. (Br.)

L. globulicollis. Muls. Unter Moos am Bacher selten (Br.)

L. piceata. Muls. Am Bacher n. Schöckl unter Moos häufig. (Br.)

L. puellaris. Hampe. Unter Moos sehr selten. (Br.)

\section{Thiasophila. $\mathrm{Kr}$.}

T. angulata. Er. In Nestern der Formica rufa am Bacher (Br.)

Euryusa. Er.

E. sinuata. Er. Im Mulme alter Bäume, in der Nähe von Ameisen. (Gr. Br.)

E. brachelytra. Kiesu. Von Kahr in Steiermark entdeckt; nnter Moos gesiebt 1 Exemplar. (Gat.)

Homoensa. Kr.

H. aruminata. Mkl. Unter Moos bei Ameisen sehr selten. (Br.)

\section{Microglossa. Kr.}

M. gentitis. Märl. Unter den von Grimmer in Steiermark gesammelten unbestimmten Käfern gefunden.

M. pulla. Gyll. Unter Moos 1 Exemplar. (Br.)

M. praetexta. Er. In der Nähe von Ameisen sehr selten. (Gat. Br.)

Aleochara. Grav.

A. ruficomis. Grav. Unter Lanb sehr selten. (Kod. Gat.)

A. erytherptera. Grav. Unter Lanb und Moos sehr selten. (Gat.)

A. fuscipes. Grav Am Aas sehr häufig.

v. lata. Grav. Einzeln unter dem Vorigen. (Br.)

A. rufipennis, Er. Unter Lanb und Noos nicht selten.

A. tristis. Grov. Unter Lanb nicht hänfig. (Br.)

A. Milleri. Kr. Unter Laub oft häufig. (Gat)

A. bipunctata. Grav. Unter Lanb und Moos. (Gat, Br.)

A. brevipennis. Grav. Bei faulenden Vegetabilien.

A. lamuginosa. Grav. Unter Laub bei Admont. (Stbl.)

A. moesta. Grav. Am Aas (Kod. Gat.), unter Moos. (Br.)

A. moerens. Gyll. Unter Moos nnd Laub. (Gat. Br.)

A. bisignata. Ei. Unter Laub. (Gat.)

A. bilineatc. Gyll. Unter Laub und Moos. (Br.)

A. nitida. Grav. Unter Laub nicht häufig. (B்r.)

A, mrion. Grav. Bei faulenden Tegetabilien. (Kod.) 


\section{Dinarda. Lac.}

D. Märelii. Kiesu. In Nestern der Formica rufa nicht häufig. (Br.)

D. dentata. Grav. In morschen Baumstöcken bei Ameisen selten. (Kod.)

\section{Lomechusa. Grav.}

L. strumosa. Fabr. Unter Steinen bei Formica rufa ïberall selten.

\section{Atemeles. Steph.}

A. paradoxus. Grav. In Nestern der Formica rufa. (Kod. Gat.)

A. emarginatus. Grav. In Nestern der Formica rufa. (Gat. Sp.)

\section{Myrmedonia. Er.}

M. Havorthi. Steph. Unter Moos und Laub sehr selten. (Ulch. Br.).

1. fulgida. Grar. Im feuchten Sande bei St. Lambrecht sehr selten. (Kod.)

1. collaris. Payk. Unter Laub und Moos selten.

1. humeralis. Grav. In der Nähe von Formica fuliginosa unter Laulb und Moos. (Gat. Br.)

I. cognatu. Märkl. Unter Moos bei St. Leonhara 1 Ex. (Br.)

M. funesta. Grav. In der Nähe von Ameisen unter Laub.

M. similis. Märkl. Unter Laub selten. (Gat.)

1. limbata. Peyk, Unter Laub in der Näle von Ameisen.

1r. lugens. Grav. Unter Laub. (Gr. Gat.)

1. ruficollis. Grimm. Von Kihr in Steiermark entdeckt.

M. laticollis. Märkel. In einem hohlen Baume in der Schönau nächst Graz bei Formica fuliginosa. (Br.)

1. Fusii. Kr. Diesen interessanten Staphylin fand ich unter den unbestimmten Käfern des Herrn Gatterer. Genauer Fundort nicht bekannt, aber jedenfalls Steiermark.

M. canaliculata. Fabr. Unter Laub und Steinen sehr häufig.

llyobates. Kr.

I. nigricollis. Payk. Untor Laub und Hoos selten. (Gat.)

I. rufus. $K r$. Ünter Laul, bei St. Leonhard 2 Exemplare. (Br.)

I. forticornis. Lac. Auf feuchten Wiesen boi St. Lambrecht unte. Holzstiicken selten (Kod.), unter Moos und Laub. (Gat. Br.)

\section{Colodera Mann.}

C. rufescens, Kr. Unt sr feuchten Moose bei st. Leonhard 1 Ex. (Br.

Chilopora. Kr.

Ch. rubicunda. Er. Am Sande eines Bächleins bei St. Leonhard (Br.)

C\%. longitursis. Lr. An Fliissen und Bächen selten. (Br.)

\section{Tachyusa Er.}

T. balteatu. En. Am Murufer gegen Schönan bei Graz häufig. (Br.)

T. constricta Er. Auf sandigen Ufeern nicht selten.

$v$. concima. Heer. Von Kahr in Steiermark gefunden,

T. coarctata. $\mathrm{Er}$. An sandigen Ufern nicht selten.

T. cyanca. Kr. Von Kahr in Steiermark geíunden. 
T. umbratica. Er. An sandigen Ufern der Mur (Gat. Br.)

T. exarata. Mann. Dieses äusserst seltene 'Thier' fand ich am linken Ufer der Mur gegen Schönan bei Graz in grösserer Anzahl, indem ich das mit Mroos bewachsene Ufer mit Wasser iiberschïttete. (Br.)

T. concolor. Er. Am Mursande bei Graz 1 Ex. (Br.)

\section{Oxypoda. Mann.}

O. ruficornis. Gyll. Unter Laub (Gat.)

O. lividipennis. Mann. Auf Pilzen häufig.

O. vittata. Märkl. In der Nähe von Formica fuliginosit selten (Br.)

O. opaca. Grav. Unter Laub und Moos selten. (Kod. Br.)

O. umbrata. Gyll. In Schwämmen und inter Licul.

O: togata. Er. Unter Laub und Moos (Gat.)

O. testaceu. Ei. Bei faulenden Vegetabilien (Kod.)

O. praecox. Er. Unter Laub und Hoos (Gat. Br.)

O. formosa. Kr. In Blätterspitzen.

O. alternans. Grav. In Blätterspitien nicht selten. (Br.)

O. solitaria. $K r$. Unter Moos am Bacher sehr selten.

O. incrassata. Muls. Unter Moos am Bacher 2 Ex. (Br.)

O. formiceticola. Märl. In Nestern der Formica rufia an Bacher sehr häufig (Br.)

O. haemorrhoa. Sahll. In Nestern der Folmica rufa an Bacher' sehr häufig. (Br.)

O. annularis Sahlb. Unter Moos und Laub (Br.)

O. ferruginea. Er. Unter Moos selten. (Br.)

\section{Homalota. Man!.}

H. granigera. Ǩiesw. Am Bacher unter Moos nicht selten (Br.)

H. umbonata. En. Unter Moos, bei Admont (Stbl.), alm Bacher bei Marburg $\left(\mathrm{Br}^{\mathrm{r}}\right.$.)

H. nitidula. $K r$. Unter Moos am Schöckl und Bacher liäutig. (Br.)

H. graminicola. Grax. Auf Aeckern unter Steinen (Kod. Gait.)

H. pavens. Er. Unter feuchtem Lauh (Br.)

H. elongatula. Grov. Unter Laub und Moos häufig.

H. labilis. Er. Unter IIoos am Bacher (Br.)

H. occulta. Er. Unter Laub (Gat.)

H. monticola Thoms. Von Kahr in Steiermark gefunden.

H. aequata. Er. Unter Laub und Hoos (Gat. Br.)

H. angustula. Gyll. Unter feuchtem Laubz (Kor. Gat)

H. arcana. Li. Unter Moos selten (Gat. Br.)

H. vufotestacea. $K v$. Unter Laub (Gat.)

H. macella. Lir. Unter Laub selten (Br.)

H. cuspidata. $E r$. Unter Rinden nicht häufig (Br.)

H. analis. Grat. Unter Laub liäifig.

H. palleola. Er. Unter Laub (Gat.)

H. exilis. Er, In Ritzen von halbtrockenem Schlamm (Kod.)

H. talpa. Heer. In Nestern der Formica rufa am Bacher sehr häufig (Br.)

H. flavipes. Grav. In den Nestern der Formica lufa nicht eben selten (Br.) 
H. anceps. Er. In Nestern der Formica rufia in Mchrahl am Bacher (Br.)

II. brumuea. Falm. Untel fenchtem Laube (Gat. Br.)

H. nigrifrons. Er. Unter Laub selten (Bro)

H. merdaria. Thoms. An Schwämmen (Gat.)

II. socialis. Thoms. In Schwämmen sehı häufig.

11. fungicolu. Thoms, An Schwämmen nicht selten (Gat. Br.)

II. nigritula. Thoms. In Blätterpilzen (Gat.)

II. sodulis. En. An Pilzen (Br.)

II. coviaria. Kir. Unter Hons am Bacher (Br.)

H. gagatina. Baudi. Unter Moos am Bacher in Meh\%ahl (Br.)

IT. nigra. Kr. An Pilzen (Gat.)

II. ditaticonis. Kr. Von Kahr in Steiermark gefunden.

II. sericer. Mruls. Unter Moos selten. (Br.)

H. livida. Inls. Unter Moos an Bacher (Br.)

H. longicornis. Grat. Unter Laub häufig.

1. villosula. Kr. Von Kahr in Steiermark gefunden.

H. laevana. Muls. Bei fanlenden Vegetabilien (Br..)

II. Lepicla. Kr. In Pilzen (Gatt. Br.)

H. melanaria. Sahlb. Unter Laub. (Gat)

H. vermacula. Er. Bei fumlenden Vegetabilien. (Kod.)

H. parce. Sallh. Unter Hoos am Bacher. (Br.)

II. celata. Er. Unter Geniste. (Gro)

II. fungi. Grar. In Pilzen läufig.

II. orphana. Er. Unter fenchtem Laube. (Gat.)

H. notha. Lin. Unter Lanb selten. (Gat.)

II. circelleris. Grav. Unter Laub und Moos. (Br.)

II. spinicllis Ki. Unter Moos am Bacher häulig. (Bro)

II. fleve. Kr. Unter Laub urd Moos. (Gat.)

Placusa. Er.

I'. infima. Er Am Bacher in Mehrzahl. (Br.)

Phloeopora. Er.

P\%. reptons. Grat. Unter Rinde am Bacher. (13r.)

P\%. corticalis. Grav. Unter Rinden und an ausfliessenden silfte nicht lä̈nfig. (Gat. Br.)

\section{Tomoglossa. Kr.}

T. Luteicornis, Lr. Von Kahr in Steiermark aufgefunden.

\section{0]igota. Mann.}

0. pusillima. Grat. Untel Laub. (Gat.)

O. granaria. Er. Bei faulenden Vegetabilien. (Gat.)

O. Flavicornis. Lac. Unter Laub selten. (Br.)

\section{Gyrophaena. Mann.}

G. nitidula. Gyll. Untel Geniste. (Gr.)

(r. pulchella. Heer. An Pilzen. (Gr. Gat.)

G. affinis. Salilb. In faulenden Pilzen nicht selten.

G. nana. Payli. Au Pilzen häufig.

G. minima. Er. In Pilzen. 
G. strictula. Eir. An Pilzen (Gat.)

G. politn. Grav. An Schwämmen. (Gat.)

G. manca Er. An Baumschwämmen. (Gat.)

G. Boleti. L. An Baumschwämmen. (Gat.)

\section{Agaricochara. Kr.}

A. laevicollis. Kr. An Sehwämmen. (Br.)

\section{Pronomea. Er.}

P. rostrata. $E r$. Bei faulenden Vegetabilien nicht häufig.

Myllaena. Er.

M. intermedia. Er. Unter Laub sehr selten. (Br.)

M. dubia. Grav. Unter Laub und Moos selten. (Br.)

\section{Hypocyptus. Maml.}

H. longicomis. Payk. Unter Laub und Moos. (Gat. Br.)

H. pulicarius. En. Unter fenchtem Laub. (Br.)

H. laeviusculus. Momn. Unter Moos. (Br.)

\section{'Trichophya. Mann.}

T. pilicomis. Gyll. Im Miihlbachgraben bei Rein unter liegenden Holzstücken in Mehrzahl gefunden. ( $\mathrm{Br}^{\circ}$.)

Habrocer'us. Er.

H. capillavicomis. Grav. In St. Gotthard bei Graz vom Gesträuch geklopft. (Br.)

Cilea. du Val.

C. silphoides. L. Bei fanlenden Vegetabilien häufig.

Tachinus. Grav.

T. humeralis. Grov. Unter Laub, bei faulen Pilzen nicht häufig.

T. rufipes. de Geer. Unter Laub und Moos.

T. flavipes. Fabr. Bei faulenden Vegetabilien. (Kod. Gat.)

T. bipustnlatus. Fabr. Unter Laub selten. (Br.)

T. subterranens. L. Unter Laub und Moos. (Gat.)

T. fimetarins. Fabr. Unter Laub und Moos. (Br. Gat.)

T. marginellus. F'abr. Unter Laulb und Mloos.

T. laticollis. Grav. Untel Laub. (Br.)

T'. collaris. Grav. Unter Laub und Moos.

T'. elongatws. Gyll. Unter Laub 1 Exemplar. (Gat.)

\section{Tachyporus. Grav.}

$T$. obtuşus. L. Unter Laub und Moos häufig.

$T$. obdominalis. Er. Unter Laub und Ioos.

T. shrysomelinus. L. Unter Laub und Hoos.

T. Hypnormm. Fabr. Unter Laub und Noos häufig.

T. ruficollis. Grav. Unter Moos nicht häufig.

T. Mnmerosus, Er. Unter Laub selten, Admont (StbJ.), am Graze ${ }^{\circ}$ Schlossberge. (Br.)

T. transversalis, Grav, Unter Lalul, am Grazer Schlossberge. (Br.) 
T. scitulus, Er. Unter Laub und Moos.

T. pusitus Grav. Unter Bamminden. (Kod. Gat.)

T. Humers. Fabr. Unter Moos liäufig.

\section{Lamprinus. Heer.}

L. erythropterus. Panz. Unter Laub sehr selten. (Gat, Br.)

Conosoma. Kr.

C. litiorerm. I. Unter feuchtem Laube. (Gat.)

C. jubesceus. Grav. Untel Laub häufig.

C. fusculum Er. Unter I aub nicht häufig:

C. pedicularium. Grav. Unter Laub und Moos. (Gat. Br.)

C. Lipustulatum. Grav. Unter Moos am Bacher bei Marburg. (Br.)

C. lipunctatum. Grax. Unter Laub. (Gat. Br.)

\section{Bolitobins. Steph.}

B. analis. Payk. Unter Laub bei St. Leonhard. (Br.)

B. formosus. Grav. Unter feuchtem Moos. (Sp. Gat.)

B. speciosus. Er. An einem faulenden Bammschwamme in Rein, 1 Exemplar. (Br.)

B. atvicapillus. Fabr. An Schwämmen häufig.

B. stricutus. Ol. An Baumschwämmen selten.

B. trinotatus. Er. An Schwämmen. (Gat.)

B. exoletus. Er. In Schwämmen nicht selten.

B. pygmaens. Falr. In faulen Schwämmen häufig.

Bryoporus. Kr.

B. mfus. Er. Unter Laub. (Gat.)

\section{Mycetoporus. Mann.}

M. punctus. Gyll. Unter Moos am Schöckl. (Br.)

M. splendens. Marsh. Unter Moos. (Gat.)

M. longulus. Mann. Unter Moos nicht häinfig.

M. ruficornis. $K r$. Unter Laub. (Gat.)

M. lepidus. Grav. Untel Laub. (Gat.)

M. nanus. Grav. Unter Laub und Moos. (Gat. Br.)

M. pronus. Er. Unter Lamb und Moos (Grat. Kod.)

M. splendidus. Grav. Unter Laub. (Gat.)

\section{Heterothops. Steph.}

H. praevins. En. Unter Moos in Wäldern um St. Lambrecht. (Kod.)

H. lissimilis. Grav. Unter Moos. (Gat.)

\section{Quedius. Steph.}

Q. dilatatus. Fabr. St. Leonhard. (Sp.)

Q. fulgidus. Fabr. An feuchten dumpfigen Stellen häufig.

$v$. erythrogaster. Mann. Bei St. Leonhard. (Br.)

Q. cruentus, Ol. Unter Rinden, an ausfliessendem Safte.

Q. xanthopus. Er. Unter fauler Rinde häufig. (Kod.)

Q. scitus. Grav. Unter Moos. (Gat. Br.)

Q. laevigatus. Gyll. Unter morseher Rinde. (Gat Br.) 
Q. impressus. Panz. Unter Moos und morscher Rinds.

Q. molochiuns. Grav. Unter Moos bei St. Leonhard. (Brr.)

Q. fuliginosus. Grav. Unter Moos um Admont. (Sthl.)

Q. brevis. Er. Unter Moos. (Gr. Gat.)

Q. ochropterns. Er. Unter Moos nicht salten. (Br.)

Q. fimbriatus. Er. Unter Steinen und Moos in Gebirg?

Q. umbrinus. Ei. In faulen Schwämmen sahr salten. (Kod.)

Q. manrorufus. Grav. Unter Moos. (Br.)

Q. monticola. Er. In Gebirge unter Moos nicht selten, beson lers häufig am Bacher bei Marburgo. (Br.)

Q. suturalis. Kiesw. Unter IIoos. (Gat.)

Q. attemuatus. Gyll. Unter Laub und Hoos. (Gat. Kod.)

Q. boops. Giar. Unter Moos im Gebirge selten. (Gat.)

Q. alpestris. Heer. Unter Moos im Gebirge. (KaJl1 Br.)

Q. scintillans. Grar. Unter Moos im Gebirge. (Br.)

\section{Creophilus. Steph.}

C. maxillosus. L. Bei Aas und faulenden Vegetabilien häufig.

\section{Emus. Curt.}

E. hirtus. L. In frischem Kuhdünger nicht selten.

\section{Leistotrophins. Perty.}

L. nebulosus. Fabr. Bei Aas häufig.

L. murinus. $L$. In frischem Kuhdiinger häufig.

Staphylinus. L.

St. lutarius. Gras. Von Grimmer als in Steiermark rorkomment angegeben.

St. stercorarius. Ol. Im Gebirge unter Steinen selten.

St. chalcocephalus. Fal,r. In trockenem Dünger, unter Moos.

St. fulvipes. Scop. Unter Hr,lustiicken und Steinen in Gebirge selten.

St. latebricola. Grav. Unter Laub und Hoos sehr selten. (Br.)

St. chloropterus. Pant. Nach Angabe Grimmers in Steiermark vorkommend

St. pusbescens. de Geer. Bəi Aas und in Kuhdïng'er.

St. erythropterus. L. In Wäldern unter Steinen selten.

St. Caesareus. Cederh. Im Gebirge mnter Steinen.

St. fossor. Scop. In Wäldern unter Steinen und Laub selten.

\section{Ocypis. Steph.}

o. olens. Müll. Unter Steinen am Schöckl (Gr.), im Aug'raben. ('T'pl.)

O. micropterus. Redt. Im Gebirge mter Steinen nicht selten.

o. macrocephalus. Grar. Unter Steinen, bei St. Lambrecht sehr selten (Kod.), häufiger am Bacher bei Marburg. (Br.)

O. alpestris. Er. In Gebirge minter Steinen nicht selten.

O. cyaneus. Payk. Unter Steinen am Plabutsch bei Graz. (Gr. Gat.)

O. similis. Fabr. Unter Steinen häufig.

O. Iminnipes. Fabr. Unter Moos und Laub. (Br.)

O. fuscutus. Grar. Unter Steinen am Jacher bei Marburg. (Br.) 
D. picipennis. Fabr. Unter Steinen im Gebirge häufig.

(). fulvipennis. Er. Unter Laub und Steinen. (Kod. Br.)

O. pedator: Grav. In Eichenwäldern um St. Leonhard unter Moos selten. (Br.)

O. morio. Grav. Unter Steinen nicht selten.

O. compressus. Marsh. Unter den in Steiermark gesammelten unbestimmten Käfern Grimmers gefunden.

v. cerdo. Er. Im Schwarzwalde bei St. Leonhard 1 Exemplar gefunden. (Br.)

\section{Philonthus. Curt.}

Ph. splendens. Fabr. Unter Laub und Moos selten.

Ph. intermedius. Lac. Unter Steinen selten. (Kod. Stbl.)

Ph. laminutus. Creutz. Unter Steinen bei St. Lambrecht (Kod.), bei Cilli (Ltgb.)

Ph. cyanipennis. Fabr. An faulen Schwämmen in Eichenwäldern um St. Leonhard selı häufig $\left(\mathrm{Br}^{\circ}\right.$.), sonst nur eirzeln.

Ph. nitidus. Fabr. In trockenem Diinger. (Kod. Stbl.)

Ph. carbonarius. Gyll. Unter Laub. (Gat.)

Ph. aeneus. Rossi. Häufig im Diinger.

Ph. scutatus. En. Unter Laub. (Gat.)

Ph. decorus. Grav. Bei Schwämmen und unter Laub selten. (Kod.Gat.)

Ph. politus. Fabr. Bei Diinger häufig.

$P h$. lucens, Mann. Unter Laub nicht häufig.

Ph. atratus. Grav. In Diinger sehr häufig.

Ph. aerosus. Kiesw. Im Gebirge unter Moos selten. (Br.)

Ph. marginatus. Fabr. Auf der Kühalpe im Diinger. (Kod.)

Ph. umbratilis. Grav. Unter Laub selten.

Ph. varius. Gyll. Unter Laub selten.-(Gr. Gat.)

v. bimaculatus. Grav. Unter Laub. (Br.)

Ph. lepidus, Grav. An Ufern in Ansspiilicht nicht selten.

Ph. sordidus. Grav. Unter Laub nicht häufig.

Ph. finetarius. Grav. In Diinger nicht häufig. (Kod. Gat.)

Ph. cephalutes. Grav. Im Diinger sehr selten. (Kod. Gat.)

Ph. ebeninus. Grav. Unter Laub und Moos selten. (Br. Gat.)

v. corruscus. Er. Unter Laub und Moos selten. (Gat. Br.)

Ph. corvinus. Er. Unter Laub ind Moos selten. (Gat.)

Ph. fumigatus. Er. Unter Laub. (Gr. Gat.)

Ph. sanguinolentus. Grav. Untel Laub und Moos.

Ph. varians. Er. Untel Laub und Moos.

Ph. debilis. Grav. Unter Laub ind Moos.

Ph. ventralis. Grav. In trockenem Dünger. (Kod.)

Ph. discoideus. Grav. In trockenem Diinger. (Kod. Gat.)

Ph. vernalis. Grav. Unter Laub und Moos.

Ph. quisquiliainus. Gyli. Bei Diinger selten. (Kod. Gat.)

Ph. splendidulus. Grav. Unter Laub selten. (Kod. Gat.)

Ph. rufimanus. El. Unter Laub und Moos selten. (Gat. Br.)

Ph. fumarius. Grav. Bei faulenden Vegetabilien. (Kod.)

Ph. micans. Grav. Unter Laub und Moos. (Gr. Kod.)

Ph. fulvipes. Fabr. An Ufern im Ausspülicht häufig.

Ph. astutus. Fir. Unter Laub selten. (Kod. Br.) 
Ph. nigritulus. Grav. Unter Laub häufig.

Ph. pullus. Nordm. In trockenem Diinger (Kod.), ünter Laub (Gat.)

Ph. tenuis. Fabr. An Ufern im Ausspüllicht nicht häufig.

Ph. rufipennis. Grav. Unter den von Grimmer in Steiermark gesammelten unbestimmten Käfern gefunden.

Ph. cinerascens. Grav. Unter Laub selten. (Gat.)

Ph. elengatulus. Er. Unter Laub bei St. Leonhard. (Br.)

Ph. procerulus. Grav. Unter Laub. (Gat.)

Ph. prolixus. Er. An Bachufern um St. Leonhard. (Br.)

\section{Xantholinus. Serv.}

X. punctulatus. Payk: Unter Rinden in faulem Holze häufig.

$X$. relucens. Grav. Unter Laub und Moos selten. (Drnk. Kod.)

$X$. ochraceus. Gyll. Unter Laub und Moos. (Br.)

$X$. tricolor. Eabr. Unter Laub. (Gat.)

$X$. decorus. Er. Unter Rinden am Fusse des Bacher beiMarburg.(Br.)

X. rufipennis. Er. Unter Rinden am Schöckl selten. (Br.)

X. glaber. Nordm. Bei Formica fuliginosa. (Br.)

$X$. longiventris. Heer. Unter Laub und IIoos. (Gat.)

$X$. linearis. Oliv. Unter Rinden und Laub nicht selten.

X. fulgidus. Fabr. Unter Rinden bei St. Leonhard. (Sp.)

\section{Leptacintis. Er.}

L. parumpunctatus. Gyll. Unter fanlenden Vegetabilien selten.(Kod.)

L. batichrus. Gyll. Unter Rinden und Lamb nicht selten.

L. linearis. Grav. Unter Rinden. (Kod.)

L. formicetorum. Märkl. In Nestern der Formica rufa am Bacher bei Marburg in Mehrzahl. (Br.)

\section{Baptolinus. Ki.}

B. alternans. Grav. Unter morscher Rinde nicht häufig. (Br.)

B. pilicornis. Payk. Unter morscher Rinde selten. (Br.)

\section{othins. Steph.}

O. fulvipennis. Fabr. Unter Laub und Moos nicht selten.

O. punctipennis. Lac. Unter Laub und Moos sehr selten. (Gat.)

O. melanocephahus. Grav. Lnter Moos am Schöckl sehr häufig: ( $\mathrm{Br}$.)

O. brevipennis. $K r$. Unter Moos am Bacher bei Marburg selten. (Br.)

O. myrmecophilus. Kiesw. Unter MLoos. (Gat.)

\section{Lathrobium. Grav.}

L. brunnipes. Fabr. Unter Laub und Moss selten. (Gr. Gat)

L. elongatum. L. Unter Laub und Moos in Wäldern nicht häufig.

L. fulvipenne. Grav. Unter Laub und Moos im Gebirge. (Kod. Gat.)

L. multipunctatum. Grav. Unter feuchtem Laub nicht häufig.

L. terminatum. Grav. Unter Laub und IIoos selten. (Gat.)

L. filiforme. Grav. Unter feuchtem Moos nicht liäufig.

L. longulum. Grat. In Wäldern unter Moos. (Gat. Stbl.)

L. pallidum. Nordm. Unter Hoos sêlten. (Br. Gat.)

L. dilutum. Heer. Unter feuc!htem IIoos bei St. Leonhard. (Br.)

L. spadiceum. Er. Unter den von Grimmer in Steiermaik gesammelten unbestimmten Kïfern vorgefuncen. 
L. augusticolle, Lac. Unter Steinen an Flussufern. (Gr.)

L. scabricolle. Er. Unter Laub und Ioos im Gebirgeselten.(Br.Gat.)

Achenium. Stepl.

A. depressum. Grav. Unter Steinen und Laub, am Turt-Teiche (Kod.), bei St. Leonhard. (Sp.)

\section{Dolicaon. Tap.}

D. biguttatus. Lac. Unter Moos. 1 Ex. (Gat.)

\section{Chryptobium. Manu.}

C. fracticorne. Payk. Unter Laub und Moos häufig.

\section{Stilicus. Latr.}

St. fragilis. Grav. Unter Laub und Moos nicht häufig.

St. rufipes: Germ. Unter Laub und Moos.

St. subtilis. Er. Untel Laub und Moos.

St. similis. Er. Unter Laub und Moos. (Kod.)

St. orbiculatus. Payts. In Gärten um St. Lambrecht. (Kod.)

St. affinis. Er. Unter Steinen und Laub. (Kod.)

Scopaeus. Er.

Sc. Erichsonii. Kolen. Unter Moos 1 Ex. (Br.)

Sc. laevigatus. Gyll. Unter feuchtem Moose selten. (Gat.)

Sc. promillus. Kiesu. Unter feuchtem Moose selten. (Gat.)

Sc. minutus, Er. Unter Moos selten. (Gat. Br.)

Sc. minimus. En. Unter Moos. (Gat.)

\section{Lithocharis. Er.}

I. fuscula. Mann. Im Ausspiilicht der Mur. (Br.)

L. brunnea. Er. Unter Laub und Moos selten. (Br.)

L. ochracea. Grav, Unter Laub und Moos. (Gat. Br.)

I. melanocephala. Fabr. Unter Laub und Moos häufig.

I. obscurella. Er. Unter Laub und Moos selten. (Gat.)

Sunius. Steph.

S. filiformis. Latr. Unter Steinen an Bächen nicht selten.

S. angusiatus. Payk. Unter Steinen.

\section{Paederus. Grav.}

P. littoralis. Grav. Unter Moos an Bächen nicht selten.

P. brevipennis. Lac. An Bächen unter Mloos und Steinen.

P. riparius. L. An Ufern nicht selten.

P. longipennis. Er. Am Ufer der Mur bei Graz. (Br.)

P. limnophilus. El. Unter Laub an feuchtem Ort, an Bachufern.

P. ruficollis. Fabr. An Ufern der Mur sehr häufig.

\section{Euaesthetus. Grav.}

E. scaber. Grav. Unter faulenden Vegetabilien sehr selten. (Kod.)

Dianous. Curt.

D. coerulescens. Gy?l. Am Mursande bei Graz gegen Schönau sehr selten (Br.), bei Marialıof (Kod.) 


\section{Stenus. Latr.}

St. biguttatus. L. An sandigen Ufern liäufig.

St. lipunctatus. Er. An sandigen Ufern.

St. longipes. Heer. Am Mursande bei Graz gegen Schönau in mehreren Exemplaren (Br.)

St. guttula. Müll. Am Mursande um Graz nicht selten. (Br.)

St. bimaculatus. Gyll. An Bachufern selten. (Gat. Stbl.)

St. Juno. Fabr. An Ufern nicht selten.

St. ater. Mann. An Ufern unter Steinen. (Kod.)

St. buphthalmus. Grar. Anf sandigen Ufern. (Gl. Stbl.)

St. ruralis. Er. Am Ufer der Enns bei Admont. (Stbl.)

St. foraminosus. Er. Am Ufer des Thayabaches sehr selten. (Kod.)

St. morio. Grav. Am Ennsufer bei Admont. (Stbl.)

St. speculator. Lac. Auf sandigen Ufern nicht selten.

St. providus. Er. An Teichen in Schlammritzen selten. (Kod.)

St. aterrimas, $\mathrm{w}$. In Nestern der Formica rufa sehr selten. (Br.)

St. proditor. Er. Unter morschem Holze an einem T'eichufer bei St. Lamblecht sehr selten. (Kol.)

St. Argus. Giav. Auf sandigen Ufern. (Gr.)

St. fuscipes. Grav. (?)Von Kodermann selbst in Zweifel grezogen.

St. humilis. Er. Unter Moos nicht häufig.

St. circularis. Grav. Auf feuchten Ufern häufig.

St. nigritulus. Gyll. Unter Moos. (Stbl.)

St. crassiventris. Thoms. Unter Moos am Schöckl häufig. (Br.)

St. unicolor. El. Unter Steinen an Ufern salten. (Kod. Stbl.)

St. opticus. Grav. Am Ennsufer bei Admont. (Stbl.)

St. binotatus. Ljungh. Am Ufersande von Lachen und Teichen um St. Lambrecht (Kod.)

St. glacialis. Heer. Auf Alpen um Admont im Noose selten. (Stbl.)

St. impressus. Germ. Untel Moos. (Gat.)

St. flavipes. Er. Im Gebirge unter Mloos häufig.

St. pallipes. Grav. An Ufern im Ausspiilicht selten. (Kod. Stbl.)

St. tarsalis. Ljungh. Unter Moos selten. (Gat. Stbl:)

St. oculatus. Grav. Auf sandigen Ufern von Laehen bei St. Lambrecht. (Kod.)

St. cicindeloides. Grav, Auf sandigen Ufern läufig*.

St. paganus. Er. An Ufern. (Gat.)

\section{Oxyporis. Fabr.}

O. rufus. I. An Schwämmen hänfig.

O. maxillosus. Fabr. An Schwämmen nicht häufig. v. angularis. Gebl. An Schwämmen sehr selten. (Gat.)

\section{Bledius. Steph.}

B. tricornis. Hrbst, Im Ufersande der Mur sello selten. (Gat.)

B. aquarius. Er. Im Ufersande der Mur selten. (Gat. Br.)

B. subterraneus, Er. Im Ufersande oft liäufig.

B. pallipes, Grav. Im Ufersande der Mur. (Gr.)

B. tibialis. Heer. Im Sande der Mur bei Graz sehr selten. (Br.)

B. fossor. Heer. Am Ufer der Mur bei Graz gegen Schönau kurze Zeit in sehr grosser Menge. (Br.) 
B. opacus Block. Im Mursande sehr häufig.

B. fracticornis. Payk. Auf sandigen Ufern. (Kod.)

B. nanus. Ei, Auf Ufersand 1 Ex. (Gat.)

B. rufpennis. Er. Auf sandigen Ufern. (Gat. Br.)

B. erraticus. Er. Auf sandigen Ufern bei Admont selten. (Stbl.)

B. agririltor. Heer. Auf Ufersand. (Gat.)

\section{Platystethus. Manu.}

P. commtus. Grav. Bei faulenden Vegretabilien sehr häufig.

P. morsitans. Payk. Wie Voriger.

P. nodifions. Sahlb. Unter Laub selten. (Gat.)

\section{Oxytelus. Grav.}

O. vugosus, Fabr. Bei faulenden Vegetabilien häufig.

O. insectatus. Grav. Unter feuchtem Lanb selten. (Gat.)

O. piceus. L. Bei faulenden Vegetabilien häufig.

O. Luteipennis. Heer. In Mistbeeten in St. Lambrecht. (Kod.)

O. sculptus. Grav. Bei faulenden Vegetabilien. (Kod. Br.)

O. inustus. Grav. Unter Laub selten. (Gat. Stbl.)

O. sculpturatus. Grav. Bei faulenden Vegetabilien. (Gr. Stbl.)

O. complanatus. Er. Bei faulenden Vegretabilien selten. (Kod. Stbl.)

O. nitidulus. Grov. Bei faulenden Vegetabilien häufig.

O. depressus. Grav. Bei faulenden Vegetabilien sehr häufig.

O. pumilus, Er. Um St. Lambrecht sehr selten. (Kod.)

Maplorlerus. Steph.

H. caelatus. Gur. In trockenem Dünger nicht selten.

Thinodromus. $\mathrm{Kr}$.

Th. dilcetutus. Er. Am Schlamme der Mur oft häufig. (Br.)

\section{Trogophloens. Mann.}

T. scrobiculatus. Er. An Ufern selten. (Gr.)

T. riparins. Lac. An fenchten Ufern. (Gat.)

T. obesus. Kiesu. Auf Uferschlamm selten. (Gat.)

T. elongatulus. Er. An Ufern von Pfützen und 'Tejelicn oft häufig.

T. fuliginosus, Grav. Auf schlammigen Ufern selten. (Br.)

T. corticinus. Grav. Häufigste dieser Gattung.

T. exigurs. Heer. Unter Laub im Viihlbachgraben bei Rein $1 \mathrm{Ex}$.(Br.)

T. punctatellus. Er. An Ufern selir selten. (Gat.)

T. pusillus. Grav. An Ufern selten. (Gat.)

T. tenellus. Er. Am Ufersande der Mur bei Graz 2 Ex. (Br.)

\section{Thinobius. Kiesw.}

Th. longipennis. Heer. An Flussufern selten. (Br.)

\section{Ancyrophorus. Kr.}

A. Longipennis. Fairm. Unter feuchtem Moose bei Leonhard. (Sp.) A. angustatus. Er. Von Grimmer als in Steiermark vorkommend angegeben. 


\section{Syntomium. Lir.}

S. aenerm. Mïll. Am Grazer Schlossberge unter Laub selten (Br.), häufiger unter Ioos bei St. Leonhard. (Sp.)

\section{Coprophilus. Kr.}

c. striatulus. Fabr. Bei trockenem Dünger selten. (Br.)

Acrognathus. Er.

A. mandibularis. Gyll. Um St. Leonhard 1 Ex. (Sp.)

Deleaster. Er.

D. dichrous. Grav. In Ausspülicht der Bächə selten. (Gat.)

\section{Anthophagis. Grav.}

A. armiger. Grav. Im Gebirge nicht selten auf blïhendem Ahorn.

A. Austriacus. Er. Im Gebirge auf blïhendem Ahorn liäufig.

A. omalinus. Zett. Im Gebirge sehr selten. (Gat.)

A. caraboides. L. Im Miihlbachgraben bei Rein anf Erlen haufig. (Br.)

A. testaceus. Grav. Auf bliilienden Biischen nicht selten.

A. nigritus. Müll. Im Ausspïlicht der Mur selten. (Br.)

v. plagiatus. Fabr. (?)

\section{Lestera. Latr.}

L. pubescens. Ham. Am schmelzenden Schnee im Gebirge in Friihjahre in grosser Menge. (Br.)

L. punctata. Er. Von Kodermann als bei St. Lambreclit vorkommend angegeben.

\section{Acidota. Stepl.}

A. crenata. Fabr. In Gartenhause inte: Blummengeschirren (Kod.)

Olophrum. His.

O. assimile. Payk. Unter Moos 1 Ex. (Gat.)

Lathrimaeum. Er.

L. melanocephalum. Ill. Unter Laub nicht selten.

Amphichroum. Kr.

A. canaliculatum. Er. Auf blühenden Sträuchern nicht selten.

A. hirtellum. Heer. Auf blithenden Büschen selten. (Gat.)

Deliphrum. Er.

D. tectum Payk, Unter Moos selten. (Gat.)

Orochares. Kr.

O. angustata. Er. Unter den in Steiermark gesammelten unbestimmten Käfern Grimmers vorgefunden.

Arpedium. Er.

A. quadrum. Grav. Unter Hoos selten. (Gat. Stbl.) 


\section{Omalium. Grav.}

O. rivulare. Payk. Unter Laub und Moos häufig.

O. fossulatum. Er. Unter Laub. (Gat.)

O. caesum. Grav. Unter I aub und Moos häufig.

O. (xycuanthae. Grav. Auf blïhendem Gesträuch. (Kod.)

O. minimum. Er. Unter Rinde am Bacher bei Marburg. (Br.)

O. monilicorne. Gyll. Unter Laub. (Gr.)

O. planum. Payk, Unter Rinden am Bacher bei Marburg. (Br.)

O. pusillum. Grav. Unter Rinden nicht häufig. (Br. Kod.)

O. elegans. $K r$. Im Schwarzwalde bei St. Leonhard unter Moos 1 Lx. gesiebt. (Br.)

O. deplanatum. Gyll. Unter Laub und Moos. (Br.)

O. concinum. Marsh. Unter Rinde. (Kod.)

O. testacerm. Er. Unter Moos und Laub sehr selten. (Gat.)

O. brunneum. Payk. Unter Moos bei St. Leonhard. (Sp.)

O. lucidum. Er. Unter Rinde selten. (Gat.)

O. florale. Payk. Auf blühenden Sträuchern nicht selten.

O. nigrum. Grav. Auf Blithen selten. (Br.)

O. translucidum. Kr. Unter Laub bei St. Gotthard 2 Ex. (Br.)

O. amabile. Heer. Unter Laub sehr selten. (Gat.)

O. inflatum. Gyll. Unter Laub und Moos selten. (Br.)

\section{Eusphalerum. Kr.}

E. triviale. Er. Auf blühenden Stränchern um Graz: (Br.)

\section{Anthobium. Steph.}

A. abdominale, Grar. Auf Bliithen selten. (Kod.)

A. limbatum. Er. Auf blühenden Sträuchern nicht selten.

A. florale. Panz. Auf blühenden Biischen.

A. excavatum. Er. Auf Blïthen am Hoch-Lantsch. (Br.)

A. minutum. Falr. Auf Bliithen häufig.

A. anale. Er. Von Grimmer als in Steiermark vorkommend.

A. montanum. En. Im Gebirge anf Bliithen. (Gat. Stbl.)

A. longipenne. Er. Auf blühenden Ahorn in Gebirge sehr häufig.

A. puberulum. Kiesw. Im Gebirge anf Blithen. (Gat.)

A. scutellare. Er. Auf der Scheibleggeratpe. (Stbl.)

A. ophthalmicum. Payk. Auf Bliithen nicht selten.

A. torruatum. Marsh. Auf Bliuthen nicht häufig. (Gat, Br.)

A. Sorti. Gyll. Auf Bliithen sehr häıfig.

\section{Proteinus. Iatr.}

P. brevicollis. Er. In faulen Pilzen. (Gr.)

P. Wrachypterus, Fabr. Bei faulen Pilzen häufig.

P. atomarius. Er: Auf Gesträuch. (Kod. Br.)

\section{Megarthrus. Steph.}

M. depressus. Payk. Unter Moos und Laub am Bacher bei Marburg. (Br.)

M. affinis. Mill. Unter Laub. (Gat.)

M. renticollis. Beck. Unter Laub und Holzstïcken. (Kod.)

M. hemipterus. Ill. Unter Lanb und Holzstiicken. (Kod. Br.) 


\section{Phloeobium. Er.}

Ph. clypeatum. Müll. Unter den in Steiermark gesammeiten unbestimmten Käfern Grimmers vorgefunden.

\section{Phloeocharis. Mann.}

Ph. subtilissima. Mann. Unter Rinden nicht häiffig.

Prognatha. Latr.

P. quadricornis. Kirby. Unter Rinden. (Gr. Drnk.)

$P$. humeralis. Germ. Unter Papelrinden. (Gr.)

Micropeplus. Latr.

M. porcatus. Fabr. Unter Laub, iber Düngerhaufen schwärmend.

\section{Pselaphidae.}

Ctenistes. Reich.

Ct. palpalis. Reich. Unter Laub und Moos in der Nähe von Ameisen um Graz.

Tyrus. Aubé.

T. mucronatus. Panz. Unter Rinden selten.

Pselaphins. Hrbst.

P. Heisei. Hrbst. Unter Laub und Moos nicht selten.

P. Dresdensis. Hrbst. Unter Moos. (Kod. Sp.)

P. longicornis. Soulcy. Unter Moos bei Graz. (Tpk.)

Tyehis. Leach.

T. niger. Payk. Unter Laub und feuchtem Moos nicht selten. (Br.)

Trichonyx. Chand.

T. sulcicollis. Reich. Unter MnIme. (Sp.)

T. Märkelii. Aub. Im Mulme alter Bäume selten. (Br.)

Batrisus. Aub.

B. formicarius. Aub. Bei Ameisen sehr selten. (Sp. Br.)

B. venustus. Reich. Im Mulm alter Weidenbä̈ume in der Schönau bei Graz. (Br.)

B. oculatus. Aul. In einem alten Weidenbaume bei Graz. (Br.)

Bryaxis. Leach.

B. sanguinea. Lin. Unter Moos und Steinen.

B. fossulata. Reich. Unter MIoos und Steinen.

B. xanthoptera. Reich. Unter Steinen und $\mathbf{H}$ oos um St. Lambrecht sehr häufig. (Kod.) 
B. Lefebvrei. Aut). Nach Angabe Grimmers.

3. transversalis, Schanm. Unter Moos selten. (Gat.)

B. haematica. Reich. Unter feuchtem Moose. (Br. Stbl.)

B. antennata. Aub. Untel Moos selten. (Gat.)

B. Helferi. Schmidt. Unter Moos. (Gat.)

\section{Bythimus. Leach.}

B. puncticollis. 7)enny. Unter Laub und Moos häufig.

B. clavicornis. Panz. Unter Moos bei St. Leonhard. (Sp.)

B. Chaudoirii. Chd. Unter Moos und Laub am Reinerkogel bei Graz häufig. (Br.)

B. femoratus. Anb. Unter Moos. (Gat.)

B. bulbifer. Reich. Unter Moos nicht häufig.

B. Curtisii. Denmy. Unter MLos. (Gat.)

B. nodicornis. Aub. Unter Moos. (Gat.)

B. securiger. Reich. Unter Moos. (Sp.)

B. Burellii. Denmy. Unter Laub und Moos. (Br.)

Euplectus. Leach.

E. Fischerii. Aub. Im Mulme alter Weiden selten..(Bi.)

E. signatus. Reich. Unter Moos und Laub. (Gr.)

E. Karstenii. Reich. In Nestern der Formica rufa. (Br.)

E. mams. Reich. Bei faulenden Vegetabilien. (Gat.)

Trimium. Aub.

T. brevicorne. Reich. Unter Laub und Moos. (Br.)

\section{Clavigeridae.}

\section{Claviger. Preys.}

C. longicornis. Mirl. Un St. Leonhard selten. (Sp.)

C. foveolatus, Miill. Unter Steinen bei Ameisen.

\section{Scydmaenidae.}

Cephennium. Miill.

C. thoracicum. Muill. Uriter Lanb und Moos häufig.

C. fulvum. Schaum. Unter Moos bei Voitsberg nicht selten. (Br.)

Euthia. Steph.

E. abreviatella. En. Unter Laub und Moos. (Sp. Gat,) 


\section{Scydmaenus. Latr.}

Sr. Godarti. Latr. In faulen Buchen. (Gr.)

Sc. scutellaris. Miill. \& Kz. Unter Moos und Laub. (Br. Gat.)

Sc. collaris. Müll. \& Kunz. Unter Moos am Bacher bei Marburg. (Br.)

Sc. pusillus. Müll. \& Kz. Unter Holzstïcken auf nassen 'Triften. (Kod.)

Sc. angulatus. Miill. \& Kz. Unter Moos. (Gat.)

Sc. elongatulus. Müll. \& Kz. Unter Moos.

Sc. rubicundus. Schaum. Bei faulen Vegetabilien sehr selten (Kod).

Sc. pubicollis. Müll, \& Kz. Unter Moos.

Sc. Styriacus. Schaum. Unter Moos am Schöckl bei Graz, besonders häufig am Bacher bei Marburg. (Br.)

Sc. oblongus. Sturm. Unter Moos am Bacher. (Br.)

Sc. Motschulskii. Stum. Unter Moos und Laub uin Graz.

Sc. denticornis. Muill. \& Kz. Unter Moos. (Gr.)

Sc. rutilipennis. Müll. \& Kz. An Ufern der Teiche um St. Leonhard selten. (Sp.)

Sc. hirticollis. Ill. Unter Moos.

Sc. claviger. Müll. \& $K z$. Von Grimmer in Steiermark gefunden.

Sc. Wetterhalii. Gyll. Unter Laub und Moos.

Sc. nanus. Schaum. Unter Steinen. (Kod.)

Sc. minutus. Chand. Unter Hoos und Lanb. (Sp.)

Sc. tarsatus. Müll. \& Kz. Unter Steinen bei Vegetabilien.

Sc. Helwigii. Fabr. Unter Moos (Sp.), bei Ameisen. (Kod,)

Sc. rufus. Müll. \& Kz. Unter Moos im Gebirge. (Gat. Sp.)

\section{Silphidae.}

Leptinus. Miill.

L. testaceus. Mäll. Unter schimmligem Moose bei St. Ulrich bei Graz selten, (Br.)

\section{Choleva. Latr.}

Ch. angustata. Fabr. In Kellern in St. Lambrecht. (Kod.)

Ch. cislelloides. Fröh. An Schwämmen selten.

Ch. ogilis. Ill. Bei faulenden Vegetabilien. (Sp.)

Ch. strigosa. $K r$. Bei faulenden Vegetabilien. (Sp.)

Ch. badia. Sturm. Bei faulenden Vegetabilien. (Gat.)

\section{Catops. Payk.}

C. picipes. Fabr. Bei faulenden Vegetabilien.

C. fuscus. Panz. Bei faulen Vegetabilien. (Sp.)

C. nigricans $v$, fuliginosu.s. Fr. Bei faulen Vegetabilien. (Kod. Gat.)

C. morio. Fabr. Bei faulen Vegetabilien. (Sp.)

C. nigirita. Er. Bei faulen Vegetabilien. (Sp. Gat.)

C. grandicollis, Er. Bei faulen Vegetabilien selten. (Gat.)

C. chrysomeloides. Panz. Bei faulen Vegetabilien nicht selten.

C. longulus. Kell. An Fässern im Keller. (Kod.)

C. tristis. Panz. Bei faulenden Vegetabilien. 
C. alpinus. Gyll. Bei faulenden Vegetabilien anf Alpen selten.

C. Wulsoni. Sp. Bei faulen Vegetabilien nicht selten.

C. sericeus: Panz. Unter Laub und Moos am Rainerkogel bei Graz. (Br.)

C. anisotomoides. Spenc. Unter Laub am Raínerkogel bei Graz. (Br.)

Colon. Hrbst.

C. Viennense. Hrbst. Auf Grashalmen. (Gat.)

C. ciavigerum. Hrbst. Auf Blïthen und Gras. (Gr.)

C. murinum. Kr. Unter Moos am Bacher. (Br.)

C. appendiculatum. Sahlbg. Auf Grashalmen. (Gat.)

C. ealcaratum. Er. Auf Grashalmen.' (Gat.)

C. brunneum. Latr. Auf Blüthen und Grashalmen selten.

\section{Necrophilus. Ill.}

N. subterraneus. Dahl. Im nördlichen Steiermark häufig bei todten Schnecken unter Steinen, seltener im suidlichen Steiermark.

\section{Silpha. L.}

S. littoralis. L. Bei Aas nicht häufig.

S. thoracica. L. Auf Aas sehr häufig.

S. quadripunctata. L. Auf jungen Eichen im suidlichen Steiermark nicht häufig. (Sp. Ltgb.)

S. rugosa. L. Auf Aas häufig.

S. sinuata. Fabr. Auf Aas.

S. dispar. Hrbst. Um St. Lambrecht sehr selten (Kod.), häufiger bei St. Leonhard. (Sp.)

S. ораєи. L. Auf Feldern unter Steinen.

S. carinata. I'l. Unter Laub und Steinen selten.

S. reticulata. Fabr. Unter faulem Laub.

S. nigrita. Creutz. Bei kleinen Aeser'u hänfig.

S. obscura. L. Unter Steinen und Laub häufig.

S. laevigata. Fabr. Unter Steinen und Laub bei St. Leonhard.(Sp.)

S. atrata. L. Unter Steinen und Laub häufig.

\section{Necrophorils. Fabr.}

N. humator. Fabr. An grösseren Aesern nicht séltèn.

N. vespillo. L. Häufig anf Aas.

N. fossor. Er. Nicht so häufig wie der Vorige.

N. ruspator. Er. Auf Aas bei St. Lambrecht. (Kod.)

N. mortuorum. Fabr. Auf kleinen Aesern.

\section{Agyrtes. Frïh.}

A. castaneus. Payk. Oft häufig herumschwärmend.

Sphaerites. Duft.

S. glabratus. Fabr. Auf todten Schnecken am Bacher. (Sp.)

\section{Hydnobis. Schm.}

H. punctatissimus. Steph. An Schwämmen im Gebirge selten. (Gat.)

H. punctatus. Sturm. Wie Voriger doch seltener. (Gat.) 


\section{Anisotoma. Ill.}

A. cinnamumea. Panz. Bei faulen Schwäinmen (Gr. Sp.)

A. rugosa. Er. In Schwämmen bei St. Lambrecht (Kod.)

A. dubia. Kug. In Schwämmen (Gat.)

A. pallens. Sturm. In Schwämmen (Gat. Br.)

A. ovalis. Sclom. In Schwämmen (Gat.)

A. calcarata. Er. In Schwämmen (Gat.)

A. badia. Sturm. In Schwämmen (Gat.)

A. hybrida. Er. In einem Birkenschwamm bei St. Lambrecht (Kod.)

A. obesa. v. brunnea. Sturm. In Schwämmen (Sp. Gat.)

\section{Cyrtusa. Er.}

C. minuta, Ahr. Bei Schwämmen (Gat.)

C. subtestacea. Gyll. Bei Schwämmen, unter Laub (Gat. Br.)

Colenis。Er.

C. dentipes. Gyll. Unter Laub am Rainerkogl bei Graz (Br.)

Liodes. Latr.

L. humeralis. Fabr. In Schwämmen nicht selten.

L. axillaris. Gyll. In Schwämmen nicht häufig.

L. glabra. Kug. In Baumschwämmen sehr selten (Kod.)

L. castanea. Hrbst. In morschem Holze (Kod. Sp.)

L. orbicularis. Hrbst. In Baumschwämmen (Kod. Sp.)

\section{Amphicyllis. Er.}

A. globus. Fabr. Unter Laub am Rainerkogel bei Graz (Br.)

A. globiformis. Sahlb. Unter Laub selten (Gat. Sp.)

\section{Agathidium. Ill.}

A. nigripenne. Falr. In morschem Holze (Gr. Gat.)

A. atrum. Payk. Unter morscher Rinde (Kod. Gat.)

A. laevigatum. Er: Unter Rinde (Kod.)

A. seminulum. L. Unter Lanb (Gat.)

A. badium. Er. Unter mor'scher Ahornrinde (Kod.)

A. mandibulare. Sturm. In morschem Holze

A. varians. Beck. Unter morscher Rinde (Kod.)

A. discoideum. Er. Unter Laub (Gat.)

A. marginatum. Sturm. Unter morschem Holze (Kod.)

\section{Clambidae.}

Clambus. Fisch.

C. Armadillo. de Geer. Bei faulenden Vegetabilien häufig:

C. pubescens. Redt. Unter fauler Rinde selten (Kod.) 


\section{$-37-$ \\ Sphaeriidae.}

Sphaerius. Waltl.

S. ucaroides. Walll. Bei St. Lambrecht in feuchten Sande selten(Kod.)

\section{Trichopterygidae.}

Ptenidium. Er.

P. pusillum. Gyll. Bei faulenden Vegetabilien.

P. apicale. Er. Wie Voriger.

Ptilinm. Er.

P. Saxonicum. Gillm. In St. Lambrecht einigemal auf Gurken gefangen (Kod.)

$P$. angustatum. En. In St. Lambrecht in Gärten (Kod.)

P. inquilinum. Er. In Nestern der Formica rufa (Br.)

P. excavatum. Fr. Bei faulenden Vegetabilien (Sp.)

Elachyx. Math.

E. abbreviatellus. Heer. St. Lambrecht (Kod.)

Trichopteryx. Kirby.

T. atomaria. de Geer. Unter Laub häufig.

T. fascicularis. Hrbst. Unter Laub häufig.

T. thoracica. Gillm. Bei faulen Vegetabilien (Kod.)

T. Urevipennis. Er. Unter Laub (Br.)

T. pygmaea. Er. Unter Laub-(Br.)

T. sericans. Hrbst. Unter laab (Kod.)

T. pumila. Er. Unter Laub (Kod.)

\section{Scaphidiidae.}

Scaphidium. 0l.

Sc. quadrimaculatum. Ol. Unter morschen Rinden, an Baumschwämmen häufig.

Scaphium. Kirby.

Sc. immaculatum. Ol. An Weidenschwämmen um Graz selten (Gr.Sp.) 


\section{Scaphisoma. Leach.}

Sc. agaricinum. Ol. In morschem Holz sehr häıfig.

Sc. boleti. Panz. An Baumschwämmen (Gat.)

Sc. assimile. Er. In moderigem Holze bei Voitsberg (Br.)

Sc. limbatum. Er. Unter morscher Rinde (Sp.)

\section{Histeridae.}

Hololepta. Payk.

H. plana. Fiiss. Unter Papelrinde selten (Gr. Sp.)

Platysoma. Leach.

P. frontale Payk. Unter Rinde selten (Gat.)

P. depressum. Fabr. Unter Rinde nicht häufig.

P. oblongrm. Fabr. Unter morscher Rinde.

$P$. lineare Er. Unter Baumrinden (Kod.)

P. angustatum. Ent. Heft. Unter Rinden nicht häıfig (Gr. Kod.)

Hister. L.

H. quadrimaculatus. L. Im Dïnger häufig.

H. unicolor. $L$. Im Diinger häufig.

H. cadaverinus. Ent. Heft. Wie Vorige.

H. terricola. Germ. Auf Viehweiden.

H. merdarius. Ent. Heft. Im Diinger häufig.

H. neglectus. Germ. An kleinen Aesern selten (Kod.)

H. purpurascens. Hrbst. Auf Alpenweiden im Diinger.

H. stercorarius. Ent. Heft. Im Düngrer häufig.

H. quadrinotatus. Scrib. Im Dünger.

H. bis-sexstriatus. Fabr. Im Dünger nicht selten.

H. bimaculatus. L. Auf Viehweiden sehr selten (Kod.)

H. duodecimstriatus. Schr. Im Dünger selten (Gat.)

H. corvinus. Gern. Im Diinger.

Paromalus. Er.

P. complanatus. Ill. Unter Rinde bei St, Leonhard (Sp.)

P. parallelopipedus. Hrbst. Unter Rinden häufig.

P. flavicornis. Hrbst. Unter Rinden nicht selten.

Hetaerius. Er.

H. quadratus. Ill. Unter Steinen bei Formica fusca.

Dendrophilus. Leach.

D. punctatus. Hrbst. Im Baummoder (Gat.)

D. pygmacus. L. In Nestern der Formica rufa am Bacher bei Marburg in Mehrzahl. (Br.) 
Saprintus. Er.

S. semipunctatus, Fabr. Von Grimmer angegeben.

S. nitidulus. Payk. In Dünger und auf Aas.

S. aenens. Fabr. In Dünger und auf Aas häufig.

S. virescens. Payk. Von Grimmer angegeben.

S. lautus. Er. An Aas (Gat.)

S. conjungens. Payk. In Dünger (Gr: Gat.)

S. quadristriatus. Ent. Heft. Am Mursande bei Gratwein (Br.)

S. rugifrons. Payk. In Diinger selten (Gat.)

\section{Gnathoncus. Duv.}

G. rotundatus. Ill. An faulen Baumstämmen.

\section{Teretrius. Er.}

T. picipes. Fabr. Unter Rinden selten (Br.)

Plegaderus. Er.

P. vulneratus. Panz. Unter Baumrinden selten (Kod. Gat.)

$P$. cuesus. Ill. Im Mulme alter Bäume nicht selten.

P. discisus. Er. Unter Rinden um Voitsberg sehr häufig (Br.)

\section{Onthophilus. Leach.}

O. sulcatus Fabr. Unter Diinger selten (Gat.)

O. striatus. Fabr. Unter Diinger selten.

O. affinis. Redt. Wie Vorige jedoch sehr selten (Gat.)

\section{Abraeus. Leach.}

A. globulus. Creutz. In trockenem Kuhdiinger häufig.

A. globosus. Ent. Heft. In trockenem Kuhdiinger (Gat.)

\section{Acritus. IL Conte.}

A. minutus. Fabr. In trockenem Dünger häufig (Gat.)

\section{Phalacridae.}

Phalacrus. Payk.

Ph. corruscus. Payk. Unter Laub häufig.

Oilbrus. Er.

O. corticalis. Sch\%. Auf Blüthen nicht "selten.

O. aеneus. Ill. Auf Bliithen selten (Gr. Br.)

O. bicolor. Fabr. Auf Blüthen häufig.

O. liquidus. Er. Auf Bliithen nicht hänfig.

O. affinis. Sturm. Auf Wiesen bei St. Lambrecht (Kod.)

O. Millefolii. Payk. Anf Blïthen. 
O. pygnaeus. Stum. Auf Blüthen (Gr.)

O. geminus. Ill. Alif Bliithen niclit selten.

O. piceus. Steph. Auf Blïthen (Kod.)

\section{Nitidulariae.}

Cercis. Latr.

C. pedicularius. L. Auf blühendem Gesträuch nicht häufig.

C. bipustulatus. Payti. Anf Blithen selten (Gr. Gat.)

C. Sambuci. Er. Auf Bluthen im Gebirge (Gat. Br.)

C. Rhenamus. Bach. Auf Bliithen selten (Gat. Br.)

C. rufiabris. Latr. Auf Blithen um St. Leonhard (Sp.)

\section{Brachẹpterus. Kлg.}

Br. gravidus. Ill. Auf Bliithen selten (Gr. Gat.)

$B r$. cinereus. Heer. Auf Bliithen (Gat.)

Br. Triticae. Fallr. Auf Bliithen nicht selten.

Epuraea. Er.

E. decemguttata. Fabr. An ausfliessendem Safte selten (Sp. Gr.)

E. silacea. Hrbst. Auf Doldenbliithen (Br.)

E. aestiva. L. Auf Bliithen nicht selten.

v. bisignata. Sturm. Unter Baumrinden (Kod.)

E. melina. Er. Auf Bliithen und Dolden häufig.

E. immunda. Er. Auf Bliithen (Kod. Br.)

E. variegata. Hibst. Auf Bluthen und Dolden.

E. castanea. Duft. Ton Kahr in Steiermark gesammelt.

E. neglecta. Heer. Auf Blithen (Sp. Gat.)

E. obsoleta. Fabr. Auf Bliithen und Dolden häufig.

E. distincta. Er. An Baumschwämmen (Gr.)

E. angustula. Er. Unter fauler Fichtenrinde nicht selten (Kod.)

E. pygmaea. Gyll. An ausfliessendem Safte (Gr. Kod.)

E. pusilla. Ill. Auf Blithen und Dolden sciten.

E. oblonga. Hrbst. An ansfliessendem Safte nicht selten (Kod.)

E. longula. Er. Anf Blithen bei St. Lambrecht I Ex. (Kod.)

E. Alorea. Er. Anf Bliitlien und Dolden (Gat. Br.)

E. melanocephala. Marsh. Enter Rinden nicht selten.

E. limbata. Fabr. Unter Rinden häufig.

Nitidula. Fabr.

1. bipustulata. Fabr. Bei fanlendem Fleische nicht häufig.

1. Aexuna. Fabr. Cm St."Leonhard selten. (Sp.)

N. vnipipes. L. Bei faulendem Fleische nicht hä̈ufig.

N. quadripustulata. Fabr. An Aas (Gr. Gat.)

Soronia. Er.

S. grisea. L. An ausfliessendem safte häufig. 


\section{Ipidia. Err.}

I. quadinotata. Fabr. Unter Rinden nicht selten.

\section{Amphotis. Er.}

A. marginata. Fabr. An ausfliessendem Safte.

\section{Omosita. Er.}

O. colon. L. An Aas häıfig.

O. discoillea. Fabr. Wie Vorige.

\section{Thalyera. Er.}

T. fervida. Gyll. Unter schimmligem Moose (Gr.), bei Voitsberg in Bovisten (Ulrch.)

\section{Pria. Steph.}

P. Dulcamarae. Ill. Auf Solanum dulcamara selten (Gat.)

\section{Meligethes. Kirby.}

M. rufipes. Gyll. Auf Blithen nicht selten.

M. lumbarius. Sturm. Arif Bliithen selten.

M. Tehes. Er. A uf Bliithen selten. (Br.)

M. veneus. Fabr. Auf Blithen sehr häufig.

1. virirescens. Falr. Anf Blithen selten.

M. coracinus. Sturn. Anf Blithen und Dolden.

M. suncueus. Stmm. Von Kahr in Steiermark gesammelt.

II. subrugosus. Gyll. An ansfliessendem Safte (Kod.)

.1. symphiti. Heer. Auf Symplyytum tuberosum (Kod.)

1. octropus. Sturm. Anf Bliithen selten (Kod.)

I. difficilis. Heer. Anf Blithen sehr selten (Kod.)

M. morosus. Er. Auf Bliithen selten.

H. brumicornis. Stum. Auf Bliithen selten.

1. viduatus. Sturm. Auf Blithen und Dolden häufig.

M. pedicularius. Gyll. Anf Bliithen häufig.

M. assimilis. Sturm. Auf Bliithen selten.

M. serripes. Gyll. Anf Bliithen häufiy.

I. umbrosus. Sturm. Auf Bliithen selten (Kod.)

M. maurus. Sturm. Auf Bliithen (Gat. Stbl.)

M. incanus. Stum. Auf Blithen und Dolden.

M. tristis. Sturm. Auf Bliithen (Stbl.)

M. murimus. Er. Auf Blithen selten (Stbl.)

M. fuliginosus. E⿰. Von Kahr in Steiermark gesammelt.

11. picipes. Sturm. Auf Bliithen (Grat,)

M. lugubris. Sturm. Auf Blithen selten (Kod.)

M. egenus. Er. Von Kahr in Steiermark gesammelt.

.. obscurus. Liv. Auf Blithen selten (Kod.)

1. cxilis. Sturm. Auf Blüthen sehr selten (Kod.)

\section{Pocadius. Er.}

P. ferrugineus. Fabr. An Baumschwämmen nicht selten. 


\section{Cyllodes. Er.}

C. ater. Hrbst. In Schwämmen am Bacher (Sp.), unter Rinden ('Tpk.)

\section{Cychramus. Kugel.}

C. quadripustulatus. Hrbst. Auf bliihenden Sträuchern (Gr. Br.)

C. fungicola. Heer. Auf blühenden Sträuchern (Gat)

C. luteus. Fabr. Wie Vorige, sehr häufig.

Cybocephalus. Er.

C. exiguus. Sahl. Bei faulenden Vegetabilien (Gat.)

Cryptarcha. Shuck.

C. strigata. Fabr. Unter morscher Rinde (Gr. Sp.)

C. imperialis. Fabr. An Baumschwämmen selten (Sp.)

$$
\text { Ips. Fabr. }
$$

I. quadriguttatus. Fabr. Unter Rinden selten (Gr. Sp.)

I. quadripunctatus. Hibst. Unter Rinden (Kod)

I. quadripustulatus. Fabr. Unter Rinden nicht selten

I. ferrugineus. Fabr. Unter Rinden nicht häufig.

\section{Rhizophagus. Hrbst.}

R. depressus. Fabr. Unter Rinden selten.

R. ferrugineus. Payk: Unter Rinden.

R. parallelocollis. Gyll. Unter Rinden häufig.

R. dispar. Payk. Unter Rinden nicht lä̈nfig.

R. bipustulatus. Fabr. Unter Rinden häufig.

R. politus. Hellw. Unter Rinden nicht selten

R. coeruieipennis. Sahlb. Unter Buchenrinde am Bacher (Sp.)

R. parvulus. Payk. Unter Rinden bei St. Leonhard (Sp.)

\section{Trogositidae.}

Nemosoma. Latr.

$N$. elongatum. $L$. Unter der Rinde dürrer Aeste selten.

Temnochila. Er.

T. coerulea. Ol. Von Grimmer als in Steiermark gesammelt angegeben.

Trogosita. 01.

T. Mauritanica. L. An Baumschwämmen, unter Rinden.

Peltis. Geoffr.

$P$. grossa $L$. Unter morscher Rinde nicht selten.

$P$. ferruginea. $L$. An Baumschwämmen, unter Rinden häufig. 
P. obronga. L. An Baumschwämmen, unter Rinden selten.

P. dentata. Fabr. Unter schimmliger Rinde sehr selten im Hochgebir.ge (Gr. Gat.)

\section{Thymalus. Latr.}

T. limbatus. Fabr. An Baumschwämmen im Gebirge nicht selten.

\section{Colydiidae.}

Sarrotrium. Ill.

S. clavicorne. L. Im Moose und Gẹniste nicht häufig.

Diodesma. Latr.

D. subterranea. Er. Unter Laub und Moos nicht selten.

Eudophloeus. Er.

E. spinulosus. Latr. Unter Rinden selten (Sp.)

Coxelus. Iatr.

C. pictus. Sturm. Auf dürrem Holze sehr häufig.

Ditoma. Ill.

D. crenata. Hrbst. Unter Rinden häufig.

Xylolaemus. Redt.

X. fasciculosus. Gyil. Unter Ahornrinde am Hoch-Lantsch 3 Exempl. (Ulrch.)

\section{Synchita. Hellw.}

S. Inglandis. Fabr. Auf dürren Aesten häufig.

S. Mediolanensis. Redt. Auf duirrem. Holze selten; bei Neuberg (Drnbk.), bei St. Leonhard (Sp.)

\section{Colobicus. Latr.}

C. emarginatus. Latr. Unter Rinden bei St. Leonhard (Sp.)

(icones. Curt.

C. variegatus. Hellw. Auf diirrem Holze bei St. Leonhard (Sp.)

Aulonium. Er.

A. sulcatum. Fabr. Aus Ulmenholz gezogen (Sp.)

Colydium. Fabr.

C. elongatum. Fabr. Unter Rinden selten.

Bothrideres. Er.

B. contractus. Gyll. Auf dürren Aesten, unter Rinden (Sp. Tpk.) 
Pycnomerus. Er.

P. terebrans. Ol. Im Moder alter Wichen (Sp. Gat.)

Cerylon. Latr.

C. histeroides. Fabr. Unter Rinden sehr häufig.

C. ungustatum. Er. Unter Rinden bei St, Leonhard (Sp.)

C. deplanitum. Gyll. Unter Rinden (Sp. Br.)

\section{Cucujidae.}

Prostomis. Latr.

P. mandibularis. Fabr. Unter Rinden selten.

Oucujus. Fabr.

C. sangrinolentus $I$. Unter Papelrinde im Miihlbachgraben bei Rein 3 Larven (Br.), bei St. Leonhard (Sp.)

Brontes. Fabr.

B. planatus. L. Unter Rinden häufig.

\section{Laemophloetis. Er.}

L. denticulatus. Prays. Unter Rinden nicht häufig.

L. muticus. Falr. Unter Erlenrinde selten.

L. castaners. En. Unter Riuden selten (Sp. Gat.)

L. testaceus. Falr. Unter Rinden.

L. duplicatus. Waltl. Unter Rinden selten (Sp. Gat.)

L. ferrugineus. Steph. Unter Rinden (Sp. Gat.)

L. ater. Ol. Unter Rinden um St. Leonhard selten (Sp.)

L. Clematidis. Er. Unter Rinden.

\section{Diphillus. Shuk.}

D. lunctus. Fals. Auf diirrem Holze sehr selten (Sp.)

Diplocoelus. Guér.

D. Fagi. Guér. Auf dürrem Holze (Sp. Ulrch.)

Phloeostichus. Reilt.

Ph. denticollis. Redt. Unter Ahornrinde an Hoch-Lantsch häufig; cinzeln auch auf anderen Alpen unter gluichen Verhältnissen.

\section{Silvanus. Latr.}

S. frumentarius. Fabr. Unter Rinden (Sp.)

S. bidentatus. Fabr. Unter morscher Rinde nicht selten.

S. unidentatus. Fabr. Unter morscher Rinde sehr häufig.

Monotoma. Hrbst.

M. picipes. Payk. Bei faulenten Vegetabilien (Gr. Gat.) 
M. scabra. Kunz. Bei faulenden Vegetabilien (Gr.)

M. quisquiliarium. Redt. B i faulen Vegetabilien (Br.)

M. conicicollis. Aub. In Nestern der Formica rufa am Bacher ( $\mathrm{Br}$. $)$

M. spinicollis. Aub. Bei faulenden Vegetabilien (Gat.)

M. quadrifoveolata. Aub. Wie Vorige (Gat.)

M. quadricollis. Aub. Wie Vorige, selten (Gat. Br.)

M. longicollis. Gyll. Bei faulen Vegetabilien (Gr. Sp.)

\section{Cryptophagidae.}

Telmatophilus. Heer.

T. Sparganii. Heer. An Teichen um St. Leonhard (Sp.)

T. Typhae. Fall. Auf Wiesen (Gr.)

T. Caricis. Ol. An Teichen um St. Iseonhard (Sp.)

T. Schönherri. Gyll. Auf Gras 1 Lxempl. geschöpft (Gat.)

\section{Antherophagus. Latr.}

A. nigricornis. Fabr. Auf Bliuthen selten (Sp. Gat.)

A. silaceus. Hrhst. Auf́ Bliithen sehr selten (Kod.)

A. pallens. Ol. Anf Blüthen und Gras nicht häufig.

\section{Emphylus. Er.}

E. minutus. miki. In Nestern der Formica rufa am Bacher in der Nähe der Heinrichskapelle in Mehrzahl gefunden (Br.)

\section{Cryptophagus. Hrbst.}

C. Lycoperdi. Hi.hst. Unter dumpfem Moose.

C. pilosus. Gyll. Bei faulenden Pflanzen selten (Kod.).

C. Buldensis. Er. Unter Moos auf (ler Spitze des Schöckl (Br.)

C. saginatus. Sturn. Unter Laub und Moos häufig.

C. umbratus. Er. Unter fiulender Baumrinde (Kod.)

C. Scanicus. L. An Baumschwämmen (Kod. Gr.)

$\because$ badius. Sturm. Bei faulenden Vegetabilien häufig (Kod.)

C. labilis. Er. In Baumschwämmen selten (Kod.)

C. cellaris. Scop. Unter Laub und Moos häıfig.

C. fumatus. Gyll. Unter Laub und Moos (Kod. Br.)

C. acutangulus. Gyll. Unter Laub und Moos (Br.)

C. dentatus. Hrbst. Unter Laub und Moos (Gat. Kod.)

C. distinguendus. Sturm. Unter Laub und Moos (Br.)

C. bicolor. Sturm. Bei faulen Vegetabilien selten (Kod. Stbl.)

C. bimaculatus. Panz. An Baumchwämmen selten. (Kod.)

C. dorsalis. Sahlbg. Unt $r$ Laub und Moos selten (Kod. Gat.)',

C. subdepressus. Gyll. Unter Lanb ind Moos (Gat.)

C. villosus. Heer. (?) Unter Laub (Br.)

C. cremulatus. Er. In Pilzen sehr selten. (Kod.)

C. pulbescens. Sturm. Unter Moos (Gat.) 


\section{Paramecosoma. Curt.}

P. melanoceplealum. Hrbst. Unter Laub bei St. Gotthard (Gat.) P. serratum. Gyll. Unter Lilub und Moos selten (Sp. Br.)

\section{Atomaria. Steph.}

A. ferruginea. Sahlb. Unter Laub (Gat.)

A. fimetarii. Hrbst. Bei faulenden Vegetabilien sehr häufig.

A. nana. Er. An schimmligem Brode (Kod.)

A. umbrina. Gyll. Unter Geniste (Gat.)

A. pulchra. Er. Von Kahr in Steiermark gesammelt.

A. elongatula. Er. Bei faulenden Vegetabilien häufig.

A. unifasciata. Er. Unter Laub selten (Sp.)

A. mesomelas. Hrbst. Bei faulenden Vegetabilien häufig.

A. gutta. Steph. (?) In Pilzen nicht häufig (Kod.)

A. fuscipes. Gyll. Unter Laub (Gr.)

A. impressa. Er. Unter Laub bei St. Gotthard (Br.)

A. bicolor. En. Von Kahr in Steiermark gefunden.

A. nigripennis. Payk. Unter Laub und Moos (Korl. Tpk.)

A. cognata. Er. Bei faulen Erdäpfeln (Kod.)

A. atra. Hibst. Bei faulenden Vegetabilien nicht selten.

A. gibbula. Er. Unter faulem Lanb (Gat.)

A. fuscata. Sch. Unter Laub (Kod. Br.)

A. apicalis. Er. Unter Laub (Gat.)

A. gravidula. Er. Unter faulem Laub (Gat.)

A. pusilla. Payk. Unter Laub und Moos nicht selten.

A. turgida. Er. Unter faulem Laub (Gat.)

A. analis. Er. Bei faulendem Kohl häufig (Kod.)

A. versicolor. Er. Unter Moos am Bacher (Br.)

\section{Ephistemus. West.}

E. globosus. Waltl. Unter fauleuden Vegetabilien.

E. gyrinoides. Marsh. Wie Voriger.

E. globulus. Payk. Wie Volige.

E. exiguzs. Er. Wie Vorige (Kod.)

\section{Lathridiidae.}

\section{Myrmecoxenus. Cherr.}

M. subterraneus. Chevr. In Nestern der Formica rufa am Bachergebirge sehr häufig (Br.)

\section{Lathridius. Ill.}

L. lardarius de Geer. Bei schimmligen Pflanzenstoffen sehr häufig (Kod.)

L. angusticollis. Hum. Unter Lanb und Moos.

$L$, alternans. Marsh. Unter Laub und Moos (Br. Sp) 
L. rugicollis. Ol. Unter Laub und Moos selten (Krit. Sp.)

L. incisus. Mann, Unter Laub selten $\left(\mathrm{Br}_{\mathrm{r}}\right.$ )

L. constrictus. Gyll. Unter Laub am Rainerkogl (Br.)

L. elongatns. Curt. Unter Laub bei St. Gutthard (Br.)

L. clathratus. Mann. Unter Laub selten.

L. liliputanus, Mamn. Unter Ahornrinde am Hoch-Lantsch (Br.)

L. exilis. Mann. (?) Bei faulenden Pflanzenstoffen sehr häufig. (Kod.)

L. rugosus. Itrbst. Unter faulendem Laube und Moos.

$L$. transversus. Ol. Unter Laub.

L. mimutus. $L$. Unter Laub.

L. assimilis. Mann. Unter Laub und Moos (Gat.)

L. scitus. Mann. Im Auskehricht häufig (Kod.)

L. carbonarius. Mann. Unter Laub und Moos (Gat. Sp.)

L. filiforniis. Gyll. Unter Laub (Gr.) (?)

Corticaria. Ill.

C. pubescens. Gyll. Im Mulme hohler Bäıme (Kod. Br.)

C. piligera. Mann. Unter faulen Vegetabilien (Sp. Kod.)

C. crenulata. Gyli. Im Moder alter Bäume (Br.)

C. impressa. Ol. Unter Laub nicht häufig. (Kod.)

C. bella. Redt. Unter Lanb (Sp.)

C. serrata. Payk. Unter Laub (Gr. Gat.)

C. Longicollis. Zetl. In Nestern der Formica rufa am Bacher häufig (Br.)

C. longicornis. Gyll. Unter Laub sehr selten (Kod.)

C. cylindrica. Mann. Unter Laub selten (Br. Stbl.)

C. elongata Gyll. 'Unter Laub und Moos häufig.

C. giblosa. Hibst. Unter Laub häufig.

C. transversalis. Gyll. Unter Laub (Gat.)

C. bvevicollis. Mann. Unter Laub (Gat.)

C. fuscula. Gyll. Unter Laub nicht selten.

$v$. trifoveolata. Redt. Bei Pflanzenresten häufig (Kod.)

C. truncatella. Mann. Bei faulen Vegetabilien.

C. distinguenda. Com。 Bei faulen Vegetabilien (Gr. Gat.)

Dasycertls. Brog.

D. sulculus. Brog. Unter Laub und Moos selten (Sp. Gatt.)

\section{Mycetophagidae. .}

\section{Mycetophagus. Hellw.}

M. quadripustulatus. L. An Baumschwämmen, unter morscher Rinde.

M. decenpunctatus. Fabr. An Baumschwämmen selten (Sp. Kahr.)

M. atomarinus. Fabr. An Baumschwämmen selten (Sp. Gat.)

M. picens. Fabr. An Baumschwämmen selten (Sp. Gr.) 
1. multipunctutus. Hellu. An Baumschwämmen nicht selten.

M. fulvicollis. Fabr. An Baumschwämmen nicht selten.

M. quadriguttatus. Müll. An Baumschwämmen um St. Leonhard. (Sp.)

\section{Triphyllus. Latr.}

T. punctatus, Fabr. An Schwämmen nicht selten (Gat. Br.)

T. suturalis. Fabr. Nach Erichs. Ins. Deutschlands in Steiermark vorkommend.

Litargus. Er.

L. bifasciatus. Fabr. Unter Rinden nicht selten.

Typhaea. Kirby.

T. fumatu, L. Unter morscher Rindo häufig.

\section{Dermestidae.}

Dermestes. L.

D. vulpims. Fabr. Auf Aas selten (Sp. Gr.)

D. Frischii. Krg. Auf Aas (Gat.)

D. murimus. L. Auf Aas bei Cilli häıfig. (Ltgb.)

D. undulatus. Bralm. Unter Eichenrinde bei St. Gotthard ('lpk.)

D. tesselatus. Fabr. Wie die Vorigen (Sp. Gr.)

$D$. ater. Ol. An Aas $u$. St. Leonhard selten (Sp.)

D. lavdarius. $I$. Bei faulenden thierischen Stoffen häufigr.

D. bicolor. Fabr. Von Grimmer angegeben.

Attagenus. Latr.

A. pellio. L. Auf bliihenden Sträuchern sehr häufig.

A. Schäfferi. Hrbst Auf' blïhendem Gestränch um Graz (Gat.)

A. megatoma. Fabr. Auf Blithen (Gr.)

A. vigintiguttatus. Fabr. Auf bliihenden Sträuchern selten.

Megatoma. Hrbst.

I. undata. L. An Schwämmen, unter morscher Rinde.

Hadrotoma. Er.

H. murginata. Payli. Auf bliihendem Gestränch (Sp. Gr.)

H. nigripes. F'abr. Auf Nadelbäumen am Schöckl (Br.)

Trogoderma. Latr.

T. versicolor. Creut:. Auf Blüthen $1 \mathrm{~m}$ St. Leonhard selten (Sp.)

T. elongatulum. Fabr. Auf Blithen (Gat.)

T. nigrum. Hrbst. Wie Vorige (Gat.)

T. villosulem. Duft. Wie Vorige (Sp. Br.) 


\section{Tiresias. Steph.}

T. serra. F'abr. In hohlen Weidenstämmen selten (Gat. Br.)

Anthrenus. Geofl.

A. Scrophulariae. L. Auf Dolden und anderen Blüthen.

A. Pimpinellae. Fabr. Wie Vorrige.

A. varius. Fabr. Wie Vorige (Gr. Gat.)

A. museorum. L. Wie Vorige, seltener (Kod, Br.)

A. claviger. Er. Wie Vorige (Kod. Br.)

\section{Trinodes. Latr.}

T. hirtus. Fabr. Auf Wiesen selten.

Orphilus. Er.

O. glatratus. Fabr. Auf Blithen um Voitsberg (Ulrch.)

\section{Byrrhidae.}

\section{Nosodendron. Latr.}

N. fasciculare. Ol. An ausfliessendem Safte, unter Rinden nicht selten.

\section{Syncalypta. Dill.}

S. setosa. Waltl. In fenchtem Sande an Bächen und Flüssen.

S. paleata. Er. In feuchtem Sande bai St. Lambrecht selur selten (Kod.)

S. setigera. Ill. An samligen Ufern; scheint sich auf NordSteiermark zu beschränken.

S. spinosa. Rossi. An sandigen Ufern häufig:

\section{Curimus. Er.}

C. erinaceus. 1)uft. An Baumstämmen unter Moos (Gr.)

C. Lariensis. Heer. Nach Erichs. Ins. Dentschlands in Steiermark vorkommend.

C. hispidus. Er. Im Gebirge an Baumstämmen unter Moos nicht selten.

\section{Byrrhis. Lin.}

B. gigas. Fabr. Aulf Alpen unter Steinen und Moos.

B. scabripennis. Steff. Im nördlichen Steiermark auf Alpen unter Steinen selten (Kod. Gat.)

B. signatus. Panz. Auf Alpen unter Steinen selten.

B. ornatus. Paiz. Unter Steinen und Moos (Gr. Sp.)

$B$. hnniger. Germ. Unter Steinen und Moos nicht häufig.

B. pilula. L. Unter Steinen und Moos häufig.

B. fasciatus. Fabr. Unter Steinen (Gr.) 
B. picipes. Duft. Nach Erichs. Ins, Deutschlands in Steiermark vorkommend.

$B$. dorsalis. Fabr. Unter Moos nicht häufig.

B. murinus. Ill. Unter Steinen und Moos (Gr.)

Cytilus. Er.

C. varius. Fabr. Unter Steinen und Moos nicht häufig.

Morychus. Er.

M. aeneus. Fabr. Unter Moos und angeschwemmten Geniste.

M. nitens. Panz. Wie Voriger, häufiger.

M. auratus. Duft. Unter Moos nicht häufig.

Simplocaria. Marsh.

S. metallica. Sturm. Unter Laub und Moos selten (Sp.)

S. semistriata. Ill. Unter Moos nicht selten.

S. acuminata. Er. Unter Moos auf Alpen nicht selten.

Limnichus. Latr.

L. versicolor. Waltl. Am Mursande bei Graz (Tpk.)

L. pygmaers. Sturn. In feuchtem Sande selten (Kod. Gat.)

L. sericeus. Duft. Im Mursande häufig.

\section{Georyssidae.}

Georyssus. Latr.

G. pygmaeus. Fabr. Auf sandigen Ufern oft häufig.

G. substriatus. Heer. Auf Ufersand (Gr.)

G. laesicollis. Germ. Am Mursande gegen Schönau bei Graz. (Br.)

\section{Parnidae.}

Parnus. Fabr.

P. prolifericornis. Fabr. Unter Steinen, im Schlamme der Fliisse häufig.

P. lutulentus. Er. Von Kahr in Steiermark gesammelt.

P. Viennensis. Heer. Wie Vorige, selten (Gr. Gat.)

P. pilosellus. Er. Wie Vorige (Gat.)

$P$. auriculatus. Ill. Auf sandigen, schlammigen Ufern.

P. nitidulus. Heer. Auf Wasserpflanzen des Furt-I'eiches bei St. Lambrecht selten (Kod.) 
Potamophilus. Germ.

P. acuminatus. Fabr. Im Ausspülicht an Ufern; bei Graz (Gat.), bei St. Leonhard (Sp.).

\section{Limnills. Miill.}

L. tuberculatus. Meill. Auf sandigen Ufern selten.

Elmis. Latr.

E. aenens. Miill. Unter raulhen Steinen in Bächen nicht selten.

E. Mangetii. Latr. Wie Vorige, seltener.

E. obscurus. Müll. In Bächen bei St. Lambrecht nicht selten (Kod.)

E. Volkmari. Panz. An Steinen in Bächen.

E. Germari. Er. Mit Vorigem.

E. parallelopipedus. Miill. Wie Vorige (Gr.)

E. angustatus. Miill. Im Bächlein des Miihlbachgrabens bei Rein.

E. cupreus. Miull. An Bächen bei St. Lambrecht selten (Kod.)

E. subviolacens. Miill. In Steiermark von Kahr gesanmelt.

E. sodalis. Er. An Wurzeln der Pflanzen in Bächen um St. Lambrecht (Kod.)

\section{Heteroceridae.}

Heterocerus. Fabr.

H. fossor. Kiesw. An schlammigen Ufern (Br.)

H. marginatus. Fcbr. Auf Ufersand (Gr.)

H. hispidalus. Kiesw. Am Schlamme der Murufer (Gat.)

H. obsoletus. Kurt. Am Ufer des Lassnitzer-'Teiches 1 Ex. (Kod.)

H. laevigatus. Panz. Am Schlamme der Mur nicht selten.

H. fusculus. Kiesw. Am Schlamme der Mur (Gat.)

H. sericans. Kiesw. Am Schlamme der Mur (Gat.)

H. crinitus. Kiesw. Auf schlammigen Ufern um Fürstenfeld (Kahr.)

\section{Luc a nid a e.}

Lucanus. Lin.

L. Cervus, L. In Eichen- und Buchen-Wäldern.

Dorcus. Mac. Leay.

D. parallelopipedus. L. In Laubwäldern häufig.

Platycerus. Geoff.

$P$. caraboides. $L$. In Laubwäldern häufig. 
Ceruchus. Mac. Leay.

C. tenebrioides. Fabr. In alten Holzstöcken selten (Sp. Ulreh.)

Aesalis. Fabr.

A. scarabaeoides. Panz. In morschen Eichen um St. Leonhard selten (Sp.)

Sinodendron. Fabr.

S. cylindricum. L. In morschen Baumstöcken niclıt selten.

\section{Scarabaeidae.}

Sisyphis. Latr.

S. Schüfferi. L. An sonnigen Anhöhen im südlichen Steiermark niclit selten.

Gymnopleurus. Ill.

G. Mopsus. Palh. Im Kuhdiunger um Cilli (Ltgb.)

Caccobins. Thoms.

C. Schreberi. L. Im Kuhdünger nicht häufig.

Copris. Geoff.

C. lunaris. L. Im Kuldiinger häufig.

Onthophagus. Latr.

O. Hïbneri, Fabr. Im Kuhdünger auf Vielıveiden.

O. Taurus. $L$. Im Kuhdünger niclit selten.

O. nutçns. Fabr. Im Kuhdiinger nicht hä̈lfig.

O. Austriacus. Panz. Im Kuhdiinger.

O. vacca. L. Im Kuhdünger läufig,

o. coenobita. Hrbst. Wie Vorige, seltener.

O. fracticomis. Preys. Wie Vorige liäufig.

O. nuchicornis. L. Wie Vorige liäufig.

$O$. Lemur. Fabr. Im Kuhdünger nicht liäufig.

O. Camelus. Fabr. Im Kuhdiinger selten, Gat.)

O. semicornis. Panz. Im Kuhdiinger selten (Gat.)

O. furcatus. Fabr. Im Kuldiunger selten (Gat.)

O. ovatus. L. Wie Vorige, häufig.

o. flavipes. Fabr. 'In Dünger läufig.

Onticellus. Lep. et. Serv.

Aphodins. Ill.

A. erraticus. L. Im Kuhdünger nicht selten.

A. subterraneus. L. Im Dünger nicht häufig (Gr. Br.) 
A. fossor. L. Wie Vorige hänfig.

v. sylvaticas. Ahr. Mit dem Vorigen vereinzelt.

A. haemorrhoidalis. L. Wie Vorige nicht liäufig.

A. scylalarius. Fabr. Unı St. Lambrecht häufig (Kod.)

A. foetens. Fabr. Im Diinger selten.

A. fimetarius. L. Im Dünger sehr hänfig.

A. granarius. L. Im Dünger sehr häufig.

A. piceus. Gyll. Auf Alpen in Kuhdünger häufig (Kahr. Gat.)

A. borealis. Gyll. Anf Viehweiden um St. Lambrecht (Kod.)

A. constans, Duft. Nach Erichs. Ins. Dentschlands in Steier-. mark vorkommend.

A. foetidus. Fabr. AufViehweiden um St. Lambrecht häufig (Kod.)

A. sordidus. Fubr. Im Kuhdiinger (Gr.)

A. rufescers. Fabr. Im Kuhdïnger (Gr. Ltgb.)

A. nitidulus. Fubr. Im Diinger (Gr. Gat.)

A. immundus. Creutz. Im Dünger (Gr.)

A. alpinus. Scop. Auf Alpen im Dünger selten (Gat.)

v. rubens. Muls. Auf der Kulalpe in frischem Dünger (Kod.)

A. corvinus. Er. Von Kahr in Steisrmark gesammelt.

A. Limaculatus. Fabr. Im Dünger nicht häufig.

A. niger Panz. Im Diinger nicht häufig (Kod.)

A. plagiatus. L. Auf der Zirbisalpe nicht häufig (Kod.)

A. rufus. Ill. Im Diinger um Admont selten (Stbl.)

A. lividus. Ol. Im Dünger bei St. Lambrecht 1 Ex. (Kod.)

A. inquinatus, Fabr. Häufig.

A. melanostictus. Schm. Häufig.

A. sticticus. Panz. Im Dïnger nicht häufig ( $\left.\mathrm{Br}_{\text {. }}\right)$

A. conspurcatus. $L$. Im Diinger (Gr.)

A. pictus Sturm. Auf Alpen selten (Kod. Gat.)

A. tessulatus. Payk. In Diiuger selten.

A. porcus. Fabr. Im Diinger selten (Gr.)

A. pusillus. Hibst. Im Diinger um Admont (Stbl.)

A. quadripustulatus. Fabr. 'Im Dünger um St. Leonhard (Sp.)

A. merdarius. Fabr. Im Diinger häufig.

A. prodromus. Brahm. Im Dünger.

A. punctatosulcatus. Sturm. Im Diinger selten (Gat.)

A. consputus. Creutz. Im Dünger liäufig.

A. serotinus. Panz. Im Dünger selten (Gat.)

A. diseus. Schn. 'In Dünger auf Alpen selten (Gat.)

A. montivagus. Er. Auf Alpen im'Dünger selten (Schüppel. Gat.)

A. rufipes. L. Häufig.

A. coccinelloides. Pall. Um Cilli selten. (Hıber.)

A. luridus. Payk. Im Dünger nicht selten.

A. depressus. Kug. Auf Alpen sehr häufig.

A. pecari. Fubr. Im Dünger um St. Leonhard selten (Sp.)

A. testudinarius. Fabr. Bei Dünger selten (Gr. Br )

A. villosus. Gyll. In trockenem Dünger häufig.

A. porcatus. Fabr. Bei Dünger sehr häıfig.

Amnoecius. Muls.

A. gibbus. Germ. Auf. höheren Alpen in Schafmist sehr häufig, 


\section{Rhyssemus. Muls.}

$R$. asper. Fabr. Bei faulenden Vegetabilien.

Psammodius. Gyll.

Ps. caesus. Panz. Unter trockenem Dünger nicht häufig.

Ps. vulneratus. Sturm. Wie Voriger.

Ps. sulcicollis. Ill. Wie Vorige.

\section{Aegialia. Latr.}

Ae. arenaria. Fabr. Um Graz 1 Exemplar gefangen (Sp.)

\section{Ochodaetus. Lep. et Serv.}

O. chrysomelinus. Fabr. Am Abend umherschwärmend, selten.

Bolboceras. Kirby.

B. unicornis. Schrant. In der Ebene bei St. Leonhard 1 Exemplar gefangen (Sp.)

\section{Odontaeus. Klug.}

O. mobilicornis. Fabr. Bei Sonnenuntergang auf Wiesen schwärmend, selten,

Geotrypes. Latr.

G. stercorarius. L. Im Dünger häufig. v. putridarius. Er. Mit Vorigem.

G. Sylvalicus. Panz. Im Dünger häufig.

G. vernalis. L. Im Dünger häufig. $v$. autumnalis. God. Mit Vorigem. v. alpinus. Hop. Auf Alpen häufig.

\section{Trox. Fabr.}

T. hispidus. Laich. Bei trockenem Aas (Gr. Gat.)

T. sabulosus. L. Auf Feldwegen, unter Steinen.

T. cadaverinus. Ill. An Aas (Sp. Gat.)

T. scaber. L. Wie Vorige.

\section{Hoplia. Ill.}

H. philantus. Sulz. Auf blühenden Sträuchern.

H. farinosa. L. Auf bliihendem Gesträuch sehr häufig.

H. pollinosa. Er. (?) Um St. Lambrecht selten (Kod.)

H. graminicola. Fabr. Um St. Leonhard selten (Sp.)

H. Hungarica. Burm. Im Sande um Marburg (Sp.)

\section{Homaloplia. Steph.}

H. ruricola. Fabr. Auf sándigen Grasp!ätzen schwärmend.

Serica. Mac Leay.

S. holosericea. Scop. Auf sandigen Grasplätzen häufig.

S. brunnea. L. Auf sandigen Grasplätzen. 


\section{Melolontha. Fabr.}

M. vu'gavis. Fabr. Manches Jahr sehr häufig. v. albida. Muls. Um St. Lambrecht (Kod.)

M. Hippocastani. Fabr. Im südlichen Steiermark oft häufig.

\section{Polyphylla. Harris.}

P. fullo. L. Im südlichen Steiermark und gegen Ungarn hin nicht selten.

\section{Rhizotrogus. Latr.}

Rh. solstitialis. L. Manches Jahr sehr häufig. .

Rh. aequinoctialis. Schh. Um Cilli (Ltgb.)

Rh. aestivus. Ol. Auf Brachen selten.

Rh. assimilis. Hrbst. Auf Brachen selten (Kod. Sp.)

\section{Anisoplia. Lap.}

A. fruticola. Fabr. Anf blïhendem Gesträuch häufig.

A. agricola. Fabr. Auf blühenden Gesträuch.

A. floricola. Fabr. Auf Gesträuch (Gr.)

A. crucifera. Hribst. Auf Gesträuch.

A. Austriaca. Fabr. Auf Gesträuch um St. Leonhard (Sp.)

A. lata. Er. Auf Gesträuch selten (Gat. Sp.)

\section{Phyllopertha. Kirby.}

Ph. horticola. L. Auf blühendem Gesträuch sehr häufig.

\section{Anomala. Koep.}

A. aurata. Fabr. In Nord-Steiermark sehr selten (Kod.), häufiger im siidlichen Steiermark und oft in grossen Massen erscheinend.

A. Junii. Duft. Auf Gesträuch (Gr. Gat.)

A. Vitis. Fabr. Auf Gesträuch (Sp.)

A. ollonga. Fabr. Wie Vorige (Gat.)

A. Frischii. Fabr. Auf Gesträuch sehr häufig.

\section{Oryctes. Ill.}

O. nasicornis. $L$. In Gartenerde und Gerberlohe einzeln.

\section{Oxythyrea. Muls.}

O. stictica. $L_{\text {。 }}$ Auf Bliithen häufig.

\section{Cetonia. Fabr.}

C. hivtella. L. Auf blïhendem Gesträuch sehr häufig.

C. viridis, Eabr. Um Cilli selten auf Blithen (Ltgb.)

C. speciosissima. Scop. Um St. Leonhard einzeln (Sp.), um Cilli (L.tgb.)

C. affinis. And. Auf Blüthen und Gesträuch (Gr.)

C. angustata. Germ. Nach Erichs. Ins. Deutschlands in Steier. mark vorkommend. 
C. mamora'a. Fabr. Anf Blïthen nicht häufirg.

C. floricola. Hr.bst. Auf Bliithen und Gesträuch.

v. aenea. Gyll. Nicht häufig.

v. metallica. Fabr. Nicht häufig.

C. aurata. L. Auf blühendem Gesträuch häufig.

Osmoderma. Lep. et Serv.

O. eremita. L. Im Moder alter Weiden nicht häufig.

Gnorimus. Lep. et Serv.

G. variabilis. L. In hohlen Bäumen, anf Gesträuch selten.

G. nobilis. L. Auf Blüthen und Gesträuch häufig.

Trichius. Fabr.

T. fasciatus. L. Auf bliihendem Gesträuch und Bliuthen häufig.

Valgus. Scriba.

$V$. he:nipterus. L。 Auf blihendem Gesträuch nicht häufig.

\section{Buprestidae.}

Buprestis. Lin.

B. Mariana. L. Anf Föhrenstöcken selten, hänfig um Cilli.

B. lugubris. Fabr. An einem Baumstamme in Gösting (Mell.)

Dicerca. Esch.

D. Berolinensis. Fabr. Anf Buchenstöcken besonders im sïdlichen Steiermark nicht selten.

D. aenea. $L$. Anf liegendem Holze (Gr.)

D. acuminata. Pall. Am Bacher selten (Ulreh.)

D. alni. Fisch. Anf Eichen um St. Leonhard (Sp.)

\section{Poecilonota. Esch.}

$P$. conspersa. Gyll. Auf Zitterpappeln im siidlichen Steiermark.

P. rutilans. Fabr. In Laubwäldern nicht hänfig.

\section{Ancylochira. Esch.}

A. rustica. L. Auf gefälltem Laubholz.

A. punctata. Fabr. Wie die Vorige.

A. flavomaculata. Falr. Auf Fölren selten (Gat.)

A. octoguttata. $L$. Auf Föhren selir silten.

Eurythyrea. Sol.

E. Austriaca. L. Anf gefälltem Lanbholz sehr selten (Sp. Ltgb.)

E. Camiolica. Herbst. Anf gefälltem Holze nm Fiurstenfeld sehr selten (Kiesling.) 


\section{Melanophila. Esch.}

1. cyanea. Fabr. Auf gefälltem Holze; lıäufig in südlichem Steiermark.

I. decostigma. Fabr. Auf gefälltem Holze selten (Sp.), häufig um Cilli (Ltgb.)

M. appendiculata. Fubr. Wie die Vorigen, selten (Gr. Sp.)

\section{Anthaxia. Esch.}

A. Cichorii. Ol. Anf bliihendem Gestränch nm St. Leonhard (Sp.)

A. Millefolii. Faln. Auf bliihendem Gesträuch (Sp. Ltbg.)

A. curvilenta. Fabr. Anf Erlen un St. Leonhard (Sp.)

A. manca. Fabr. Auf gefialltem Holze 1 m St. Leonhard (Sp.)

A. Sulicis, Fabr. Auf bliibendem Gebiisch selten ('Tpk. Br.)

A. candens. Panz. Auf Kirschbäumen um St. Leonhard (Sp.), um Cilli (Huber.)

A. nitida. Rossi. Auf blïhenden Büschen häufig.

A. nitidula. $L$. Wie die Vorige.

A. morio. Fabr. Auf Dolden un St. Leonhard (Sp.)

A. sepulchalis. Fabr. A uf bliihendem Gestriuch mu Graz ('Tpk. Gat.)

A. quadrimaculatc. L. Auf Blüthen und Gesträuch häufig.

Ptosima. Sol.

Pt. Alavoguttata. Ill. Auf liegendem Holze selten.

v. sexmaculata. Irbst. Mit der Vorigen.

\section{Acma eodera. Wsch.}

A. 18-guttata. Pill. et Mit. Auf gefiillten Eichen um St. Leonhard selten (Sp.)

A. taeniata. Fabr: Auf gefälltem Holze selten.

Sphenoptera. Sol.

Spl. antiqua. Ill. Auf gefälltem Holze un Graz (Gr. Sp.)

Chysobothrys. Esch.

Ch. chrysostiyma. L. Auf Klafterhol\% selten (Sp.), lı̈ufiger Ium Cilli (Ltgb.)

Ch. affinis. Fahn. Auf liegendem Holze nicht selten.

Ch. Solieri. Lap. Auf' Scheiterholz selten.

\section{Coraebus. Lap.}

C. unclatus. Fabr. Auf gefälltem Hr,lze um St. Leonhard seh" selten (Böckh.)

C. Rubi. L. Auf Scheiterholz selten (Sp. Gat.)

C. elatus. Falı. Auf Wiesen besonders auf Poterium Sanguisorba lebend.

\section{Agrilus. Sol.}

A. sexguttatus. Hibst. Auf Eichen sehr selten um St. Leonhard (Sp.), um Cilli (Ltgb.)

A. biguttatus. Fabr. Auf Eichen um St. Leonhard (Sp.) und Cilli (Ltgb.)

A. sinuatus. Ol. Auf Dolden und Bliithen nicht häufig.

A. suban atus. Gebl. Anf Blithen und Sträuchern selten. 
A. viridis. L. Auf Gesträuch und Gras häufig.

A. coeruleus. Rossi. Auf Blithen um St. Leonliard (Sp.)

A. pseudocyaneus. Kiesw. Auf Blüthen um St. Leonhard (Sp.)

A. pratensis. Ratz. Auf Gesträuch um Graz selten (Gat.)

A. angustulus. Ill. Auf Blüthen $u$ Im St. Leonhard (Sp.)

A. olivicolor. Kiesw. Auf Blüthen (Ltgb. Gat.)

A. derasofasciatus. Lac. Auf blühendem Gesträuch (Gat.)

A. litura. Kiesu. Auf Bliithen (Sp. Kahr).

A. cinctus. Ol. Von Kahr in Steiermark gessmmelt.

A. aurichalceus. Redt. Auf Blüthen (Gat.)

A. convexicollis. Redt. Auf Blïthen $\mathrm{um}$ St. Leonhard (Sp.)

A. integerrimus. Ratz. Auf Bliithen (Gat. Sp.)

A. Hyperici. Creuta. Auf Hypericum perforatum (Gat.)

A. obscuricollis. Kiesu. Von Kahr in Steiermark gesammelt.

\section{Trachys. Fabr.}

T. minutus. L. Auf Blithen und Gesträuch häufig.

T. pygmaeus. Fabr. Auf Blüthen und Gras.

T. troglodytes. Gyll. Auf bliihendem Gesträuch selten (Gat.)

T. pumilus. Ill. Auf Bliithen selten (Gat.)

T. nanus. Hrbst. Auf Bliithen um St. Leonhard (Sp.)

Aphanisticus. Latr.

A. emarginatus. Fahn. Auf blihendem Gesträuch um Graz (Gat.) A. pusillus. Ol. Auf Gesträuch auf den Kalkleiten (Gr.)

\section{Eucnemidae.}

Drapetes. Redt.

D. equestris, Fabr. Im siidlichen Steiermark nicht selten.

Throscus. Latr.

Th. dermestoides. I. Auf bliihendem Gesträuch nicht selten.

Th. obtusus. Curt. Wie der Vorige, seltener.

Melasis. 01.

M. buprestoides. $L$. In morschem Holze um St. Leonhard (Sp.)

Tharops. Lalp.

Th. melasoides. Lap. Am Bachergebirge bei Harburg in alten Buchen selten (Sp.)

Eucnemis. Ahr.

E. capucina. Ahr. In hohlen Bäumen selten.

Dromacolus. Kiesw.

D. barnabita. Villa. In altem Holze um St. Leonbard sehr selten(Sp.) 


\section{Microrhagus. Esch.}

M. pyrmaeus. Fabr. An morschen Zännen um St. Leorhard (Sp.)

\section{Nematodes. Latr.}

N. filum. Fabr. In morschem Holze un St. Leonhard (Sp.)

\section{Elateridae.}

Adelocera. Latr.

A. lepidoptera. Gyll. Unter Rinden sehr selten (Kod. Ulrch.)

A. fusciata. I. Unter Rinden selten.

A. varia. Ol. In alten Eichen um St. Leonhard selten (Sp.)

\section{Lacon. Lap.}

L. murinus. L. Aut blühendem Gesträuch sehr häufig.

\section{Anchastus. le Cont.}

A. acuticornis. Germ. Auf morschen Pappeln bei Marburg sehr selten (Sp.)

\section{Drasterins. Esch.}

D. bimaculatus. Fabr. Auf Ufersand nicht selten.

Elater. Lin.

E. sanyuineus. L. Unter morschen Rinden.

E. lythopterus. Germ. Unter Rinden, auf Gesträuch.

E. ephippium. Fabr. Unter Rinden nicht selten.

E. praeustus. Fabr. Auf bliihendem Gestränch selten.

E. pomorum. Geoff. Auf bliihenden Buischen häufig.

E. crocatus. Geoff. Auf Gesträuch um St. Leonhard (Sp.)

$E$. elongatulus. Ol. Auf bliihenden Buischen (Br.)

E. balteatzis. L. Unter Rinden, auf Gesträuch.

E. elegantulus. Schönh. Auf Gestränch um St. Leonhard (Sp.)

E. sinuatus. Germ. Auf blühenden Büschen nicht häufig.

$E$. cuneiformis. Hampe. Auf Gebiisch sehr selten (Hampe.)

$E$. erythrogonus. Mïll. Auf Gestränch selten (Sp. Gat.)

E. aethiops. Lac. Auf Gebiisch nicht hänfig.

v. scrofa. Germ. Unter Rinden selten (Sp. Br.)

E. nigerrimus. L. Auf Gesträuch um St. Leonhard (Sp.)

E. nigrinus. Hibst. Auf Gesträuch selten.

\section{Megapenthes. Kiesw.}

M. sanguinicollis, Panz. In der Marburger $A u$ in alten Weiden selten. (Sp.)

M. tibialis. Lac. In hohlen Bäumen selten.

M. lugens. Redt. In alten Bäumen səlten (Sp. Gat.) 


\section{Betarmon. Kiesw.}

B. bisbimaculatus. Schh. Auf Wiesen an der Mur nicht selten; scheint im suidlichsten 'T'heile Steiermarks zu fellen.

\section{Cryptohypuis. Esch.}

C. riparius. Fabr. Auf sandigen Stellen an Ufern.

C. frigidus. Kiesw. Unter Steinen im Hochgebirge liäufig (Gat.)

C. 4-pustulatus. Faln. Unter Steinen auf sandigen Ufern.

C. pulchellus. L. Auf sandigen Ufern nicht häufig.

C. 4-guttatus. L. Auf Ufersand unter Steinen (Gat.)

C. lapidicola. Geim. Auf sandigen Ufern um St. Leonhard (Sp.)

C. minutissimus. Germ. Kommt um Graz und siidlicher sehr hiäufig auf bliihendem Gesträuch vor.

\section{Cardiophorus. Esch.}

C. thoracicus. Fabr. Auf bliihendem Gesträuch.

C. discicollis. Hrbst. Auf Gestrïuch selten.

C. ruficollis. L. Wie Vorige.

C. rufipes. Tourer. Auf bliihendem Gesträuch sehr hänfig.

C. nigerimus. En. Wie der Vorige.

C. ebeninus. Germ. Wie Vorige, selten (Gr. Gat.)

C. atramentarius. Er. Auf Bliithen und Gebiisch selten (Kod. Gat.)

C. cinereus. Hrbst. Auf Gesträuch nicht häufig.

$v$ testaceus. Fabr. Mit dem Vorigen.

C. Equiseti. Irbst. Auf Gesträuch (Gr. Ltgb.)

Melanotus. Esch.

M. niger. Fabr. Auf Gesträuch. nicht selten.

M. tenebrosus. Er. Auf Gesträuch $1 \mathrm{~m}$ St. Leonhard selten. (Sp.)

M. Urunnipes. Germ. Unter morscher Rinde, auf Gesträuch.

M. castanipes. Payk. Wie der Vorige.

M. rufipes. Hrbst. Wie dis Vorigen.

M. crassicollis. Er. Um St. Lambrecht sehr selten (Kod.)

\section{Limonius. Esch.}

L. violaceus. Mirll. Auf Inglansregia um St. Leonhard (Sp.)

L. nigripes. Gyll. Auf Gesträuch selten (Sp. Gr.)

L. cylindricus. Payk. Auf bliihendem Gesträuc!ı häufig.

L. minutus. L. Wie ler Vorige, häufig.

L. parvulus. Panz. Wie der Vorige, liäufi:

L. lythrodes. Germ. Auf Gesträuch im Gebirge selten (Gri.Gat.)

L. Bructeri. Fabr. Im nördlichen Steiermark sebr selten (Kod.) sonst häufig.

\section{Athous. Esch.}

A. rufus. de Geer. Auf Föhren sehr selten; um St. Leonhard (Sp.), bei Nenhaus (Ltgb.)

A. rhombeus. Ol. Auf Eichen 1 m St. Leonhard selı' selten (Sp.), auf Castanea vesca am Bacher (Ulrchi)

A. niger. $L$. Auf Gesträuch. $v$. scrutator. Hrbst. Mit dem Vorigen. 
A. haemorrhoidalis. Fabr. Auf Gesträuch sehr häufig.

A. vittatus. Fabr. Auf Gestränch sehr häufig.

A. longicollis. Ol. Auf Gesträuch nicht häufig.

A. undulatus. de Geer. Unter der Rinde morscher Stöcke sehr selten; 'Teichalpe (Ulrch.), Bacher (Sp.)

A. subfuscus. Müll. Anf Gesträuch sehr haufig.

A. circumductus. Ménètr. Auf blühendem Gesträuch selten (Br.)

A. Dejeconii. Cast. Auf Gesträuch selten (Gat.), am Schöckl (Gr.)

\section{Corymbites. Latr.}

C. pectinicornis. L. Im Gebirge auf Blïthen häufig.

C. Heyeri. Sax. Im Kaina chgraben bei Voitsberg lä̈ufig (Ulrch.)

C. cupreus. Fabr. Auf bliihenden Gesträuch nicht selten. $v$. aeruginosus. Eabr. Wie der Vorige.

C. haematodes. Fabr. Wie Vorige, häufig.

C. castaneus, L. Auf Bliithen um St. Leonlard selten (Sp.)

C. sulphuripennis. Germ. Von Kahr in Steiermark gesammelt.

C. auizcus. Panz. Auf Gesträuch nicht selton. $v$ signatus. Panz. Mit dem Vorigen.

C. tesselatus, L. Auf Gesträuch häiffig.

C. Quercus. Gyll. Um St. Leonhard selten (Sp.)

C. montivagus. Rosh. Im Gebirge auf Bäumen selten (Sp. Gat.)

C. insitivus. Germ. Auf bliihenden Biischen un Graz und siidlicher nicht selten.

C. holosericeus. L. Auf Blüthẹn und Gesträuch häufig.

C. aeneus. L. Auf blühendem Gesträuch sehr häufig. $v$. nitens. Scop. Mit dem Vorigen.

v. Germanus. L. Mit dem Vorigen.

C. rugosus. Germ. Auf der Kuhalpe bei St. Lambrecht häufig (Kod.)

C. metallicus. Payle. Auf Bliithen um St. Leonhard (Sp.)

C. latus. Fabr. Auf Gesträuch häufig.

$v$ gravidus. Germ. Mit dem Vorigen.

C. melancholicus. Fabr. Auf der Kuhalpe sehr selten (Kod.)

C. bipustulatus. L. Auf Gesträuch selten (Gr. Gat.)

C. cinetus. Panz. Im Gebirge selten (Gat.), auf duirrem Holze um St. Leonhard (Sp.)

c. cruciatus. Fabr. Auf́ Gesträuch selten.

C. guttatus. Germ. Auf höheren Alpen nicht eben häufig.

Dima. Esch.

D. elateroides. Charp. Am Bachergebirge sehn selten (Sp.)

Tudius. Latr.

L. fermugineus. L. Auf Eichen und Weiden; um Graz (Tpk. Gro), um St. Leonhard (Sp.)

\section{Agriotes. Esch.}

A. pilosus. Panz. Auf bliuhendem Gesträuch liạ̈fig.

A. ustulatus. Schall. Ailf Bliithen nicht häufig (Gr. Gat.)

A. sputator. L. Auf Blüthen lıäufig.

A. lineatus. L. Auf Blïthen häufig.

A. obscurus. I. Auf Bliithen häirfig. 
A. aterrimus. L. Auf Blüthen nicht häufig (Sp. Gat.)

A. umbrinus. Germ. Auf Blïthen häufig (Gat.)

A. picipennis. Bach. Im Gebirge auf Gesträuch häufig.

Sericosomus. Redt.

S. brunneus. I. Anf Bliithen hänfig.

$v$ fugax. Fabr. Mit dem Vorigen.

S. subaeneus. Redt. Im Gebirge nicht eben selten.

S. marginatus. L. Auf Gesträuch häufig.

\section{Ctenonychus. Steph.}

Ct. filiformis. Fubr. Auf Gesträuch häufig.

\section{Adrastus. Esch.}

A. limbatus. Fabr, Auf bliihendem Gesträuch (Gat. Br.)

A. axillaris. Er. Auf Dolden und Gestränch nicht häutig.

A. pallens. Er. Auf Bliithen selten (Kod. Stbl.)

A. lacertosus. Er. Auf Bliuthen selten (Br.)

A. pusillus. Fabr. Auf Bliithen (Gat.)

A. humilis. Er. Auf Bliuthen (Br. Gat.)

Campylus. Fisch.

C. rubens. Pill. et Mitt. Im Gebirge auf Bliithen selten.

C. linearis. L. Auf Blüthen und Gras häufig.

\section{Dascillidae.}

Dascillus. Latr.

D. cervinus. L. Auf Blüthen und Gras sehr häufig.

Helodes. Latr.

H. minuta. L. Auf Blumen und Gras.

H. Hausmanni. Gredl. Auf der Choralpe (Miller), auf der LaaAlpe selten (Gat.)

H. marginata. Fabr. Auf Blïthen und Gesträuch selten.

H. flavicollis. Kiesw. Um Graz auf Bliithen und Gebiisch nicht selten.

H. testacea. L. Auf Bliithen um St. Lambrecht sehr selten (Kod.)

Cyphon. Payk.

C. coarctatus. Payk. Auf Bliithen (Gat.)

C. variabilis. Thunbg. Anf Blüthen und Gras häufig.

C. Padi. L. Auf Bliithen und Gras häufig.

Prionocyphon. Redt.

P. servicornis. Müll. Auf Gras geschöpft (Gat.) 


\section{Hydrocyphon. Redt.}

H. deftexicollis. Mïll. An Bächlein anf warmen Steinen sitzend, selten (Br.Gr.)

\section{Scirtes. Ill.}

S. hemisphuericus. L. Auf Wiesen (Tpk.)

S. orbicularis. Panz. Auf Wiesen 1 m St. Leonhard selten (Sp.)

Encinetus. Germ.

E. hemornhidalis. Germ. Unter feuchtem Moos und Laub selten; an Plabutsch bei Graz (Gat.), um St. Leonhard (Sp.)

Eubria. Rellt.

E. palustris, Germ. Auf nassen Gebirgswiesen.

\section{ma lacodermata.}

Dictyoptera. Latr.

D. sanguinec. L. Auf Dolden sehr häufig.

Eros. New.

E. Aurora. Fabr. Auf Dolden nicht häufig.

E. rubens. Gyli. Auf Dolden nicht seiten.

E. minutus. Fabr. Auf Dolden und Gesträuch.

E. affinis. Payk. Auf Dolden selten.

E. Cosnardi. Chevr. Auf Dolden um St. Leonlrard selten (Sp.)

\section{Homalisus. Geoff.}

H. suturalis. Fabr. Auf bliihendem Gesträuch nicht häufig.

Lampyris. Lin.

L. noctiluca. $L$. Oft häıfig umhersehwärmend.

Lamprorrhiza. Duv.

L. splendidula. L. Nicht häufig.

\section{Phosphaenus. Lap.}

Ph. hemipterus. Geoff. Auf dem Rosenberge bei Graz (Ulrch.), um St. Leonhard (Sp.)

Cantharis. Lin.

C. alpina. Payk. Anf Alpen nicht selten.

C. abdominulis. Fabr. Auf Gesträuch im Gebirge nicht selten.

C. violacea. Payk. Wie die Vorige.

C. fusca. L. Auf Gesträuch sehr häufig.

C. rustica. Fall. Wie die Vorige. 
C. tristis. Fulr. Auf Nadelbäumen im Gebirge niclit selten.

C. obscura. L. Auf bliihendem Gesträuch sehr häufig.

C. prlicaria. Fabr. Auf Gesträuch um St. Leonbard (Sp.)

C. fibulata. Märk. A uf Gesträuch im Hoch-Gebirge (Gat.)

C. albomarginata. Märk. Im Gebirge auf Gesträuch selten.

C. nigricans. Müll. Auf (esträuch nicht selten.

C. pellucida. Fabr. A uf Gesträuch häufig.

C. livida. L. Auf Gestränch nicht liäufig.

v. scapularis. Redt. Auf Gesträuch um St. Leonhard (Sp.)

v. dispar. Falbr. Auf Bliithen und Gesträuch nicht selten.

C. assimilis. Payk. Auf Gesträuch nicht selten.

C. haemorrhoidalis, Fatr. Auf Nadelbäumen nicht selten.

C. mufa. L. Anf Gebiischen nicht häufig. $v$. liturata. Fall. Mit der Vorigen.

C. bicolor.-Panz. Auf Birken um Admont (Stbl.)

C. palliata. Gyll. Um St. Leonhard (Sp.)

C. fulvicollis, Fabr, Auf Gesträuch selten im Gebirge.

C. thoracica. Ol. Im Gebirge hänfig auf Bliithen.

C. flavilabris. Fall. Am Bacher selten (Sp.)

C. paludosa. Full. Auf Wiesen nicht häufig.

C. lateralis. Gyll. Am Schöckl selten (Gat.)

C. pilosa. Payk. Im Gebirge selten.

\section{Ragonycha. Esch.}

R. fulva. Scop. Auf Blüthen sehr häufig.

R. terminalis. Redt. Auf Alpen an der steirischen Grenze.

R. nigriceps. Waltl. Auf Dolden und Gesträuch um Graz (Gat. Br.)

R. fusciconnis. Ol. Auf Nadelbäumen nicht häufig (Kod. Gat.)

R. testacea. L. Auf blühenden Sträuchern nicht häufig.

$R$. nigripes. Redt. Wie die Vorigre.

R. femorelis. Brull. Wie die Vorigen.

R. pallida. Fabr. Auf Gestränch.

R. atrc. L. Im Gebirge auf Nadelbärmen nicht selten (Gat.)

R. denticollis. Sclurn. Anf Alpen nicht häufig.

\section{Silis. Latr.}

S. nitidula. Fabr. Am Schöckl (Grr.), um St. Leonhard selten (Sp.)

\section{Ilalthinus. Latr.}

M. fasciatus. Fall. Auf bliilıendem Gesträuch (Gr.)

II. glabellus. Kieswo. Auf Gesträuch selten (Gat.)

M. punctatus. Fourer. Auf blühendem Gesträuch häufig.

M. liguttatus. L. Auf Gesträuch häufig.

\section{Malthodes. Kiesw.}

M. sanguinolentus. Fall. Auf Gesträuch selten. (Gr. Tpk.)

M. pellucidus. Kiesw. Anf Gesträuch selten. (Gat.)

M. trifurcatus. Kiesw. Auf Gesträuch selten. (Gat.)

M. atramentarius. Kiesw. Nach Erichs. Ins. Deutschlands von Miller in den steierischen Alpen gesammelt.

M. dispar. Germ. Auf Gesträuche (Kod. Gat.) 
M. maurus, Redt. Auf Gesträuch nicht selten.

M. misellus. Kiesu. Auf Gesträuch selten (Gat.)

M. pulicarins. Redt. Auf Gesträuch (Gr. Gat.)

\section{Drilus. 01 .}

D. pectinatus. Fabr. Um St. Leonhard sehr selten (Sp.)

Melachius. Fabr.

M. aencus. L. Auf Bliathen und Gesträuch selu häufig.

M. scutellaris. Er. Anf Gesträuch $11 \mathrm{~m}$ Graz selten (Gat.)

M. rubidus. Er. Anf Gestränch $1 \mathrm{~m}$ Graz selten (Gat.)

M. bipustulatus. L. Anf Gesträuch häufig.

M. marginellus Ol. Auf Gesträuch selten (Gat. Stbl.)

M. geniculatus. Germ. Auf Gestläuch häufig.

M. affinis. Ménéti. Anf Gesträuch um St Leonhard (Sp.)

$M$. viridis, Fubr. Anf Gesträuch häufig.

\section{Axinotarsus. Motsch.}

A. pulicarius. Fuhr. Auf Bliithen und Gesträuch häufig.

A. marginalis. Er. Wie der Vorige, seltener.

A. ruficollis. Ol.॰ Wie Vorige, häufig.

\section{Anthocomis. Er.}

A. sanguinolentus. Fal,r. Auf Bliithen (Gr.)

A. equestris, Fabr. Anf Blüthen und Gesträuch.

L. fasciatus. L. Wie der Vorige.

\section{Attalus. Er.}

A. analis. Panz. Anf Bliuthen und Gesträuch.

Ebaeus. Er.

E. pedicularius. Schruk. Auf Bliithen und Gesträuch häufig.

E. flavicornis. Er: Auf Blithen selten (Kod. Gat.)

E. coerulescens. EN. Auf Blithen $1 \mathrm{~m}$ St. Leonhard selten (Sp.)

E. thoracicus. Ol. Auf Gesträuch um St, Leonhard (Sp.)

\section{Hypebaens. Kiesw.}

H. flavicollis. Fr. Auf Bliithen um St. Leonhard (Sp.)

H. Havipes. Fabr. Auf Blithen 1 m St. Lambrecht (Kod.)

\section{Charopus. Er.}

Ch. pallipes, Er. Auf Bliithen nicht selten.

Ch. concolor. Fabr. Wie der Vorige, selten.

\section{Troglops. Er.}

T. albicans. L. Auf Blüthen und Gras nicht selten.

\section{Dasytes. Payk.}

D. viger. L. Auf Gesträuch häufig.

D. subaeneus. Schh. Auf Gesträuch um St. Leonhard. (Sp)

D. cocruleus. de Geer. Anf Blithan nicht salten. 
D. plumbeus. O!. Auf Bliithen hänfig.

D. obscurus. Gyll. Auf Blüthen häufig.

D. fusculns. Ill. Auf Bliithen um St. Leonhard (šp.)

\section{Dolichosoma. Steph.}

D. lineare. Rossi. Auf Wiesen um St. Leonhard (Sp.)

\section{Haplocnemus. Steph.}

H. tarsaiis. Redt. Faun. Aust. Ed. II. p. 543. 3. Um St. Lambrecht (Kod.), am Schöckl von Nadelbäumen oftmals geklopft (Br.) H. Pini. Redt. Auf Föhren selten (Sp. Gat.)

H. nigricornis. Fabr. Auf Nadelbäumen nicht selten.

H. aestivus. Kiesu. Im Gebirge auf Nadelhols (Gat.)

\section{Danacea. Lap.}

D. pallipes. Panz. Auf Blithen sehr hänfig'.

\section{Byturus. Latr.}

B. fumatus. Fabr. Auf Gesträuch häufig.

B. tomentosus. Fabr. Wie der Vorige.

\section{Cleridae.}

Tillus. 01.

T. elongatus. L. Auf liegentem Holze selten und einzeln.

T. unifasciatus. L'abr. Auf Eichenstämmen $n$ St. Lennharil (Sp.)

\section{0 pilus. Tatr.}

O. mollis. L. Auf gefälltem Holze nicht sulten.

O. domesticus. Sturm. Um St. Lambrecht nicht selten (Kond.)

O. pallidus. Ol. Auf Eichen um St. Leonhard (Sp.)

Clerus. Geoff.

C. mutillarius. Fabr. Auf gefälltem Holze nicht selten.

C. formicarius, L. IVie der Vorige, lıäutis.

C. rufipes. Bratm. Auf gefälltem Holze 1 m St. Leonliard selten (Sp.), um Fuirstenfeld (Kiesling.)

\section{Trichodes. Hrbst.}

T. alvearius. Fabr. Auf Blithen selten.

T. apiarius. L. Auf Bliithen und resträuch häufig.

T. faviarius. Ol. Wie der Vorige, seltener.

\section{opthopleura. Spin.}

O. sanguinicollis. Fabr. Auf einem Eichenstock bei St. Leonhard selten (Sp.), um Cilli (Ltglo.) 


\section{$-67-$}

\section{Corynetes. Hrbst.}

C. coemuleus. de Geer. Auf Aas und faulenden thierischen Stoffen.

C. ruficomis. Stum. Wie der Vorige, selten (Sp.)

C. violacens. L. Wie die Vorigen häufig.

C. rufipes. Fabr. Um St. Leonhard selten (Sp.)

C. scutellaris Ill. An Manern in St. Leonliard solten (Sp.), auf Bliithen selten (Gat.)

\section{Laricobius. Rosh.}

L. Erichsmi. Rosh. Unter Moos am Selöckl 1 Exemplar gesiebt (Br.)

\section{Hylecetus. Latr.}

H. dermestoides. $L$. In alten Baumstämmen nicht selten. v. molscidaeus. Faln. Wie die Vorige (Gr.)

\section{Lymexylon. Fabr.}

L. nacale. $L$. In alten Baumstimmen IIm Gra\% (Gr.), um St. Leonhard selten (Sp.)

\section{Ptinidae.}

\section{Hedobia. Sturm.}

17. pubescens. Fabr. Im Mithlbachgraben bei Rain 1 Exempl. (Ullrich.)

H. imperialis. L. Auf liirren Aesten nicht häufig.

H. regalis. Duft. Wie die Vorige.

\section{Ptinus. Lin.}

P. Germanus. Fabr. Von diirem Holze geklopft (Drnbk.)

P. variegatns. Rossi. In alten Holzgebäinden um St. Lambrecht sehr häufig (Kod.)

P. sexpunctatus. Pan:. Un St. Lambrecht selten (Kod.)

P. dulins. Sturm. In Holzgebäuden Im St. Lambrecht sehr länfig (Kod.)

P. rufipes. Fabr. Bei morschem Holze selten (Gr. Gat.)

P. ornatus. Miill. Um St. Leonhard selten (Sp.)

P. fur. L. Sehr häufig.

P. pusillus. Sturm. Auf diirrem Holze se!ten (Sp. Gat.)

P. Spitayi. Tilla. Nach Spitzy's Angabe un St. Leonhard vorkommend.

P. pilosus. Müll. Unter Moos und Laub selten.

P. latro. Fabr. Unter Moos selten (Gat.)

P. testaceus. Ol. Auf diirren Aesten (Sp.)

P. bidens, Ol. Sehr selten (Gat.) 


\section{Niptus. Boiel.}

A. crenutus. Fabr. Untel Moos selten (Gat.)

Gibbium. Scop.

G. scotias. Fabr. An Mauern, in Kellern selten.

\section{Anobiidae.}

\section{Dryophilus. Cherr.}

D. pusillus. Gyll. Auf Fichten im Gebirge oft häufig.

Anobium. Fabr.

A. denticolle. Panz. Auf Holz (Gr.)

A. pertinax. $L$. Auf trockenen Stämmen nicht selten.

A. domesticum. Fourcr. Anf diirrem Holze und Blithen.

A. fulvicorne. Sturm. Anf diirrem Holze (Sp.)

v. morio. Tilla. Auf diirren Aesten (Sp. Gat.)

A. encarginctum. Duft. Auf Nadelbäumen nicht selten.

A. nitidum. Hrbst. Auf trockenen Aesten (Gat.)

A. rufipes. Fatr. Anf diirrem Holze um St. Leonhard (Sp.)

A. paniceum. L. Sehr häufig in Speisekammern.

\section{Xestobium. Motsch.}

$X$. tesselatum. Fabr. In alten Baumstämmen nicht selten.

$X$. plumbeum. Ill. Auf blühendem Gesträuch um Graz (Gat.)

\section{Ernobius. Thoms.}

E. abietinus Gyll. Auf Nadelbäumen nicht selten.

E. abietis. Fabr. Wie der Vorige.

E. mollis. L. Seltener.

E. nigrinus. Sturm. Auf Nadelbäumen selten (Gat.)

Oligomerus. Redt.

O. Lrunueus. Ol. Um St. Leonhard selten (Sp.)

Gastrallus. du Val.

G. imnarginatus. Redt. Auf Gesträuch sehr selten (Gat. Sp.)

Ptilinus. Geoff.

P. pectinicornis. L. Auf trockenen Baumstämmen.

\section{Ochina. Steph.}

o. Latreillei. Bon. Auf Ahorn am Hoch-Lantsch (Gat. 'Tpk.), am Schöckl auf diirrem Holze (Br.)

O. Hederae. Müll. Auf Epheu selten (Gr. Sp.) 


\section{Trypopitys. Redt.}

T. Carpini. Hrust. In altem Ho'ze sehr selten (Gat.)

\section{Xyletinus. Latr.}

$X$. ater. Panz. In altem Holze nicht selten.

$X$. pectinatus. Fabr. Wie der Vorige.

X. laticollis. Duft. Wie die Vorigen.

\section{Lasioderma. Steph.}

L. serricorne. Fabr. Bei altem Holze selten.

\section{Dorcatoma. Hrbst.}

D. Dresdensis. Hrbst. In altem Holze, an Schwämmen (Sp. Gat.)

D. Alavicornis. Fubr. Wie die Vorige.

\section{Enneatoma. Nuls. et. Rey.}

E. subalpina. Bon. In Bovisten selten.

\section{Sphindus. Chevr.}

S. dubius. Gyll. An Schwämmen um Graz (Gr.), Voitsberg (Ulrch.)

\section{Aspidiphorus. Latr.}

A. orbiculatus. Gyll. Unter Moos selten (Gat. Ulrch.)

\section{Xylopertha. Guér.}

X. sinuata. Fabr. In altem Holze selten (Gr. Sp.)

Apate. Fabr.

A. capucina. $L$. In altem Holze nicht selten.

\section{Dinoderus. Payk.}

D. elongaters. Payk. Am Hoch-Lantsch auf Ahorn 1 Exemplar (Gat.)

D. substriatus. Payk. Um St. Lambrecht in Erlen selten (Kod.), um St. Leonhard (Sp.)

\section{Psoa. Hrbst.}

P. Viennensis. Hrbst. Auf Bliithen selten (Tpk. Mell.)

\section{Lyctus. Fabr.}

L. canaliculatus. Fabr. Auf liegendem Holze häufig.

L. pubescens. Panz. Auf dürrem Holze (Ulrch.)

L. bicolor. Com. Wie der Vorige, selten (Gr. Gat.)

\section{Hendecatomus. Mellié.}

H. reticulatus. Hrbst. In altem Holze um St. Leonhard selten (Sp.)

Xylographus. Mellié.

X. bostrychoides. Dufour. Auf diurrem Holze 1 Exempl. (Br.) 


\section{Rhopalodontus. Mellié.}

Kh. perforatus. Gyll. Auf diirrem Holze um St. Leonhard selten (Sp.)

Rh. fronticornis. Panz. An Baumschwämmen nicht selten.

\section{Cis. Latr.}

C. Boleti. Scop. In Baumschwämmen häufig.

C. micans. Hrl,st. Wie der Vorige, häufig.

C. hispidus. Payk: Wie Vorige.

C. quadridens. Mellié. In Schwämmen um Neuberg (Drnbk.)

C. lidentatus. Ol. An Baumschwämmen selten (Stbl. Gat.)

C. nitidus. Hibst. Wie der Vorige, selten.

C. Alni. Gyll. Auf dïren Aesten an Schwämmen, häufig.

C. oblongus. Mellié. An Schwämmen selten (Gat.)

C. glabratus. Mellié. An Schwämmen (Gr.)

C. festirus. Panz. Häufig um St. Lambrecht in Schwämmen auf Lerchenstämmen (Kod.)

C. castaneus. Mellié. In Baumschwämmen selten (Gat.)

\section{Ennearthron. Mellié.}

E. cornutum. Gyll In Baumschwämmen nicht selten.

E. affine. Gyll. In Baumschwämmen nicht liäufig (Gr. Gat.)

Orophins. Redt.

U. mandibularis. Gyll. In Baumschwämmen nicht selten.

Octotemuns. Mellié.

0. glabriusculus. Gyil. In Baumschwämmen nicht selten.

\section{Tenebrionidae.}

Blaps. Fabr.

B. mortisaga. L. In Kellern, an dumpfigen Orten hänfig. B. similis. Latr. Um St. Lambrecht nicht häufig (Kod.)

\section{Platyscelis. Latr.}

P. polita. Sturm. Um Cilli (Ltgb.)

P. gages. Fisch. Unter Steinen $11 m$ Graz nicht selten.

Crypticus. Latr.

C. quisquilius. L. Anf sonnigen Feldwegen, unter Steinen häufig.

0patrum. Fabr.

O. sabulosum. L. Auf sonnigen Feldwegen sehr häufig. 


\section{Microzoun. Redt.}

M. tibiale. Fabr. Auf trockenen Aeckerı um Lind unter Steinen (Kod.)

\section{Bolithophagns. III.}

$B$. reticulatus. $L$. In Baumschwänmen um St. Leonhard (Sp.)

$B$. interruptus. Ill. Wie der Vorige (Sp.)

B. armatus. Panz. Wie die Vorigen (Gr. Sp.)

\section{Eledona. Latr.}

E. agaricola. Hrbst. An Baumschwämmen nicht häufigg.

Diaperis. Geoff.

D. Boleti. L. An Baumschwämmen häufig.

\section{Hoplocephala. Lap.}

H. haemorrhoidalis. Fabr. In Baumschwänmen am Bacher selten. (Sp.)

\section{Scaphidema. Redt.}

Sc. aeneum. Pagk. An Schwämmen, auf diirrem Holze.

\section{Platydema. Lap.}

P. violacem. Fabr. Unter Rinden, in moderigen Bäumen.

P. Dejeanii. Lap. Wie die Vorige, seltener (Gr. Sp.)

\section{Pentaphyllus. Latr.}

P. testaceas. Hellu. Unter Rinden nicht häufig.

\section{Alphitophagus. Steph.}

A. 4-pustulatus, Steph. Bei fanlenden Vegetabilien um St. Leonhard (Sp.)

\section{Tribolium. Mac Leay.}

T. ferruginerm Fabr. In Vorrathskammern nicht selten.

T. madens. Charp. In Getreidekammern bei Bäckern oft häufig.

\section{Hypophloeus. Hellw.}

H. depressus. Fabr. In alten moderigen Bäumen nicht läufig.

$H$ castaneus. Fabr. Unter morscher Bamminde.

H. Pini. Panz. Wie der Vorige, selten.

H. bicclor. Ol. Unter Rinden nicht selten.

H. fasciatus. Fabr. Auf diirren Aesten un St. Leonhard (Sp.)

H. inearis. Fabr. Unter Rinde, auf diurren Aesten (Sp.)

\section{Uloma. Redt.}

$U$. culinaris. $L$. In alten Bammstöcken nicht häufig.

$U$. Perroudi. Muls. In Weingärten um St. Leonharil (Sp.)

\section{Alphitobius. Steph.}

A. chrysomelinus. Hrbst. Im Moder alter Baumstöcke um St. Leonhard (Sp.) 


\section{Tenebrio. Lin.}

T. opacus. Duft. Im Moder alter Bäume um St. Leonhard (Sp.)

T. obscurus. Fabr. Im Moder alter Bäume un St. Leonhard (Sp.)

T. molitor. L. Im Moder alter Bäime häufig.

I. transversalis. Duft. Im Moder alter Bäume.

\section{Menephilus. Muls.}

M. curvipes. Fabr. Unter Rinden alter Stöcke, im Moder.

\section{('alcar. Latr.}

C. elongatum. Hrbst. Von Grimmer als in Steiermark vorkommend angegeben.

\section{Laena. Latr.}

L. Viennensis. Sturm. Unter moderigem Moose in Wäldern nicht selten.

\section{Helops. Fabr.}

H. lanipes. L. Unter Laub und Moos häufig.

H. caraboides. Panz. Wie der Vorige, seltener.

\section{Cistellidae.}

Allecula. Fabr.

A. morio. Fabr. In morschem Holze nicht selten.

A. aterrima. Küst. Auf alten Bäumen selten und einzeln.

Cistela. Fabr.

C. Luperus, Hrbst. Auf blïhendem Gesträuch häufig.

C. ceramboides. L. Auf Bluithen selten (Gr. Sp.)

C. fusca. Ill. Auf Bliithen nicht häufig.

C. antennata. Panz. Auf Blithen $m$ St. Leonhard selten (Sp.)

C. murina. L. Auf bliihendem Gesträuch häufig.

v. Evonymi. Fabr. Mit der Vorigen.

C. atra. Fabr. Im Moder alter Bäume, besonders Weiden.

Mycetochares. Latr.

M. axillaris. Payk. Unter Rinden im Moder alter Bäume.

$v$. morio. Redt. Wie die Vorige.

$v$. linearis. Redt. Wie die Vorigen.

11. Alavipes. Fabr. Unter Rinden an Schwämmen alter Bäume.

M. bipustulata. Ill. Unter morscher Rinde alter Bäume, Gat. $\mathrm{Br}$.

M. barbata. L. Unter morscher Rinile alter Stämme. 


\section{Cteniopus. Sol.}

Ct. sulphureus. L. Auf blïhendem Gesträuch besonders im siidlichen Steiermark häufig.

\section{Omophlis. Sol.}

O. Tepturoides Fabr. Auf blühendem Gesträuch häufig.

O. pinicola. Redt. Auf blïhenden Nadelbäumen (Kod. Sp.)

O. picipes. Redt. Auf Gesträuch um St. Leonhard (Sp.)

\section{Py thida e.}

Salpingus. Ill.

S. ater. Payk. Auf Erlen am Steinfeld bei Bruck (Gat.), um St. Leonhard (Sp.)

S. castaneus. Panz. Auf diurren Aesten im Gebirge selten (Kod. Br.) S. mutilatus. Beck. Auf düren Aesten im Gebirge nicht selten.

Lissodema. Curt.

L. denticolla. Gyll. An alten Baumstämmen selten (Gr. Sp.)

L. cursor. Gyll. An alten Baumstöcken um St. Leonhard (Sp.)

\section{Rhinosimus. Latr.}

Rh. ruficollis, L. Auf diirren Aesten im Gebirge häufig.

Rh. viridipennis. Latr. Wie der Vorige, seltener.

Rh. planirostris. Fabr. Wie die Vorigen.

Rh. aeneus. Ol. Wie die Vorigen, selten (Gr. Gat.)

Agnathus. Germ.

A. decoratus. Germ. Auf Prunus Padus bei St. Leonhard 1 Ex.(Sp.)

\section{Melandryidae.}

Tetratoma. Fabr.

T. fungorum. Fabn: An Baumschwämmen nicht häufig:

T. ancora. Fabr. Auf diurren Aesten im Gebirge nicht selten.

Mycetoma. Muls.

M. suturalis. Panz. Um St. Leonhard J. Ex. gefunden (Sp.)

Eustrophus. Latr.

E. dermestoides, Fabr. In alten Eichenbäumen um St. Leonhard (Sp.) 


\section{Orchesia. Latr.}

O. micans. Panz, Auf diirren Aesten im Gebirge nicht selten.

O. minor. Walk. Auf dürren Aesten im Hochgebirge häufig.

O. fasciata. Payk. Auf diirren Aesten im Gebirge selten.

O. undulata. Kr. Auf diirren Aesten im Gebirge selten; bei Neuberg (Drnbk.), am Bacher (Sp.)

O. laticollis, Redt. Auf dürren Aesten im Gebirge selten (Gat.Sp.)

\section{Hallomenus. Panz.}

H. humeralis. Panz. Auf dürren Aesten, an Baumschwämmeu.

II. fuscus. Gyll. Auf diurren Aesten, an Schwämmen (Kod.Gat.)

\section{Serropalpus. Hellen.}

S. striatus. Hellen. In altem Holze selten (Sp. Gat.)

\section{Phloeotrya. Steph.}

Ph. rufipes. Gyll. Auf morschen Zäunen sehr selten (Gat. Sp.)

\section{Dircaea. Fabr.}

D. quadriguttata. Payk. Am Bacher auf dürrem Holze sehr selten (Sp.)

D. laevigata. Hellen. Auf morschen Zäunen am Schöckl, auf dürren Aesten nicht häufig (Gat. Br.)

\section{Anisoxya. Muls.}

A. fuscula. Ill. In morschem Holze selten (Sp. Gat.)

Abdera. Steph.

A. triguttata. Gyll. Auf morschen Zäunen am Schöckl (Gat.)

A. affinis. Payk. Auf morschem Holze selten.

A. flexusa. Payk. Auf düren Aesten, morschem Holze selten (Sp. Gat.)

\section{Hypulus. Payk.}

H. quercinus, Payk. In morschen Eichen um St. Leonhard (Sp.) H. bifasciatus. Fabr. In morschem Holze nicht häufig.

\section{Mclandrya. Fabr.}

M. caraboides. $L$. Unter morscher Rinde nicht häufig.

M. canaliculata. Fabr. Auf morschem Holze um St. Leonhard (Sp.)

M. Aavicurnis. Duft. Auf duirrem Holze ober Andritz bei Graz 1 Exemplar (Gat.)

\section{Conopalpus. Gyll.}

C. testaceus. Ol. Um St. Leonhard sehr selten (Sp.)

\section{Phryganophilus. Sahl.}

Ph. ruficollis. Fals. Am Bacher an einem Baumstock 1 Exemp. gefingen (Sp.) 
Osphya. III.

O. bipunctata. Fabr. Anf Gras und Blüthen selten (Gat. Sp.)

\section{Lagriariae.}

Lagria. Fabr.

L. hirta. L. Auf blïhendem Gesträuch häufìg.

\section{Pedilidae.}

\section{Xỳlophilus. Latr.}

X. nigrinus. Germ. Im Mulme morscher Bäume (Gr. Gat.)

$X$. pygmaeus. de Geer. Wie der Vorige.

$X$. populneus. Panz. Wie die Vorigen, hänfig.

\section{Anthicidae.}

Notoxis. Geofle.

N. najor. Scten. Auf Gras (Gr.)

N. monoceros. $L$. Auf Gras und Bliithen läufig.

N. commetus. Fabr. Auf Gras und Bliithen nicht häufig.

Mecynotarsus. Latr.

M. rhinoceros. Fabr. Auf sandigen Grasplätzen (Gr.Sp.)

Formicomus. Laf.

F. pedestris, Rossi. Um St. Leonhard sehr häufig (Sp.)

Anthicus. Payk.

A. humilis. Germ. "An sandigen Stellen auf Gras selten (Gr. Sp.)

A. floralis. Fabr. An sandigen Orten nicht häufig.

A. bifasciatus. Rossi. An Bächen und Fliissen um St. Lambrecht lä̈ufig (Kod.), seltener um St. Leonhard (Sp.)

A. gracilis. Panz. An sandigen Orten selten.

A. antherinus. $L$. Auf Bliithen häufig.

A. hispidus, Rossi. Auf Bliuthen selten (Sp.) 
A. ater. Panz. Um St. Leonhard selten (Sp.)

A. uxillaris. Sctrm. Im Mursande gegen Schönau bei Graz (Br.)

\section{Pyrochroidea.}

Pyrochroa. Fabr.

P. coccinea. L. Auf Gras und Blithen nicht selten.

P. rubens. Fabr: Wie die Vorige.

P. pectinicornis. Fabr. Bei Marburg 1 Exemplar gefunden (Sp.)

\section{Mordellonae.}

Tomoxia. Costa.

T. biguttata. Gyli. An alten Baumstämmen in Eggenberg (Gat.) Mordella. Lin.

M. 12-punctata. Rossi. Auf Dolden sehr selten; im Miihlgraben bei Rain (Gat. Br.), um St. Leonhard (Sp.)

M. maculosa. Naez. An Baumschwämmen, auf Geländern nicht selten.

M. bisignata. Redt. Auf Dolden selten.

M. fasciata. Fabr. Auf Dolden häufig.

M. Lipunctata. Germ. Auf Dolden um St. Leonlard selten (Sp.)

M. aculeata. L. Auf Dolden sehr häufig.

M. vittata. Gemm. Auf morschem Holze um St. Leonhard (Sp.), auf Dolden (Gat.)

\section{Mordellistena. Cost.}

M. abdominalis. Fabr. Auf Dolden nicht selten.

$M$. Tumeralis. $L$. Auf Dolden nicht häufig.

M. axillaris. Gyll. Auf Dolden selten.

M. brunnea. Fabr. Auf Dolden um St. Leonhard selten (Sp.)

$M$. lateralis. Ol. Auf Dolden nicht haufig.

M. pusilla. Redt. Auf Dolden häufig

M. grisea. Muls. Auf Dolden (Sp.)

M. pumila. Gyll. Auf Dolden häufig. •

M. minima. Cost. Auf Dolden selten (Gat. Sp.)

A. rufilabris. Gyll. Auf Dolden.

\section{Anaspis. Geoff:}

A. frontalis. $L$. Auf Dolden häufig.

A. ruficollis. Fabr. Auf Dolden nicht häufig. 
A. thoracica. I. A uf Dolden nicht selten.

A. flava. L. Auf Dolden häufig.

A. phalerata. Germ. Auf Dolden selten (Gat. Sp.)

A. picta. Hampe. Um St. Leonhard von Spitzy entdeckt.

\section{Rhipiphoridae.}

Metoecus. Gerst.

M. paradoxus. L. Von Grimmer gesammelt.

Rhipiphoriss. Falbr.

Rh. bimaculatus. Fabr. Bei St, Peter auf einer Wiese 1 Exemplá (Mglch.), bei Marburg (Sp.)

\section{Meloidae.}

Meloë. Lin.

M. proscarabaeus. $L$. Im Grase häufig.

M. cyanea. Muls. Um St Leonhard (Sp.)

M. violacea. Marsh. Nicht selten.

$M$. autumnalis. Ol. Nicht häufig.

M. cicutricosa. Leach. Um St. Laubrecht selten (Kod.)

M. rugosa. Marsh. Nicht häufig (Gr. Gat.)

M. scabriuscula. Br. et Er. Nicht selten (Kod. Gat.)

M. brevicollis. Ol. Nicht häufig (Kod. Gat.)

Lytta. Lin.

$L$. vesicatoria. $L$, Auf Fraxinus excelsior und Ligustrum vulgare nicht selten im siidlichen Steiermark.

Epicanta. Relt.

E. verticalis. Ill. Auf trockenen Grasplätzen selten (Gr. Sp.)

Zonitis. Fabr.

Z. quadripunctata, Fabr. Auf trockenen Grasplätzen selten (Gr.Sp.)

Hapalis. Fabr.

H. bipunctatus. Germ. Auf Wiesen um St. Leonhard selten (Sp.)

Sitaris. Latr.

S. Tumeralis. Fabr. An einer Maner in (Uraz 1 Exemplar (Drfmstr.), um St. Leonhard sehr selten (Sp.) 


\section{Oedemeridae.}

Calopus. Fabr.

C. serraticornis. L. Am Schöckl von dürrem Holze geklopft 3 Exemplare (Br.)

\section{Xanthochroa. Schmidt.}

X. Carniolica. Gistl. Um St. Leonhard auf blühenden Linden, selten ( $\mathrm{Sp}$.

X. gracilis. Schm. Wie die Vorige, sehr hänfig (Sp.)

\section{Asclera. Schmidt.}

A. sanguinicollis. Fabr. Auf blühendem Gesträuch nicht häufig. A. coerulea. L. Auf bliihenden Gesträuch nicht selten.

Oedemera. Oliv.

Oe. Podagrariae. L. Auf Dolden und Blüthen häufig.

Oe. flavescens. L. Wie die Vorige.

Oe. subulata. Ol. Auf Dolden selten (Kod. Gat.)

O.e. coerulea. L, Auf Blüthen um St. Lambrecht sehr selten (Kor.)

Oe. tristis. Schm. Auf Blüthen und Dolden (Sp. Gat.)

Oe. flavipes. Fabr. Auf Dolden und Bliithen häufig.

Oe. virescens. L. Auf Dolden häufig.

Oe. lurida. Marsh. Auf Dolden häufig.

\section{Anoncodes. Schmidt.}

A. adusta. Panz. Auf Dolden und Blüthen häufig.

A. rufiventris. Scop. Wie die Vorige.

A. ustulata. Fabr. Wie die Vorigen, seltener.

A. fulvicollis. Scop. Wie die Vorigen, häufig.

A. viridipes. Schm. Auf Dolden selten (Sp. Gat.)

A. azurea. Schm. Anf Dolden selten (Gr.)

\section{Chrysanthia. Schmidt.}

Ch. viridissima. L. Auf Dolden selten.

Ch. viridis. Schm. Auf Dolden selten (Gat.)

Mycterus. Oliv.

M. curculionoides. Ill. Auf Bliithen und Gras häufig.

M. umbellatarum. Fabr. Auf Dolden und Blithen selten (Gr. Gat.)

\section{Curculiones.}

Mylacus. Schönh.

M. rotundatus. Fabr. Unter Steinen nicht selten. 


\section{0tiorhynchis. Germ.}

o. pulverulentus. Germ. Anf Gesträuch selten (Sp. Kod.)

O. obsoletus. Stierl. Auf Gesträuch selten.

o. geniculatus. Germ. Auf Gesträuch, unter Moos und Laub.

O. inflatus. Gyll. Unter Moos am Bacher (Br.)

O. nastix. Ol. Auf Gesträuch nicht häufig.

O. Carinthiacus. Germ. Auf Gesträuch häufig. v. longicollis. Gyll. Mit dem Vorigen.

O. sulphurifer. Fabr. Auf Gesträuch um St. I,enhard selten (Sp.)

O. planatus, Fabr. Auf Gesträuch und Nadelbäumen häufig:

o. laevigatus. Fabr. Auf Gesträuch häufig.

8. multipunctatus. Fabr. Auf Gesträuch $1 \mathrm{~m}$ Admont (Stbl.)

O. niger. Fabr. Auf Gesträuch im Gebirge.

v. villosopunctatus. Gyll. S. Auf Fichten im Gebirge.

O. unicolor. Hrbst. Im Gebirge auf Gesträuch, unter Stsinen.

v. ebeninus. Gyll. S. Im Gebirge häufig.

O. orbicularis. Fabr. Auf Gesträuch selten (Gat. Sp.)

O. petrensis. Boh. S. Am Fusse des Bacher bei Marburg (Sp.)

O. chrysocomus. Germ. Auf höheren Alpen auf Pinus pumilo nicht selten.

O. vaucus. Fabr. Aut Gesträuch, unter Laub und Moos.

O. perdix. Germ. Auf Fichten im Gebirge häufig.

O. chalceus. Stierl. Im -Gebirge selten (Gat.)

O. scabrosus. Marsh. Um St. Leonhard selten (Sp.)

O. alpestris. Stierl: Um St. Leonhard selten (Sp.)

O. foraminosus. Boh. S. Auf Alpen selten (Gat.)

O. pigrans. Stierl. Schnee- und Veitsch-Alpe unter Steinen selten (Gat.)

O. porcatus. Hibst. Im Gebirge selten.

O. septentrionis. Hi⿱sst. Auf Alpen sehr häufig.

O. manur. Gyll. Im Gebirge an Fichten (Gat.)

v. demotus. Boh. S. Am Bachergebirge unter Moos (Br.)

O. Schmidtii. Stierl. Auf Alpen selten (Gat.)

O. lavandus. Germ. Auf Alpen selten (Gat.)

O. picipes. Fabr. Uin St. Leonhard (Sp.)

O. pupillatus. Gyll. S. Auf Fichten im Gebirge häufig.

O. subdentatus. Bach. Am Bachergebirge selten (Br.)

O. tenuicornis. Mill. Auf jungen Fichten am Bacher bei Marburg selten (Sp, Gat.) *)

o. subquadratus. Rosh. Am Bacher selten (Sp. Br.)

O. difficilis. Stierl. Auf Alpen selten (Gat.)

O. signatipennis. Gyll. S. Im Pösnitzthale selten (Gat.)

O. Duinensis, Germ. Ebendaselbst (Gat.)

O. gemmatus. Fabr. Auf Gestrånch und Nadelbäumen häufig. v. chlorophanus. Boh. S. Um St. Leonhard (Sp.)

O. squamosus. Mill. Auf Alpen nicht selten.

o. lepidopterus. Fabr. Auf Fichten im Gebirge sehr häufig.

* Diese nov. species durfte mehreren Entomologen von mir und Grazer Entomologen als eremicola mitgetheilt worden sein. 
O. sulcatus. Fabr. Un St. Leonhard selten (Sp.)

O. Austriacus. Eabr. Auf Alpen nicht selten.

O. costatus. Stierl. Um St. Leonliard selten (Sp.)

O. auricapillus. Germ. Auf Alpen unter Steinen nicht selten.

O. Ligustici. L. Auf Gesträuch häufig.

O. alpicola. Boh. S. Auf Alpen selten (Gat.)

O. rugifrons. Gyll. Auf Alpen selten (Gat.)

O. picitarsis. Rosh. Um St. Leonliard selten (Sp.)

O. pinastri. Hrbst. Auf nassen Wiesen um St. Leonhard (Sp. Br.)

O. ovatus. L. Auf Gesträuch, unter Moos häufig.

O. velutinus. Germ. Um St. Leonhard selten (Sp.)

O. Zebra. Fabr. Um St. Leonhard selten (Sp.)

\section{Tyloderes. Schönh.}

T. chrysops. Frbst. Unter Steinen auf Alpen nicht selten.

\section{Stomodes. Schönh.}

St. gyrosicoilis. Boh. S. Unter Steinen selten (Gat. Sp.)

\section{Peritelus. Germ.}

P. hirticomis. Hrbst. Auf Gesträuch selten (Kod. Br.)

P. senex. Boh. S. Auf Gesträuch selten (Gat.)

P. leucogrammus. Germ. Unter Steinen und Laub (Br.)

\section{0mias. Schönh.}

O. concinnus. Boh. S. Unter Laub selten, am Fusse des Schöckl $(\mathrm{Br}$.

O. forticornis. Boh. S. Unter Laub nicht häufig.

\section{Barypeithes. du Val}

B. Chevrolati. Boh. S. Unter Laub um Graz häufig.

$B$. brunnipes. Ol. Unter Laub? selten (Mglch. Gat.)

B. mollicomus. Ahr. Unter Laub (Gr. Sp.)

\section{Platytarsus. Schönh.}

P. villosulus. Germ. Unter Steinen nicht selten.

P. hirsutulus. Fabr. Unter Steinen und Laub.

P. setulosus. Boh. S. Wie die Vorig'en.

\section{Trachyphlosus. Germ.}

T. scabriusculus. L. Unter Steinen.

T. scaber. L. Wie der Vorige.

T. alternans. Gyll. Wie die Vorigen.

\section{Phyllobius. Schönh.}

Ph. calcaratus. Fabr. Auf Gesträuch häufig.

Ph. alneti. Fabr. Auf Gesträuch nicht selten.

Ph. canus. Gyll. S. Auf Gestränch um St. Leonhard (Sp.)

Pr. psittacinus. Germ. Auf Gesträuch (Gr. Gat.)

Ph. pineti. Redt. Auf Gesträuch (Gr. Kod.)

Ph. argentatus. L. Auf Gesträuch läufig. 
Ph. naculicornis. Germ. Auf Gesträuch (Gat.)

Ph. oblongus. L. Auf Gesträuch häufig.

Ph. mus. Fabr. Auf Gesträuch nicht selten.

Ph. sinuatus. Fubr. Auf Gesträuch um St. Lambrecht (Kod.)

Ph. Piri. L。 Auf Gesträuch.

Ph. cinereus. Gyll. S. Auf Gesträuch (Gat.)

Ph. pictus. Stev. Auf Gesträuch (Gat.)

Ph. Betulae. Fabr. Auf Gesträuch.

Th. pomonae. Ol. Auf Gesträich.

Ph. miformis. Mursh. Auf Gesträuch selten (Sp. Gat.)

Ph. vividicollis. $F_{4} l_{2}$. Auf Gesträuch nicht häulig.

\section{Tropiphorus. Schönh.}

T. mercurialis. Fubr. Unter Steinen im Gebirge.

T. carinatus. Miill. Unter Steinen im Gebirge selten (Gat. Sp.)

$T$. cinereus, Boh. S. Unter Steinen selten.

T. globatus. Hibst. Unter Steinen auf Alpen selten (Gat. Br.)

T. ochraceosignatus. Boh. S. Auf der Grebenze unter Steinen selten (Kod.)

\section{Liophloens. Giem.}

L. mbilus Faln. Auf Gesträuch häufig.

L. Herbstii. Gyll. Auf (Gesträuch selten (Gat.)

L. lentus. Germ. Auf Gesträuch selten (Kod. Gat.)

Barynotus. Germ.

B. olscurus. Fubr.'Unter Steinen häufig.

B. moereus, Fabr: Wie der Vorige, seltener.

B. alternans. Boh. S. Unter Steinen (Gr.)

\section{Strophosomus. Billb.}

St. Coryli, Fabr. Auf Gesträuch, unter Laub häufig.

St. faber. Hobst. Auf Gesträuch, unter Laub.

St. hispidus. Boh. S. Auf Gesträuch um St. Leonhard (Sp.)

St. squamulatus. Hibst. Auf Gesträuch um St. Leonhard (Sp.)

\section{Sciaphilus. Schönh.}

Sc. muricatus. Fabr. Auf Gestråuch, unter Laub häufig.

Sc. micans. Fabr. Wie der Vorige.

Sc. setulosus. Germ. Auf Gesträuch nicht selten.

Sc. barbatulus. Germ. Auf Gesträuch selten (Gat. Br.)

Sc. scitulus. Germ. Auf Gesträuch selten (Gat.)

Eusomus. Germ.

E. ovulum. Ill. Auf Gesträuch häufig.

\section{Brachyderes. Schionl.}

B. incanus. L. Auf Gesträuch häufig.

\section{Sitones. Schönh.}

S. griseus. Fabr. Auf Gesträuch un St. Leonhard (Sp.) 
S. fiavescens. Marsh. Auf Gesträuch, unter Laub.

S. sulcifrons. Thunb. Auf Gesträuch, unter Laub.

S. tibialis. Hrbst. S. Auf Gesträuch, nnter Laub.

v. ambiguns. Schh. Wie der Vorige.

v. brevicollis. Schh. Wie die Vorigen.

S. lineellus. Gyll. Auf Gestränch, unter Laub.

S. crinitus. Ol. Auf Gesträuch und Gras.

S. puncticollis. Steph. Auf Gras (Gat.)

S. lineatus. L. Auf Gesträuch und Gras.

S. discoideus. Gyll. S. Auf Getreidefeldern um St. Lambrecht (Kod.)

S. hispidulus. Fabr. Anf Gestrïinch und Gras.

S. tibiellus. Gyll. Auf Gesträuch und Gras (Gat.)

S. homeralis. Steph. Auf Gesträuch und Gras (Ltgb. Gat.)

\section{Metallites. Schönh.}

M. mollis. Germ. Auf Gestränch häufig.

$M \cdot$ atomarius. Ol. Auf Gesträuch.

11. ambiguus. Schh. Auf Gesträuch häufig.

\section{Polyilrusus. Germ.}

P. undatus. Fabr. Auf Gesträuch häufig.

P. intermedins. Zett. Anf Gesträuch selten (Gat. Sp.)

P. fulviconis. Fabr. Auf Gestränch um St Leonhard (Sp.)

P. planifrons. Gyll. S. Auf Gesträuch 1 m St. Leonhard (Sp.)

P. paradoxus. Stierl. Auf Erlen im nördlichen Steiermark (Gat)

P. Alavipes. de Geer. Auf Gesträuch häufig.

P. pterygomalis. Boh S. Auf Gestränch (Gat.)

P. flavovirens. Gyll. S. Auf Gesträuch (Gat)

P. cervinus. Gyll. L. Auf Gesträuch häulig.

P. chrysomela. Ol. Auf Gesträuch nicht selten.

$P$. confluens. Steph. Auf Gesträuch selten (Gat.)

P. Picus. Fabr. Auf Gesträuch nicht häufigg.

P. sericeus. Schall. Auf Gesträuch häufig.

\section{Thylacites. Germ.}

T. pilosus. Fabr. Auf Gesträuch um St. Leonhard (Sp.)

\section{'Tanymecus. Gierm.}

T. palliatus. Éabr. Auf Gesträuch häufig.

Chlorophanus. Ger'm.

Chl. viridis. L. Auf Weidengebüsch sehr häufig.

Chl. pollinosus. Fabr. Auf Gisträich nicht selten.

Chl. salicicola. Germ. Auf Weidengebiisch.

Chl. graminicola. Gy?l. S. Auf Weidengebiisch um Cilli (Ltgb.)

Chl. sellatus. Fabr. Um St. Leonhard selten. (Sp.)

Psallidium. Ill.

Ps. maxillosum: Fabr. Auf Feldwegen um St. Lambrecht (Kod.) 


\section{Minyops. Schönh.}

M. variolosus. Fabr. Unter Steinen, auf Feldern.

Gronops. Schönl.

G. lunatus. Fabr. Unter Steinen selten (Sp. Br.)

Orthochaetes. Schionh.

o. setiger. Germ. Auf Gesträuch (Gr. Gat.)

\section{Molytes. Schönl.}

M. coronatus, Latr. Nicht häufig (Stbl. Gr.)

M. Germanus. L. Auf Gesträuch nicht selten.

M. glabratus. Fabr. Um Cilli nicht häufig (Ltgb.)

\section{Liosomus. Kirby.}

L. ovatulus. Clairv. Auf Alpen häıfig auf Alchemilla vulgaris.

I. cyanopterus. Redt. Auf Alchemilla vulgaris am Hoch-Lantsch und Laa-Alpe sehr selten (Gat.), am Schöckl (Ulrch.)

L. cribrum. Gyll. Mit den Vorigen in Gemeinschaft selten (Gat. Br.)

L. concinmun. Boh. S. Wie die Vorigen (Gat.)

\section{Plinthiss. Germ.}

Pl. Megerlei. Panz. Im Gebirge unter Steinen.

Pl. Sturmii. Germ. Im Gebirge unter Steinen selten.

Pl. porculus. Fabr. Um Graz mehrfach, gefangen worden, aber sehr selten; scheint in Baumstöcken zu leben.

\section{Trachodes. Germ.}

T. hispidus, L。 Auf diirrem Holze im Gebirge häufig.

\section{Alophus. Schönh.}

A. triguttatus. Schönh。 Auf Gesträuch, unter Laub häufig.

\section{Hypera. Germ. *)}

H. punctcta. Fabr. Unter Steinen, auf Aeckern häufig.

H. fasciculata. Hrbst. Auf Kleefeldern um St. Lambrecht (Kod.)

H. maculata. Redt. Auf Verbascum um St. Lambrecht (Kod.)

H. Salviae. Schrnk. Auf Gesträuch um St. Leonhard (Sp.)

H. palumbaria. Germ. Auf Gras nicht selten.

H. comata. Boh. S. Auf Gras, unter Steinen häufig.

H. tesselata. Hrbst. Um St. Leonhard 1 Exempl. (Sp.)

H. contaminata. Hrbst. Auf Gras und Gesträuch nicht luäufig.

H. Oxalidis. Hrbst. Auf Gras selten (Gat. Br:)

H. elongata. Payk. Um St. Leonhard selten (Sp.)

H. oblonga. Boh. S. Auf Gras selten (Gat.)

H. Arandinis. Fabr. Auf Wiesen um St. Leonhard (Sp.)

H. Rumicis. L. Auf Gräsern und Gesträuch.

H. Pollux. Fabr. Auf Gräsern (Gr. Sp.)

*) Eine wahrscheinlich newe Hypera habe ich Herrn Dr. Clement Hampe eingeschickt, aber nichts Endgiltiges dariiber erfahren. 
H. suspiciosa. Hrbst. Auf Gräsern und Gebiisch.

H. Plantaginis. de Ğeer. Auf Gesträuch und Gräsern häufig.

H. murina. Fabr. Auf Gräsern (Gr. Gat.)

H. veriabilis. Hrbst. Auf Gesträuch und Gräsern häufig.

H. Polygoni. Fabr. Wit die Vorige.

H. meles. Fabr. Auf Gras, unter Steinen (Gr.)

II. nigrirostris. Fabr. Auf Gesträuch und Gras sehr häıfig.

\section{Limobius. Schönh.}

L. dissimilis. Hrbst. Auf Gesträuch und Gräsern nicht häıfig.

\section{Cleonus. Schönh.}

Cl. ophthalmicus. Rossi. Unter Steinen, auf Feldwegen (Gr. Gat.)

Cl. narmoratus. Fabr. Wie der Vorige, häıfig.

Cl. trisulcatus. Hrbst. Wie die Vorigen selten (Gr. Gat.)

Cl. roridus. Fabr. Um Cilli nicht selten (Ltgb.)

Cl. grammicus. Panz. Um Graz selten (Sp. Gat.)

$C l$. sulcivostris. $L$. Unter Steinen, auf Feldwegen häufig.

Cl. turbatus. Fubr. Nicht häufig; um Graz (Gat.), um Cilli (Ltgb.)

Cl. obliquus. Fabr. Wie die Vorigen, nicht selten.

Cl. excoriatus. Gyll. Um St. Leonhard selten (Sp.)

Cl. cinereus. Schrnk. Um St. Leonhard (Sp.)

Cl. alternans. Ol. Unter Steinen um Graz selten (Gr. Gat.)

Cl. albidus. Fabr. Wie der Vorige, häufiger.

Cl. varius, Hrbst. Um Graz sehr selten (Gat.)

Cl. glaucus. Fabr. Um St. Leonhard (Sp.)

\section{Rhynocyllus. Germ.}

Rh. antiodontalgicus. Gerbi. Auf Carduus um St. Leonhard (Sp.)

\section{Larinus. Germ.}

L. Sturnus. Ol. Auf Carduus Arten nicht salten.

L. Jaceae. Fabr. Wie der Vorige.

L. obtusus. Gyll. S. Auf Carduus Arten selten (Gat.)

L. Carlinae. Ol. Wie die Vorigen häufig.

L. Ursus. Fabr. Von Grimmer gesammelt.

L. senilis. Fabr. Auf Carduus Arten (Gr. Sp.)

Lixus. Fabr.

L. paraplecticus. L. Auf Schilf, in Stängeln des Wasserschiorlings.

L. turbatus. Gyll. S. Auf Carduus Arten (Gat.)

L. Ascanii. L. Wie der Vorige.

$L_{\text {. }}$ sanguiners. Rossi. Wie die Vorigen selten (Gat.)

L. elegantulus. Boh. S. Wie die Vorigen selten (Gat.)

L. angustatus. Fabr. Wie die Vorigen nicht selten.

L. licolor. Ol. Bei Ulrichsbrunn bei Graz (Gat.)

L. pollinosus. Germ. Um St. Leonhard selten (Sp.)

L. filifornis. Fabr. Auf Carduus Arten nicht lıäufig (Gat. Sp.)

Lepyrus. Germ.

I. colon. Fabr. Auf Gesträuch häufig.

L. bino:atus. Fabr. Wie der Vorige, seltener. 


\section{Hylobius. Schönh.}

H. pineti. Fabr. Auf Nadelbäumen häufig.

II. Abietis. L. Wie der Vorige.

H. pinastri. Gyll. Wie die Vorigen, selten (Gat.)

H. fatuus. Rossi. Auf nassen Wiesen um St. Leonhard (Sp.)

\section{Pissodes. Germ.}

P. Picae. Ill Auf Nadelholz nicht selten.

P. Pini. L. Wie der Vorige.

P. notatus. Fabr. Wie die Vorigen häufig.

P. strolili. Redt. Um St. Gotthard bei Graz (Gat.)

P. Hercyniae. Hrbst. Auf Nadelbäumen selten.

P. piniphilus. Hrbst. Um St. Leonhard selten (Sp.)

P. scabricollis. Mil. Von Gatterer als vorkommend angegeben?

\section{Grypidins. Schönl.}

Gr. Equiseti. Fabr. An Wasserpflanzen, auf Grasplätzen.

Gr. brunnicornis. Fabr. Um St. Leonhard selten (Sp.)

\section{Eriprinus. Schönlı.}

E. bimaculatus. Fabr. Auf Gesträuch und Grïsern (Sp. Gr.)

$E$. accridulus. $L$. Wie der Vorige.

E. aethiops. Fabr. Auf Gesträuch um St. Leonhard (Sp.)

E. pillumus. Gyll. S. Auf Gesträuch und Gräisern (Gat.)

E. infirmus. Hrbst. Auf Gesträuch (Gr. Sp.)

E. Festucae. Hrbst. Auf Wiesen nicht häufig.

E. vorax. Fabr. Auf Gesträuch sehr häufig.

E. macropus. Redt. Wie der Vorige.

E. Tremulae. Payl. Auf Gesträuch nicht häufig (Gat.)

E. costirostris. Gyll. S. Auf Gesträuch hä̈ufig.

E. affinis. Payk. Auf Gesträuch nicht häufig (Gat.)

E. validirostris. Gyll. S. Wie der Vorige.

E. taeniatus. Fabr. Um St. Leonhard nicht häufig (Sp.)

F. occalescens. Gyll. S. Auf Gesträuch selten (Gat.)

E. flavipes. Panz. Wie der Vorige (Gat.)

E. agnathus. Boh. S. Um Admont (Stbl.), bei Neuberg (Drnbk). selten.

E. maialis. Payk. Auf Gesträuch nicht häufig.

E. pectoralis. Panz. Wie der Vorige.

E. minutus. Gyll. S. Auf Gesträuch und Gräsern selten (Kod. Gat.)

E. villosulus. Gyll. S. Auf Gesträuch (Gr. Gat.)

E. Tortrix. L. Auf Gesträuch häufig.

E. dorsalis. Fabr. Um St. Leonhard selten (Sp.)

\section{Mecinus. Germ.}

M. piraster. Hrbst. Auf Gesträuch nicht häufig.

M. circulatus. Marsh. Um St. Leonhard selten (Sp.)

M. jänthinus. Germ. Um St. Leonhard selten (Sp.)

\section{Hydronomus. Schönh.}

H. Alismatis. Marsh. Auf Wasserpflanzen nicht häufig. 


\section{Bagous. Germ.}

B. cylindrus. Payk. Auf Wasserpflanzen nicht häufig.

B. binodulus. Hrbst. Auf Wasserpflanzen um St. Leonhard (Sp.)

B. subcarinatus. Gyll. S. Wie der Vorige (Sp.)

B. frit. Hrbst. Auf sandigen Ufern häufig.

B. lutulosus. Gyll. Auf Wasserpflanzen (Gat.)

B. cylindricus. Rosh. Auf Wasserpflanzen um St. Leonhard (Sp.)

\section{Tanysphyrus. Germ.}

S. Lemnae. Fabr. Auf Wasserpflanzen nicht selten.

\section{Smicronyx. Schönh.}

Sm. cicur. Reich. Auf Gesträuch häufig.

Sm. coecus. Reich. Wie der Vorige (Gat.)

\section{Anoplins. Schoinh.}

A. plantaris. Naetz. Auf Gesträuch nicht selten.

A. Roboris. Suffir. Wie der Vorige.

\section{Brachonyx. Schönh.}

Br. indigena. Hrbst. Auf Nadelbäumen sehr häufig:

Balaninus. Germ.

B. E'ephas. Gyll. S. Auf Gesträuch um Fiirstenfeld im Pärchen (Br.)

B. villosus. Hrbst. Auf Gesträuch nicht selten.

B. glaudium. Marsh. Anf Gesträuch (Sp.)

B. nucum. I. Auf Gesträuch nicht selten.

B. turbatus. Gyll. S. Wie der Vorige.

B. crux. Fabr. Wie der Vorige, häufig.

B. Cerasorum. Hrbst. Auf Gesträuch selten (Gat.)

B. Brassicae. Fabr. Auf Gesträuch häufig.

B. pyrhoceras. Marsh. Wie der Vorige.

\section{Anthonomus. Germ.}

A. Ulmi, de Geer. Auf Gestränch häıfig.

A. pedicularius. I. Auf Gestränch um St. Leonhard (Sp.)

A. cinctus. Redt. Un St. Leonhard (Sp.)

A. undulatus. Gyll. S. Auf Gesträuch selten (Gat.)

A. pomorum. L. Auf Gesträuch häufig.

A. Piri. Koll. Auf Gesträuch nicht selten.

A. spilotus. Redt. Um St. Leonhard (Sp.)

A. incurvus. Panz. Um St. Lambrecht nicht selten (Kod.)

A. pubescens. Payl: Anf Gesträuch nicht häufig.

A. varians. Payk. Anf Gestränch häufig.

A. Rubi. Hrbst. Auf Gestränch häufig.

A. druparum. L. Wie die Vorig'en.

\section{Bradybatis. Germ.}

Br. Creutzeri. Germ. Auf blïhendem Achorn um Graz (Gat. Br.) 


\section{Acalyptus. Schönh.}

A. Curpini. Holst. Auf Gesträuch nicht häufig.

A. vifipemis. Gyll. S. Wie der Vorige.

\section{Opcliestes. Ill.}

O. Quercus. L. Auf Gesträuch nicht selten.

O. rufus. Ol. Auf Gesträuch, seltener.

O. scutelluris. Fabr. Auf Gesträuch liäufig.

O. Alni. L. Auf Gesträuch nicht selten.

O. Llicis. Fabr. Auf Gesträuch selten (Gr. Sp.)

O. sul.fasciatus. Gyll. S. Auf Gesträuch um St. Leonhard (Sp. Br.)

O. Fagi. L. Auf Gesträuch nicht selten.

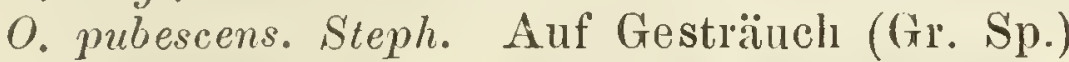

O. pratensis. Germ. Aut Gesträuch nicht selten.

O. Lonicerae. Hrbst. Auf Lonicera Xylosteum nicht selten.

O. Populi. Fabr. Auf Gesträuch selu häufig.

O. Rusci. Hrbst. Auf Gesträuch selten (Kod. Sp.)

O. Avellanae. Donov. Auf Gesträuch selten (Sp. Br.)

O. Stignn. Germ. Auf Gesträuch niclıt häulig.

O. suliceti. Falr. Auf Gesträuch (Gr. Gat.)

$O$. Salivis, $L$. Auf Gesträuch selı lıäufig.

O. decoratus. Germ. Auf Gesträuch selten (Br. Sp.)

\section{Coryssomerus. Schönh.}

C. capucinus. Beck. Von Gesträuch 1 Exempl, geklopft (Br.)

\section{Euryommatus. Roger.}

E. Mariae. Ro\%. Um St. Leonliard auf alten Läunen sitzend, sehr fluchtig, und wahrscheinlich in dem Stängel irgend einel Wiesenpflanze lebend (Sp.)

\section{Lignyodes. Schönh.}

L. emucleator. Pans. Auf Fraxinus excelsior nicht häufig.

\section{Elleschus. Schönh.}

E. Scanicus. Payk. Auf Gesträuch häufig.

L. bipunctatus. L. Auf Salix caprea häufig.

\section{Tychius. Ger'll.}

T. quinquepunctatus. L. Auf Gesträuch und Gras häufig.

T. vemustus. Frabr. Wie der Vorige.

T. Schneideri. Hrbst. Auf Gesträuch (Sp.)

T. Genistae. Boh. S. Auf Gesträuch (Gat.)

T. tomentosus. Hrbst. Auf Gesträuch ind Gräsern.

T. junceus. Reich. Wie der Vorige.

T. sparsutus. Ol. Wie die Vorigen.

T. cupvifer. Panz. Um St. Leonhard selten (Sp.)

T. picirostris. Fabr. Auf Gesträuch und Gräsern häufig.

Sibynia. Germ.

S. Viscariae. L. Auf Gesträuch und Gräsern nicht häufig. 
S. femoralis. Germ. Auf Grässern (Gat.)

S. sodalis. Germ. Auf Gesträuch (Gr.)

Cionus. Clairr.

C. Scrophuiariae. L. Auf Verbascum Thapsus häufig.

C. Verbasci. Fabr. Wie der Vorige.

C. Olivieri. Rosen. Wie die Vorigen, selten (Gat.)

C. hortulanus. Marsh. Wie die Vorigen.

C. olens. Fabr. Wie die Vorigen, seltener.

C. Blattariae. Fabr. Wie die Vorigen.

C. pulchellus. Hobst. Auf Scrophularia hä̀fig (Kod. Sp.)

C. Solani. Fabr. Auf Verbascum und Scroplimlaria nicht selten.

\section{Nanophyes. Schön!.}

N. lythri. Fubr. An Gewässer auf Lythrum Salicaria häufig.

N. Clevierii. Boh. S. Auf Wasserpflanzen um St. Leonhard (Sp.)

\section{Gynetron. Schönl.}

G. Beccalungue. L. Auf Veronica Beccabunga nicht häufigo $v$. Veronicae. Germ. Auf Pflanzen an Ufern, und Wiesen.

G. labiiis. Hrbst. Auf Pflanzen um St. Iseonhard selten (Sp.)

G. rostelim. Hrbst. Auf Wiesen (Gr.)

G. Asellus. Grav. Auf rerschiedenen Pflanzen (Gat.)

G. netus. Germ. Wie der Vorige (Sp. Gat.)

G. spilotus. Gem. Wie der Vorige, häufig.

G. Linariae. Panz. Wie die Verigen, selten (Gat)

G. teter. Fabr. Auf Wiesen (Gr. Sp.)

G. noctis. Hrbst. Auf verschiedenen Pflanzen (Gat.)

G. Campanulae. L. Wie rler Vorige, hänfig.

G. plantarum. 1)ej. Anf Wiesen (Gr.)

\section{Orobitis. Germm.}

O. cyaneus. L. Auf Gräsern nicht häufig.

\section{Acalles. Schönh.}

A. denticollis. Germ. Anf diiren Aesten nicht selten.

A. Camelus. Fabr. Auf diirren Aesten selten.

v. Quercus. Buh. S. Auf vertrockneten Aesten selten.

A. Aubei. Boh. S. Auf diiren Aesten in Wäldern selten

A. alstersus, Boh. S. Auf diurren Aesten in Wäldern niclit selteu.

A. Lemur. Germ. Auf diiren Aesten am Bacher (Sp.)

A. turbatus. Boh. S. Auf diirren Aesten.

v. missellus. Boh. S. WVie der Vorige läutig.

A. ptinoilles. Marsh. Wie die Vorigen nicht selten.

A, hypocita. Boh. S. Wie die Vorigen nicht selten.

\section{Cryptorhynchits. Ill.}

Cr. Lapathi. L. Auf durren Aesten nicht selten.

\section{Rhamphus. Clairv.}

Rh. flavicornis. Clairv, Auf Birken nicht sclten. 


\section{Hononychns. Schönh.}

11. Pserdacori. Fabr. Auf Wiesen um St. Leonhard selten (Sß).)

\section{Coeliodes. Schönh.}

C. zonatus. Gern. Anf Evonymus europaens um Graz nicht selten.

C. Queveus. Fabr. Allf Pflanzen und Gesträuch selten.

C. ruber. Marsh. Wie der Vorige, selten (Sp. Gat.)

C. rubicundus. Payk. Anf (iesträuch um St. Leonhard (Sp.)

C. Epilobii. Payk. Auf Pflanzen selten.

C. guttula. Fabr. Wie der Vorige.

C. fuliginosus. Marsh. A uf Pflanzen selten (Gat.)

C. subrufus. Hrlst. Auf Pflanzen selten (Gat. Sp.)

C. quadrimaculatus. L. Auf Pflanzen (Gat.)

C. Lanii. Hrbst. Auf Pflanzen selten (Gat.)

C. Geranii. Payk. Auf Wiesen häufig.

C. exiguus. Ol. Auf Pflanzen nicht häufig (Kod. Sp.)

\section{Sclopopterus. Schönh.}

Sc. serratus. Germ. Auf Alpen im nördlichen Steiermark anf Alchemilla vulgaris oft sehr hänfig.

\section{Coutorlyychus. Schoinh.}

C. allovitlatus. Germ. Auf Wiesen $n$ m St. Leonhard (Sp.)

C. macula-alba. Hrost. Auf Wiesen selten (Kod. Sp.)

C. syrites. Germ. Auf Pflanzen nicht selten.

C. assimilis. Payli. Auf Pfanzen (Gat.)

C. Erysimi, Fubr. Auf Wiesen selı häufig.

C. rontractus. Marsh. Auf Blithen häufig.

C. setosus. Boh. S. Am Buchkogel bei Graz (Gat.)

C. querceli. Gyll. Anf PHanzen um St. Leonhard (Sp.)

C. Éricae. Gyll. Auf Pfianzen selten (Gat.)

C. variegatus. Ol. Um St. Leonhard (Sp.)

C. pultiarins. Geoff. Um St. Leonhard (Sp.)

C. Echii. Fabr. Auf Echinm vulgare nicht selten.

C. redula. Gyli. S. Auf trockenen Grasplätzen (Kod. Stbl.)

C. ablreviutulus. Gyll. S. Um St. Leonhard (Sp.)

C. crucifer. Ol. Auf Pflanzen selten.

C. litura. Fabr. Auf Wiesen (Kod. Gat.)

C. trimaculatus. Fabr. Auf Wiesen nicht häufig.

C. albosignatus. Gyll. S. Auf Pflanzen (Gat.)

C. asperifoliarum. Gyll. S. Auf Pflanzen.

C. campestris. Gyll. S. Auf Pflanzen (Gat.)

C. signatus. Gyll. S. Um Mariahof nicht selten (Kod.)

C. Chrysanthemi. Gyll. S. Auf Pflanzen (Gat. Sp.)

C. arquatus. Hibst. Auf Pflanzen am Bacher (Sp.)

C. melanostictus. Marsh. Auf Wiesen nicht selten.

C. quadridens. Panz. Auf Wiesen selten (Sp. Gat.)

C. marginatus. Payk. Auf Wiesen häufig.

C. quercicola. Fabr. Auf Pflanzen (Gat.)

C. poilinarius. Forst. Auf Pflanzen (Gat.) 
C. sulcicollis. Gyll. S. Auf Pflanzen (Kod. Gat.)

C. Rapae. Gyll. S. Auf Cochlearia selten (Kod.)

C. Robertii. Boh. S. Im Gebirge selten (Gat. Sp.)

C. cyanopterus. Redt. Auf Alpen selten (Gat. Sp.)

C. ignitus. Germ. Um St. Leonhard selten (Sp.)

C. cyanipennis. Germ. Auf Alpen nicht selten (Gat.)

C. pubicollis. Gyll. S. Um St. Leonhard (Sp.)

Rhytidosomus. Schönh.

Rh. globulus. Hrbst. Am Bacher bei Marburg selten (Sp. Gat.)

Poophagus. Schönh.

P. Sisymbrii. Fabr. Auf Wiesen um St. Leonhard (Sp.)

Phytobius. Schönh.

Ph. velatus. Beck. In der Hungerlache an Wasserpflanzen (Kod.)

Ph. leucogaster. Marsh. An Wasserpflanzen (Gr. Gat.)

Ph. granatus. Gyil. Auf sandigen Ufern der Mur (Gat. Br.)

Ph. notula. Germ. Auf sandigen Ufern der MIur (Gat.)

Ph. velaris. Gyll. Auf sandigen Ufern der IIur bei Graz (Br.)

Ph. quadrinodosus. Gyll. Auf sandigen Ufern (Gr. Sp.)

Ph. Comari. Hrbst. Auf Ufersand nicht selten.

Ph. 4-tuberculatus. Fabr. Auf Ufersand selten (Gr. Gat.)

Ph.4-comis. Gyll. Auf Ufersand der Mur (Gat.)

Rhinoncus. Schönh.

Rh. topiarius. Germ. Um St, Leonhard (Sp.)

Rh. Castor. Fabr. Auf Blïthen nicht selten.

Rh. bruchoides. Hrbst. Auf Bliithen selten (Gat. Sp.)

Rh. inconspectus. Hrbst. Auf Blüthen liäufigr.

Rh. pericarpius. Fabr. Wie der Vorige.

Rh. guttalis. Grav. Auf Bliithen selten (Br. Sp.)

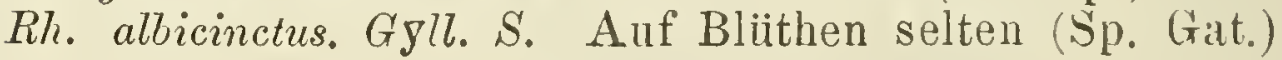

Amalus. Schönli.

A. scortillum. Hrbst. Auf Wiesen häufig.

A. horridus. Fabr. Auf Pflanzen selten (Kol. Gat.)

A. troglodytes. Fabr. Auf Bliithen hänfig:.

A. floralis. Payk. Auf Bliithen häufig.

A. pulvinatus. Gyll. S. Wie der Vorige.

A. Achilleae. Gyll. S. Auf Bliithen selten (Kod. Gat.)

A. pumilio. v. posthumus. Germ. Auf Bliithen nicht selten.

\section{Baris. Germ.}

B. Artemisiae. Hrbst. Auf Artemisia vulgaris nicht läufig.

B. picinus. Germ. Auf verschiedenen Pflanzen nicht häufig.

B. scolopaceus. Germ. Auf Wiesen selten (Gat.)

B. chloris. Panz. Auf Pflanzen (Sp, Gat.)

B. coerulescens. Scop. Um St. Leonliard (Sp.)

$B$. chloricans. Germ. Auf Pflanzen nicht selten.

B. Lepidii. Germ. Auf Pflanzen liäufig. 
B. ATrotani. Germ. Auf Pflanzen (Gat. Gr.)

B. Villae. ('om. Von Grimmer angegeben.

B. T-album. L. Auf Pflanzen häufig.

\section{Sphenophorus. Schönh.}

Sph. piceus. Pall. Auf Gesträuch selten (Gat.)

Sph. abbreviatrs. Fabr. Auf Gesträuch selten (Br. Gat.)

Calandra. Clairv.

C. granaria. L. Bei Getreidevorräthen häufig.

C. oryzae. L. Wie der Vorige.

\section{Dryophthorus. Scaonh.}

Dr. lymexylon. Fubr. Untər Rinden nicht häufig .

Cotaster. Motsch.

C. uncipes, Schönh. Am Bacher nicht häufig (Gat. Sp.)

Cossunis. Clairv.

C. Tinearis. L. In alten Pappelstämmen oft sehr häufig.

C. fermginens. Clairv. Wie der Vorige.

C. cylindricus. Sahlb. Wie der Vorige, seltener (Br.)

Phloeophagus. Schönh.

Pli. spadix. Hrbst. Unter Rinde am Bacher (Gat.)

Rhyncolis. Crentz.

Rh. cylindricus. Boh. S. Unter Rinden nicht selten,

Rh. chloropus. Fabr. Unter Rinden nicht häufig (Kod. Br.)

Rh. elongatus. Gyll. Unter Rinden (Gat. Br.)

Rh. porcatus. Germ. Unter Rinden (Sp.)

Rh. culinaris. Reich. Unter morscher Rinde (Gat. Br.)

Rh. truncorum. Germ. Unter morscher Rinde (Gat. Br.)

Rh. cylindrinostris. Ol. Unter morscher Rinde (Gat, Br.)

Rh. rejlexus. Ol. Unter morscher Rinde (Gat. Sp.)

Rh. punctatulus. Boh. S. Unter morscher Rinde selten (Br.)

\section{Magdalinus. Schönh.}

M. violàceus. L. Auf bliihendem Gesträuch häufig:

M. frontalis, Gyll. Wie der Vorige, seltener (Gat.)

M. duplicatus. Gern. Wio die Vorigen.

I. pflegmaticus. Hrlst. Auf Föhren am Rainerkogl bei Gra\% $(\mathrm{Br}$.)

M. nitidus. Gyll. Auf bhiihendem Gesträuch (Gat. Sp.)

M. linearis. Gyll. Anf Gesträuch selten (Gat.)

M. Cerasi. L. Auf Gesträuch nicht selten.

M. memnominus. Fald. Auf Eichen selten (Gat. Sp.)

M. asphaltinus. Germ. Auf Gesträuch (Gat.)

M. aterrimus. Fabr. Auf Gesträuch häufig.

M. rufus. Germ. Auf Folren um Graz selten (Gat.) 
M. Prumi. L. Auf blïhendem Gesträuch.

M. flavicornis. Gyll. S. Auf Gesträuch (Sp. Br.)

\section{Apion. Hrbst.}

A. Pomonae. Fabr. Auf Gesträuch häufig.

A. Ciaccae. L. Auf Wiesen häufig.

A. subulatum. Kirb. Auf Gesträuch häufig.

A. ochropus. Germ. Auf Gesträuch (Stbl. Gat.)

A. penetrans. Germ. Auf Gesträuch (Stbl. Gat.)

A. Onopordi. Kirb. Auf Gesträuch und Bliithen (St. Gat.)

A. confuens. Kirb. Auf Blïthen (Gat. Kod.)

A. holosericeum. Gyll. S. Auf Blüthen um St. Leonhard (Sp.)

A. atomarium. Kirb. Auf Gesträuch.

A. Alavimanum. Gyll. S. Auf Gesträuch (Gat.)

A. Hoockeri. Kirb. Um St. Leonhard (Sp.)

A. difficile. Hrbst. Auf Gesträuch (Gat. Sp.)

A. fuscirostre. Fabr. Auf Gesträuch (Sp.)

A. Genistae. Kirb. Auf Gesträuch.

A. Alavofemoratum. Hrbst. Auf Gesträuch (Sp.)

A. vernale. Fabr. Auf Gesträuch, unter Laub häufig.

A. aeneum. Fabr. Auf Gesträuch nicht selten.

A. validum. Germ. Auf Gesträuch (Gr. Gat.)

A. radiolus. Kirb. Auf Gesträuch (Gr. Gat.)

A. Astragali. Payk. Auf Gesträuch nicht häufig.

A. clispar. Germ. Auf Gesträuch (Gat.)

A. curvirostre. Gyll. Auf Gesträuch (Gat. Sp.)

A. immune. Kirb. Auf Gesträuch (Stbl.)

A. pubescens. Kirb. Auf Gesträuch nicht selten.

A. seniculum. Kirb. Auf Gesträuch nicht selten.

A. millum. Gyll. S. Auf Gesträuch (Sp. Kod.)

A. rifirostre. Fabr. Auf Gesträuch (Gat. Sp.)

A. Viciae. Payk. Auf Wiesen häufig.

A. dissimile. Germ Auf Gestränch (Sp.)

A. varipes. Germ. Auf Gesträuch sehr hänfig.

A. Fagi. L. Auf Gesträuch (Gat. Sp.)

A. assimile. Kirb. Auf Gestränch (Gr. Gat.)

A. Trifolii. L. Auf Wiesen (Gat. Sp.)

A. favipes. Fabr. Auf Gestränch häufig.

A. nigritarse. Kirb. Auf Gesträuch nicht häufig.

A. ebeninum. Kirb. Unter Laub nicht häifig.

A. tenue. Kirb. Auf Bliithen (Gr. Gat.)

A. punetigerum. Payk. Auf Gesträuch (Kol. Gat.)

A. virens. Hrbst, Auf Bliithen und Gestränch häufig.

A. Gyllenhalii. Kirb. Auf Wiesen um St. Lambrecht (Kod.)

A. Ervi. Kirb. Auf Bliithen (Sp. Gat.)

A. filirostre. Kirb, Auf Nesseln (Kod.)

A. minimum. Hibst. Auf Gesträuch häufig.

A. Pisi. Fabr. Auf Blüthen häufig.

A. Aethiops. Hrbst. Auf Gesträuch (Gr. Gat.)

A. Sorbi. Hrbst. Auf Gesträuch nicht häufig:

A. Meliloti. Kirb. Auf Gesträuch (Sp.) 
A. angustatum. Kirb. Anf (Gesträuch (Gr. Gat.)

A. columbinum. Germ. Auf Gesträuch.

A. Spencei. Kirb. Anf Gesträuch (Gr.)

A. vorax. Hrbst. Auf Gesträuch.

A. pavidum. Germ. Auf Wiesen (Kod.)

A. miniatum. Germ. Auf Wiesen nicht selten.

A. frumentarium. L. Auf Kleefeldern nicht hänfig.

A. sanguineum. de Geer. Um St. Leonhard selten (Sp.)

A. Malvae. Fabr. Nicht häufig.

A. brevirostri. Hrbst. Auf Bliithen (Kod. Sp.)

A. violaceum. Kirb. Auf Gesträuch nicht selten.

A. humile. Germ. Auf Gesträuch (Sp.)

A. simum. Germ. Auf Wiesen (Gr. Korl.)

\section{Scolytidae.}

Hylastes. Er.

H. ater. Payk. Unter Rinden häufig.

H. canicularius. Er. Unter Föhrenrinde.

H. linearis, Er. Unter Rinden selten (Sp.)

H. attematus, Er. Unter Rinden (Gat, Br.)

H. angustatus. Hrbst. Unter Rinden nicht häufig.

H. opacus, Er. Unter Rinden selten (Gat. Br.)

H. decumanus. Er. Am Bacher selten (Sp.)

H. palliatus. Gyll. Unter Rinden häufig.

\section{Iylurgus. Latr.}

H. ligniperda. Fabr. Unter Föhrenrinde salten (Sp. Gat)

H. piniperda. L. Unter Föhrenrinde sehr häufig.

H. ninor. Hart. Um Fiirstenfeld nicht selten (Kahr.)

\section{Phloeophthorus. Woll.}

Phl. rhododactylus. Marsh. Unter Rinden selten (Gat.)

Phl. tarsalis. Först. Um St. Leonhard sehr selten (Sp.)

\section{Hylesinms. Fabr.}

H. crenatus. Fabr. Unter Eschenrinde bei Mariahof nicht selten (Kod.)

H. Fraxini. Fabr. Häufig.

H. vittatus. Fabr. Unter Rinden nicht selten.

Polygraphus. Er.

P. pubescens. Er. Untel Rinde selten (Grr. Br.) 


\section{Scolytus Geoff.}

Sc. destructor. Ol. In Ulmen häufig.

Sc. pygmaen.s. Hibst. Von Grimmer angegiben.

Sc. multistriatus. Marsh. Unter Erlenrinile (Kod.)

Sc. mgulosus. Ratz. Unter der Rinde von P'faimmenbäuman.

Sc. Prmi. Ratz. Unter der Rinde von P'flamenbämmen.

('rypturgus. Er.

C. pusillas. Gyll. Unter Nadelholzrinden sehr häufig.

C. cinereus. Hrbst. Unter Rincien am Bacher (Br.)

Cryphalus. Er.

Cr. aspercstus Gyll. Unter Nadelholzrinde selten.

Cr. Tiliae. Fabr. Unter Rinden 1 m St. Leonhard (Sp.)

Cr. Abietis. Ratz. Am Grazer Schlossberge schwärmend (Br.)

Bostrychus. Fabr.

B. stenographus. Duft. Unter Kieferrinde häuñg.

B. typographus. L. Unter Fichtenrinde häufig.

B. acuminatus. Gyll. Unter Nadelholzrinde am Sch"̈ckl sehr häufig ( $\left.\mathrm{B} r^{\circ}\right)$

B. Laricis. Fabr. Unter Nadelholzrinde sehr häufig.

B. curvidens. Geim. Wie der Vorige, nicht so häufig.

B. nigritus. Gyll. Unter Nadelholzrinde selten (Drnbk. Gat.)

$B$. chalcographus. $L$. Unter Fichtenrinde häufig.

B. bidens. Fabr. Unter Föhrenrinde.

Xylocleptes. Ferr.

$X$. bispinus. Duft. Unter Fichtenrinde.

Pityophthoris. Eich.

P. micrographus. Gyll. Unter Nadelholzrinde.

P. ramusorm. Per. Am Bacher von dïrren Aesten geklopft (Br.)

Dryocetes. Eich.

D. autograplus. Ratz. Auf Alpen unter Rinde selten (Gat.)

D. villosus. Fabr. Unter Nadelholzrinden.

D. bicolor. Hrbst. Unter Rinden selten (Ltgb. Gat.)

Xyleboris. Eich.

X. dispar. Fubr. Auf dürren Aesten selten.

$X$. curygraphus. Ratz. Von Kahr in Steiermark gefunden.

X. Pfeilii. Ratz. Unter Rinden selten (Br. Kaln'.)

X. monographus. Fabr. Unter der Rinde von Lambbäumen.

$X$. dryographus. Ei: Um St. Lambrecht selten (Kod.)

Xyloterus. Er.

X. domesticus, L. Auf dürren Aesten nicht selten.

$X$. lineatus. Er. Wie der Vorige. 


\section{$-95-$ \\ Platypidae. \\ Platypus. Hrbst.}

1'. cylindrus. Fabr. Unter Rinden in alten Baumstöcken.

\section{Attelabidae.}

A poderus. 01 .

A. Coryli. L. Auf Gesträuch häufig.

A. inte?medius. Hellw. Auf Wiesen um St. Leonhard (Sp. Br.)

Attelabus. I.

A. curvulionoides. L. Auf Gesträuch nicht häufig.

\section{Rhinomaceridae.}

Rhynchites. Hrbst.

R. Hungaricus. Fabr. Um St. Peter bei Graz selten.

R. giganteus. Kryn. Auf Apfelbliithen um St. Leonhard (Sp.)

R. curatus. Scop. Anf Gesträuch nicht selten.

R. rectirostris. Gyll. S. Auf Gesträuch um St. Leonhard (Sp.)

R. Bacchus. L. Auf Gestränch nicht selten.

R. parellinus, Gyll. Auf Gesträuch selten (Gat. Sp.)

R. aequatus. L, Auf Gesträuch häufig.

R. cupveus. Is. Auf Gesträuch häufig.

R. aeneovirens. Marsh. Auf Gesträuch.

R. planirostris. Gyll. S. Auf (Gesträuch (Sp.)

R. Alliariae. Payk. Auf Gesträuch nicht selten.

R. conicus. Ill. Auf Gesträuch nicht selten.

R. pauxillus. Germ. Anf Gesträuch nicht häufig.

R. Germanicus. Hrbst. Auf Gesträuch nicht selten.

R. nanus. Payk. Anf Gesträuch nicht selten.

R. betuleti. Fabr. Auf Gesträuch häufig.

R. Populi. L, Auf Gesträuch häufig.

R. sericeus. Hrbst. Auf Gesträuch nicht häufig.

R. pubescens Hrbst. Auf Gesträuch nicht häufig.

R. opthalmicus. Steph. Auf Gesträuch häufig.

R. Betulae. L. Auf Gesträuch häufig.

\section{Auletes. Schönh.}

A. basilaris. Germ. Auf Wiesen um St. Leonhard auf Poterium Sanguisorba (Sp. Br.) 
Diodyrhynchis. Schh.

D. Austriccus. Ol. Auf Föhren nicht häufig.

Rhinomacer. Fabr.

Rl. atteiaboides, Fabr. Auf Föhren selten.

Nemonyx. Redt.

N. lepturoides. Fabr. Auf Nadelbäumen am Rainerkogl bei Graz in Mehrzahl (Tpk.), um St. Leonhard (Sp.)

\section{Anthribidae.}

Platyrhimus Clairv.

Pl. latirostris. Fabr. Auf dürrem Holze im Gebirge nicht selten.

Tropideres. Schönh.

T. albirostris. Hr.st. Auf dürren Aesten, unter morscher Rinde häufig.

T. dorsalis. Thunb. Auf diurren Aesteu selten (Gat. Sp.)

T. untulatus. Panz. Auf dürren Aesten um St. Leonhard (Sp.)

T. Edgreni. Schi. Auf diurren Aesten $u$ St. Leonhard (Sp.)

T. sepicola. Hrbst. Auf Gesträuch und diirren Aesten selten.

T. niveirostris. Fabn. Anf Gestränch $11 m$ Graz (Gat. Tpk.)

T. bilineatus. Germ. Auf diirren Aesten und Gesträulch (Gat. Sp.)

T. cinctus. Payk. Auf diirren Aesten selten (Gat. Sp.)

Anthribus. Geofi.

A. albinus. L. Auf dürrem Holze im Gebirge nicht häufig.

\section{Brachytarsus. Schönh.}

B. scabrosus. Fabr. Auf blïhendem Gesträuch häıfig.

B. varius. Fabr. Auf bliihendem Gesträuch nicht selten.

B. tessellatus. Bolt. S. Auf Gestränch (Gr.)

Choragus. Kirb.

Ch. Sheppardi. Kirb. Auf einem alten Stamme 1 Ex. (Br.)

Ch. piceus. Schaum. Auf diirrem Holze um St. Leonhard (Sp.)

\section{Cerambycidae.}

Spondỵlis. Fabr.

Sp. buprestvides. $L$. In alten Banmstämmen nicht hä̈ıfig. 


\section{Ergates. Serv.}

F. fulier. L. In alten Baumstöcken nicht selten.

\section{Aegosoma. Serv.}

Ae. scabricorne. Scop. Auf Gebisch an der Mur bei Graz (Tbk.), bei Marburg (Sp.)

\section{Tragosoma. Serv.}

T. repsarium. L. In einem alten Lerchenstocke am Hochschwab 1 Ex. (Sp.)

\section{Prionils. Geoff.}

$P$. coricuceus. $L_{0}$ In fanlen Bäumen nicht selten.

\section{Cerambyx. Lill.}

C. heros. Fabr. Auf gefällten Eichen $u m$ St. Leonhard (Sp.), $1 \mathrm{~m}$ Cilli (I.tgb.)

C. cerdo. Scop. Auf blïhendem Gesträuch häufig.

\section{Purparicenus. Serv.}

P. Koehleri. L. Auf gefälltem Holze um St. Leonhar.l nicht salten (Sp.), häıfiger um Cilli (L.tgb.)

\section{Rosalia. Serv.}

R. alpina. L. Anf frischgefälltem Holze nicht selten.

\section{Aromia. Serv.}

A. moschata. I. Auf Weiden häufig.

\section{C:allidium. Fabr.}

C. insubricum. Germ. Auf der Klein-Alpe (Sp.), Teich-Alpe (Gat.)

C. clavipes. Fabr. Auf gefälltem Holze selten.

C. femoratum. L. Auf gefälltem Holze (Gat. Sp.)

C. violaceum. L. Auf gescheitertem Holze häufig.

C. dilatatum. Payk. A uf gescheitertem Holze selten

C. sanguineum. L. Auf gescheitertem Holze selten.

C. unifasciatum. Ol. Auf Scheiterholz um St. Leonhard 2 Exempl. (Sp.)

C. Alni. L. Auf gefälltem Eichenholz (Sp.)

C. rufipes. Fabr. Auf gefälltem Holze selten.

C. variabile. L. Auf gefälltem Holze häufig.

v. praeustum. Fabr. Mit dem Vorigen (Gat.)

C. angustatum. Kriech. Bei Voitsberg auf Gras 2 Exempl. (Ulrch)

C. melancholicum. Fabr. Auf Scheiterholz um Fiürstenfeld sehr selten (Kiesling.)

C. Kollari. Redt. Bei St. Leonhard 1 Exempl. (Sp.)

C. coriaceum. Payk. Bei Maria Zell 1 Exempl. (Sp.)

C. undatum. L. Im Gebirge anf altem Holze nicht häufig. 


\section{Hylotrypes. Serr.}

H. bajulus. L. Auf gefälltem Holze.

\section{Saphanus. Serv.}

S. piceus. Laich. An alten Bammstöcken nicht selten.

Tetropium. Krby.

T. luridum L. Auf liegrendem Holze, unter morscher Rinde.

v. aulicum. Fabr. Wie der Vorige.

v. fulcratum. Fabr. Wie der Vorige.

T. fuscum. Fabr. Unter morscher Rinde (Br.)

\section{Asemum. Esch.}

A. striatum. L. Auf gefälltem Holze, unter morscher Rinde häufig.

\section{Criocephalus. Muls.}

C. rusticus. L. In morschen Baumstöcken nicht selten.

Clytus. Fabr.

C. detritus. I. Auf gefällten Eichen, häufig um St. Leonharr (Sp.), $11 \mathrm{~m} \mathrm{Cilli} \mathrm{(Ltgb)}$

C. arcuatus. L. Auf gefälltem Nadelholz häufig.

C. liceatus. L. In Eichen- und Pappelstämmen nicht selten.

C. foralis. Pall. Um St. Teonhard selten (Sp.)

C. tropicus. Fanz. Anf Holz in St. Leouhard (Sp.), un Cilli selten (Ltgb.)

C. arvicola. Ol. Un St. Leonhard auf Blithen selten (Sp.)

C. arietris. L. Auf Scheiterholz häufig.

C. Capra. Germ. In St. Leonhard auf gefälltem Holze 3 Ex. (Sp.)

C. Rhamni. Germ. Anf gefälltem Nadelholz auf Alpen bei st. Lambrecht (Kod.)

C. semipunctatus. Fabr. Auf Pflamenbäuman um St. Leonhard (Sp.)

C. Verbasci. Fabr. Auf blühendem Gestränch und Lagerholz.

C. ornatus. Fabr. Wie der Torige.

C. Massiitensis. L. Auf blühendem Gesträuch nicht häufig.

C. plebeius. Fabr. Auf blihbendem Gesträrch und Drilden häufig.

C. mysticus. L. Wie der Vorige, häufig:

Obrillin. Latr.

O. brunneum. Fabr. Auf bliihendem Gesträuch nicht selten. Anisartinon. Redit.

A. barbipes. Charp. Anf Gesträuch selten (sp. Gat.)

Giacilia. Serr.

G. pygmaea. Serv. Auf TVeinfässern in St. Leonhard (Sp.). bei Voitsberg (Ulrch.)

Axinopalpus. Redt.

A. gracilis. Erym. Auf Gestränch selten; nm St.Leonhard (Sp.), am Galgenberge hei Cilli (Ltgb.) 


\section{Uallimus. Huls.}

C. cycneus. Fabr. Auf blühendem Gesträuch selten (Gat. Sp.)

Stenopterus. 01.

St. mufus. L. Auf blühendem Gesträuch, auf Dolden.

St. praeustu. Fabr. Wie der Vorige selten (Gr. Gat.)

St. flavicornis. Kïster. Um Fuirstenfeld selten (Kahr).

\section{Dorcadion Dal.}

D. fulvum. Scop. Anf Feldwegen selten (Kod. Sp.)

D. moriv. Fabr. Anf Feldwegen, Feldgräben nicht selten.

D. rufipes. Fabr. Wie die Vorigen, häulig.

D. motitor. Fabr. Um St. Leonhard selten (Sp.)

\section{Morimus. Serv.}

1. tristis. Fubr. Auf Buchenstöcken; am Bacher (Sp.), um Cilli häufig (Ltgb.)

\section{Lamia. Falbr.}

L. textor. L. Im nördlichen Steiermark nicht vorkommend, häufig um Cilli auf Weiden (Ltgb.)

\section{Honochamus. Inatr.}

1. surtor. Fabr. Auf Nadelholzstänmen im Gebirgo häufig.

II. sutor. L. Wie der Vorigie.

\section{Acanthoderes. Serv.}

A. varins. Fuln. Auf liegendem Holze im Gebirge nicht selten.

Astynomis. Steph.

A. aedilis. L. Auf gefälltem Nadelholz im Gebirge.

A. atomarius. Fabr. Anf gefälltem Nadelholz um St. Leonhard (Sp.)

A. griseus. Fubr. Wie ter Vorige, selten (Sp.)

A. alpinus, Redt. Auf liegenden Nadelholz bei Voitsberg (Ulrch.)

\section{Liopus. Serv.}

L. nebulosus. L. Auf Nadelholz nicht seiten.

Exocentrus. Muls.

E. lalteatus. Fabr. Um St. Leonhard sehr hänfig (Sp.), um Fiirstenfeld (Kahr).

\section{Mesosa. Serv.}

1\%. curculionoides. L. Auf trockenem, liegendem Holze nicht häufig.

M. nebulose. Fabr. Wie der Vorige. seltener.

\section{Anaesthethis. Muls.}

A. testacea. Fabr. Auf Gesträuch und liegendem Holze selten (Gat. Sp.) 


\section{Agapanthia. Serr.}

A. Asphocleli. Latr. Auf Verbascum Thapsus (Gr.)

A. angusticollis. Gyll. Auf der Laa-Alys salten (Gat.), Mariahof (Kod.)

A. Cardui. L. Auf liegendem Holze in der Göstinger Au (Gat.)

A. violacea. Fröhl. Am Nikolaiberge bei Cilli sulten (Ltgb.)

Saperda. Fabr.

S. carcharias. L. Auf Populus tremula nicht selten.

S. Phoca. Fröhl. Auf Populus tremula selten (Gat. Sp.)

S. scalaris. L. Auf liegendem Holze selten.

S. Seydlii. Fröh. Auf liegendem Holze nm St. Leonhard selten (Sp.)

S. Tremulae. Fabr. Auf Linden um St. Leonhard häufig (Sp.)

S. punctata. L. Aus Ulmenholz gezogen (Sp.)

S. populnea. L. Auf Populus tremula nicht selten.

\section{Polyopsia. Muls.}

P. praeusta. L. Auf Gesträuch liäufig.

Menesia. Muls.

M. bipunctata. Zupk. Auf Nusshäumen um St. Leonhard (Sp.)

Stennstola. Redt.

St. nigripes. Fabr. Auf Gesträuch selten.

\section{Oberea. Muls.}

O. oculata. L. Auf Populus tremula nicht solten.

O. pupillata. Schh. Wie die Vorige, səltener.

O. crythrocephala. Fabr. Auf Wolfsmilch s'iten.

O. linearis. L. Auf Gestränch; selten um St. Lambrecht (Kod.', im südlichen Steiermark häufig.

\section{Phytoecia. Muls.}

Ph. affinis. Punz. Auf Gras und Gesträuch selten

Ph. punctum. Muls. Auf Gras und Bliithen selten.

Ph. lineola. Fabr. Wie die Vorige, häufig.

Ph. rufimuna. Schrart. Um St. Leonhard selten (Sp.)

Ph. ephippium. Fabr. Auf Gras und Blithen häufig

Ph. Solidaginis. Bach. Anf Grasplätzen selien (Gr. Sp.)

Ph. cylindrica. L. Um St. Leonhard (Sp.)

Ph. nigricornis. Fabr. Auf Grasplätzen nicht häufig (Gr. Sp.)

Ph. virescens. Fabr. Auf Echium vulgare häufig.

P7. molybdaena. 7)ulm. Auf Gestränch selten (Gat.)

Calamobius. Guér.

C. gracilis. Creutz. Auf Wiesen selten; um Fürstenfeld (Kahr.), um St. Leonhard (Sp.)

Necydalis. L.

N. major. Guér. Um Fürstenfeld selten (Kahr.) 
N. nimur. L. Auf Gesträuch mnd Bliithen häuti

N. umbellatarum. L. Auf Bliithen selten.

\section{Rhamunsium. Latr.}

Rh. Salicis. Fubr. Auf Weiden und Pappelstämmen nicht häufig.

\section{Rhagium. Fabr.}

Rh. mmlax. Fabr. Unter morscher Rinde, auf Baumstöcken häutign.

Rh. inquisitor. Fubr. Wie der Vorige.

Rh. imlagator. L. Wie die Vorigen.

Rh. bifrasciatum. Fabr. Wie die Vorigen.

\section{Toxotus. Serv.}

T. cursor. L. Unter morscher Rinde, an Baumstöcken nicht selten.

T. meridianus. L. Anf Banmstöcken, und Gesträuch nicht häıfigr.

T. Quevcus. Götz. Auf bliihendem Gesträuch sılten (Kod. Sp.)

\section{Pachyta. Serv.}

P. Lamed. L. Auf Blumen um St. Lambrecht sehr selten (Kod.), auf der Choralpe.

P. quadrima:ulata. L. Auf Dolden im Gebirge häufig.

$P$. interrogationis. L. Auf der Laa-Alpe auf Alpenwiesen (Gat.)

P. clrthrata. Fabr. Auf Alpenwiesen im nördlichen Steiermark häufig.

P. strigilata. Falr. Auf Dolden im Gebirge selten.

$P$. sexmaculatc. L. Auf Dolden und Bliithen sehr häufig. v. trifasciatu. Fabr. Wie die Vorigen, selten.

P. octomaculata. Fabr. Auf Dolden und Blüthen häufig.

$P$. virgineu. $L$. Wie die Vorige.

$P$. collaris. L. Wie die Vorige.

\section{Strangalia. Sâr.Y.}

St. anulevta. Fabr. Auf Blüthen und Dolden sehr selten.

St. quadrifasciata. L. Auf Dolden und Blüthen häufig.

St. villica. Fabr. Auf jungen Eichen selten.

St. pubescens. Fabr. Auf Dolden und Blüthen häufig.

St. atra. Fubr. Auf bliihendem Gesträuch nicht häufig.

St. armatu. Hibst. Anf Dolden und Bliithen hänfig.

St. annularis. Fabr. Anf Dolden und Spiraea.

St. attemuata. L. Auf Dolden und bliihendem Gesträuch häufig.

St. nigia. L. Auf bliihendem Gesträuch häufig.

St. bifasciatu. Niull. Auf Dolden und Blüthen sehr häufig.

St. melanu'ci. L. Wie die Vorige.

St. septenpunctata. Fahr. Auf Dolden un I Spiraza håufir.

\section{Leptura. Lin.}

L. virens. L. Auf Dolden aiff Alpenwiesen nicht selten.

L. Lestucea. T. Auf Dolden und Bliuthen häufig.

L. scutellata. Fabr. Anf Do'den und Bliithen nicht selten.

L. fulka. de Geer. Auf Dolden im Gebirge selten. 
L. cinctu. Faim. Auf Dolelen und Bliithen im Gebirge bänfig:

L. sanguinolentu. L. Auf Dolden und. Blüthen häufig.

L. maculirormis. de Geer. Wie die Vorige.

L. rufipennis. Muls. Auf Buchenstöcken am Bacher 4 Exempl. (Sp.)

L. livida. Fabr. Auf Dolden häufig.

\section{Anoplodera. Inuls.}

A. sexguttuta. Fabr. Auf bliihendem Gesträuch selten.

A. rufipes. Schall. Auf blühendem Gesträuch häufig.

A. lurida. Fabr. Auf Dolden und Bliithen häufig.

\section{Cortodera. II uls.}

C. quadriguttata. Fabr. Auf Dolden 11 St. Leonhard selten (Sp.)

\section{Gramoptera. Serv.}

G. laevis. Fabr. A uf Dolden und Gesträuch häufig:

G. holosericea. Fabr. Auf Dolden um St. Leonhard (Sp.)

G. analis. Panz. Auf Dolden und blühendem Gesträuch selten.

G. ruficomis. Fabr. Auf Dolden und Bliithen häufig.

G. praęusta, Fabr. Wie die Vorige.

\section{Bruchida e.}

Urodont. Schïinh.

U. rufipes. Fubr. Auf Resed á lutea um Graz nicht selten (Gat. Br.)

\section{Spermophagus. Ster.}

Sp. Cardui. Gyll. Auf Blüthen häufig.

Bruchits. Lin.

B. variegatus. Germ. Auf IViesen. anf Blithen selten.

B. dispergatus. Gyll. S. Auf Wiesen selten (Gat.)

B. marginellus. Fabr. Auf Wiesen nicht hänfig.

B. imhricornis. Panz. Anf Bliithen selten (Sp. Gr.)

B. Cisti. Faln. Auf Dolden und Blithen nicht selten.

B. olivacens. Germ. Auf Erbsenfeldern selten (Kod.)

B. Pisi. L. Auf Erbsenfeldern häufig.

B. rufimanus. Boh. S. Auf Bliithen (Gr. Gat.)

B. Alavimanus. Boh. S. Anf Bliithen und Gras (Gr. Gat.)

B. sertatus $v$, signaticornis. Gyll. S. Auf Blithen und Lolden (Gat.)

B. seminarins. L. Auf Hülsenfrichten häufigg.

B. luteicornis. Ill. Auf Blithen und Dolden (Gat.)

B. mubilus, Boh. S. Wie der Vorige (Gat.)

B. Viciae. Ol. Auf Bliuthen und Dolden (Gat.)

B. Lentis. Boh, S. Wie der Vorige (Git.) 
B. pubescens. Germ. Auf Blüthen und Dolden (Gr. Gat.)

B. ater. Marsh. Auf Blüthen und Dolden (Gr. Gat.)

\section{Chrysomelidae.}

\section{Orsodacna. Latr.}

O. Cerasi. Fabr. Um St. Leonhard nicht häufig (Sp.)

O. nigriceps. Latr. Um St. Leonhard selter (Sp.)

Donacia. Fabr.

D. crassiques. Fabr. Anf Sumpfpflanzen (Sp. Kod.)

D. lidens. Oi. Auf Pflanzen in Simpten um St. Leonhard (Sp.), Voitsberg (Ulreh.)

D. dentatu. Hop. Auf Wasserpflanzen selten (Gat. Sp.)

D. reticulata. Schh. Auf Sumpfpflanzen $u$ im St. Leonhard selten (Sp.)

D. dentipes. Fabr. Auf Wasserpflanzen nicht häufig.

D. Iemnae. Fabr. Auf Wasserpflanzen.

$r$. Sargittariae. Fabr. Wie die Vorige.

D. obscura. Gyll. Anf Wasserpflanzen um St. Leonhard selten (Sp.)

D. hrevicomis. Ahr. Auf Wasserpflanzen (Sp. Kod.)

D. i'pressa Payk. Auf Wasserpflanzen (Gl.)

D. sericea. I. Auf Wasserpflanzen nicht selten. $v$ violacea. Gyll. Mit ller Vorigen (Gr.)

D. nigia. Fulr. Auf Wasserptlanzen nicht selten.

D. discolor. Hop. Auf Wasserpflanzen häufig.

D. uffinis. Lumz. Anf Wasserpflanzen selten (Gr. Sp.)

D. semicuprea. Panz. Auf Wasserpflanzen (Gr. Kod.)

D. Meryanthidis. Fabr. Auf Wasserpflanzen selten.

D. lineavis. Hop. Anf IV asserptlanzen hänfig.

D. Hydrocharidis. Fubr. Aut Wasserpflanzen um St. Leonhard (Sp.)

D. tomentosa. Ahr. Auf Wasserpfianzen selten (Gat. Sp.)

\section{Zeugophura. Kunge.}

7. suthpinosa. Fabr. Anf Gräsern und Bliuthen.

Z. scutellaris. Suffi. Auf nassen Wiesen un St. Leonhard (Sp.

Z. Aavicollis. Marsh. Auf Gräsern und Blürhen (Br. Gat.)

\section{Lema. Fabr.}

L. puncticollis. Curt. Alif Gräsern und Blithen nicht häutig.

L. cyanella. L. Auf Gräsern und Blüthen häufig.

L. Evichsonii. Suffr. Auf Gras und Blithen selten (Br.)

L. favipes. Suffr. Auf Gräsern (Gr. Kalı.)

L. melanopa. L. Auf Gräsern und Bliithen häufig. 


\section{Crioceris. Geoff.}

C. merdigera L. Auf Liliaceen nicht selten:

C. bmunea. Fabr. Auf Lilium Martagon nicht selten.

C. alpina. Redt. Auf Lilium Martagon am Hoch-Lantsul und der Hinter-Alpe selten. (Gat.)

C. 14-punctata. Scop. Auf Gräsern sehr selten (Gat.)

C. 12-punctata. L. Anf Spargel nicht selten.

C. i-punctata. Fabr. Auf Wiesen sehr selten (Gat.)

C. Asparayi. L. Auf Spargel häufig.

\section{Clythra. Laich.}

C. pilicollis. Tac. Auf Gesträuch um St. Lambrecht solten (Kod.)

C. tridentata. L. Auf Gesträuch nicht selten.

C. humeralis. Schneid. Auf Gesträuch selten.

C. longimana. L. Auf Gesträuch häufig.

C. longipes. Fabr. Auf Gesträuch häufig.

C. quadripunctata. I. Auf Gesträuch selten.

C. laeviuscula. Rat:. Auf Gesträuch sehr häufiun.

C. cyanea. Fahr. Auf Gesträuch häufig.

C. affinis. III. Auf Gesträuch nicht selten.

C. xanthaspis. Germ. Auf Gesträuch selten.

C. aurita. L. Auf Gesträuch nicht häufig:

C. bucephala. Fabr. Auf blühendem Gesträuch (Sp. Kod.)

C. cyanocephala. Lar. Um St. Leonhard (Sp.)

C. scopolina. L. A uf Gesträuch und Bliuthen nicht solten.

C. quadrimaiulcila. L. Auf Gesträuch und Bliithen richt selton.

\section{Lamprosoma. Kirby.}

L. concolor. Sturm. Auf Pflanzen neben der Ulrichskapelle bei Graz sehr häufig (Br.)

\section{Eumolpus. Kug.}

E. obscums. L. Auf Gesträuch nicht häufig.

E. Vitis. Fabr. Wie der Vorige.

Chrysoclius. Redt.

Ch. pretiosus. Fubr. Auf Cynanchum Vincetoxicum nicht selten

Pachuephorus. Redt.

P. tesselatus, Duft. Auf sandigen Grasplätzen an der Mur (Br.)

P. villosus. Dnft. Auf sandigen Stellen 1 m St. Leonhard (Sp.)

$P$. arenarius. $\dot{F} a b r$. Auf sandigen Ufern der Jur häufig.

Colaphus. Rerlt.

C. Sophiae. Schall. Auf Wiesen selten (Gat. Br)

Cryptocephalus. Geoffi.

C. laetus. Fabr. Auf Bluthen sehr selter (Br. Kalli.)

C. bimaculatus. Ol. Auf Blüthen sehr häufig. 
C. Coryli. L. Auf Gesträich nicht selten.

(: corliger. L. Auf Gesträuch nicht selten.

C. variabilis. Schneid. Auf Gesträuch häufig.

C. sexpnnctatus. I.. Auf Gesträuch häufig.

C. intermptus. Suffr. Auf Gesträuch und Biithen.

C. soloratus. Falr. Auf Blüthen selten $\left(\mathrm{Br}^{\circ}\right.$ )

C. flexuosus. Krym. Um St. Leonhard auf Bliithen (Sp.)

C. elongatus. Germ. Auf Bliithen selten ( $\mathrm{Br}$.)

C. violaceus. Fubr. Auf Bliithen und Gesträuch.

C. virens. Suffr. Auf Wiesen um St. Lambrecht sehr selten (Kod.)

C. sericeus, $L$. Auf Blithen sehr häufig.

C. cureolus, Suffr. Wie der Vorige, seltener.

C. Hypochoeridis. L. Auf Blüthen häufig.

C. lobatus. Fabr. Auf Gesträuch und Bliithen.

C. villosulus. Sriffr. Auf Bliithen selten (Gat.)

C. Pini. L. Auf Gesträuch nicht häufig.

$v$. Abietis. Suffr. Wie der Vorige.

C. 12-punctatus. Faln. Auf Blithen selten (Br.)

( . nitens. I. Auf Blithen selten (Gat.)

C. nitidulus. Gyll. Auf Blithen und Gesträuch.

C. marginellus. Ol. Auf Blithen selten (Gat. Ltglo.)

C. quadriguttatus. Germ. Auf Blithen selten (Sp.)

C. Moraei. L. Auf Blithen im Gebirge häufig.

C. Alavipes. Fabn. Auf Gebiisch und Bliithen håufig.

C. Alavescens $v$. frenatus. Fabr. Auf Gesträuch nicht selten.

C. marginatus. Fabr. Auf Gesträuch und Blüthen nicht häufig.

C. vittatus. Fabr. Auf Bliithen selten.

C. tesselatus. Germ. Auf Bliithen selten (Gat.)

C. bilinealus. $L$. Auf Bliithen und Gestränch.

C. connexus. Ill. Auf Blüthen selten (Gat. Kahr).

C. vittula. Suffr. Um St. Leonhard selten (Sp.)

C. pygnaeus. Fubr. Auf Gesträuch selten (Kod. Sp.)

C. minutus. Fabr. Auf Gesträuch und Blithen nicht selten.

C. Populi. Suffr. Auf Bliithen und Gesträuch.

C. pusillus. Faln. Anf Gesträuch und Bliithen (Gat. Br.)

C. gracilis. Fabr. Auf Gesträuch nicht häutig.

C. Hübneri. Fabr. Auf Gesträuch und Blüthen nicht selten.

C. labiatus. L. Auf Gesträuch nicht liäufig (Gat. Sp.)

C. geminus. Gyll. Auf Gesträuch und Bliithen.

C. strigosus. Germ. Auf Blithen selten.

C. 8-guttatus. Redt. Auf Gesträuch nicht häufig (Sp. Ltglo.)

C. bistripunctatus. Germ. Auf Gesträuch selten (Br. Sp.)

C. bipunctatus. L. Auf Gestiäuch nicht selten.

C. bipustulatus. Fabr. Anf Gesträuch häufig.

\section{Pachybraehys. Sufle.}

P. hieroglyphicus.' Fabr. Auf Gestråuch häufig:

P. histrio. Ol. Auf/Gesträuch nicht selten.

$v$. bisignatus. Redt. Auf Gesträuch (Gat.)

P. fimbriolatus. Suff?. Auf Gesträuch um St. Jeonhard.(Sp.) 


\section{Timarcha. Latr.}

T. tenebricosa. Fabr. Unter Steinen, auf Gras selten.

T. coriaria. Fabr. Wie die Vorige, häufiger.

T. glohosa. H. Schäff. Unter Steinen im Gebirge nicht selten.

T. metallica. Fabr. Wie die Vorige.

\section{Chrysomela. Lin.}

Ch. staphylea. L. Unter Steinen, auf Gras liäufig.

Ch. marcasitica. Germ. Im Gebirge unter Steinen nicht selten. Ch. crassimargo. Germ. Im Gebirge unter Steinen nicht selten. Ch. purpurascens. Germ. Unter Steinen am Hoch-Lantsch (Gat.) Ch. vufa. Duft. Unter Steinen im Gebirge selten.

Ch. varians. Fabr. Auf Gras und anderen Pflanzen.

Ch. Goettingensis. L. Unter Steinen, auf Pflanzen häufig.

Ch. Rossia. Ill. Auf Pflanzen um Fuirstenfeld (Kiesling.)

Ch. haemisphaerica. Duft. Unter Steinen nicht selten.

Ch. globasa. Panz. Unter Steinen im Gebirge nicht häufig.

Ch. Menthate. Schrnk. Um Admont (Stbl.)

Ch. haemoptera. L. Unter Steinen nicht häufig.

Ch. femoralis. Ol. Auf Pflanzen (Gr.)

Ch. sanguinolenta. L. Unter Steinen, auf Pflanzen häufig.

Ch. limbata. Fabr. Auf Pflanzen selten (Sp. Ltgb.)

Ch. carnifex. Fabr. Um St. Leonhard selten (Sp.)

Ch. marginata. L. Unter Steinen nicht selten.

Ch. analis. I. Unter Steinen and Moos.

Ch. violacea. Panz. Auf Gras und Pflanzen nicht selten.

Ch. Menthastri. Suffr. Auf Pflanzen selten (Gat.)

Ch. graminis. $L$. Auf Pflanzen häufig.

Ch. fastuosa. L. Auf Pflanzen häufig.

Ch. cerealis. D. Ünter Steinen, auf Pflanzen häufig.

r. Megerlei. Fabr. Unter Steinen, auf Gras (Gat. Kod.)

Ch. poitita. L. Unter Steinen, auf Gras selten.

Ch. lamina. Fabr. Unter Steinen im Gebirge selten (Bl. Stbl.)

Ch. fucata. Fabr. Besonders auf Hypericum.

Ch. geminata. Payl. Unter Steinen, im Grase nicht häufig.

Ch. Islandica. Germ. Auf Alpen am Grase nicht häufig.

Ch. luctuosa. Duft. Auf Bergwiesen nicht selten im nördlichen Steiermark.

Ch. speciosa. $L$.

v. pretiosa. Suffr. Im nördlichen Steiermark, anf Alpen-Wiesen, besonders auf Adenostyles alpina.

v. gloriosa. Fabr. Auf Alpen-Wiesen nicht häufig.

Ch. phalerata. Germ. Nach Angabe Kodermanns anf AlpenWiesen um St. Lambrecht sehr häufig.

Ch. speciosissima. Scop. Auf Alpen selten (Stbl.)

Ch. tristis. Fabr. Auf Alpen selten (Gat.)

v. Cacaliae. Schrnk. Anf Alpen nicht selten (Gat. Stbl.)

v. Senecionis. Schum. Auf Alpen mit den Vorigen.

Ch. melanocephàla. Duft. Auf der Schnee-Alpe (Gat.), am Bacher unter Steinen (Sp.) 


\section{Lima. Rellt.}

$L$ aenea. $L$. Auf Gesträuch häufig.

L. 20-punctata. Scop. Auf Gestränch sehr häufig.

L. cupraea. Fabr. Anf Gestränch und Pfanzen.

L. Populi. L. Auf Gesträuch sehr häufig.

L. Tremulae. Fabr. Wie die Vorige.

\section{Entomoscelis. Rerlt.}

E. Aclonidis. Fabr. Anf Pflanzen selten (Gat.)

\section{Gonioctena. Redt.}

G. rufipes. de Geer. Auf Gesträuch häufig.

G. viminalis. $L$. Wie die Vorige.

G. affinis. Schh. Am Bacher auf Gesträuch (Sp.)

G. sexpunctata. Panz. Anf Gesträuch selten (Kod.)

G. pallida. L. Auf Gesträuch nicht häufig.

G. 5-punctata. Fabr. Auf Gesträuch auf der 'Teichalpe (Br.)

Gastrophysa. Redt.

G. Polygoni. L. Auf Gras häufig.

G. Raphani. Fabr. Auf Pflanzen nicht häufig.

Plagiodera. Redt.

P. Armoraciae. L. Anf Gebüsch sehr häufig.

Phaedon. Latr.

Ph. orbicularis. Suffir. Am Mursande $11 \mathrm{~m}$ Graz häufig (Br.)

Ph. Carniolicus. Germ. In Gebirge unter Moos selten.

Ph. pyritosus. Ol. Auf Pflanzen nicht selten.

Ph. sabulicola. Suffro. Anf Pflanzen häufig.

Ph. Cochleariae. Fabr. Auf Pflanzen nicht selten.

\section{Phratora. Redt.}

Ph. Titellinae. L. Auf Weidengebüsch sehr häufig. Ph. tibialis. Suffr. Auf Weiden um St. Leonhard (Sp.)

Ph. vulgatissimu. L. Auf Weidengesträuch häufig.

Prasocuris. Latr.

P. aucta. Fcbr. Auf Gesträuch, unter Moos häufig.

$P$. marginella. L. Auf nassen Wiesen selten (Gr. Stbl.)

P. Phellandrii. L. Entwickelt sich im Wasserschierling.

P. violacea. Fabr. Auf nassen Wiesen an Bächen.

\section{Adimonia. Laich.}

A. Tanaceti. L. Unter Steinen, auf Gras häufig.

A. rustica. Schall. Wie die Vorige.

A. aptera. Bon. Auf blühendem Gestränch selten (Sp. Gat.)

A. rufa. Duft. Auf Gesträuch selten (Br.)

A. sanguinea. Fabr. Auf Gesträuch häufig.

A. Capreae. L. Auf Gesträuch häufig. 
Galleruca. Fabr.

G. Viburni. Payk. Auf blühendem Gesträuch häufig.

G. elongata. Brull. Auf Gesträuch selten.

G. Crataegi. Forst. Auf Gestränch nicht selten.

G. Nymphaeae. L. Anf Gesträuch um St. Leonhard (Sp.)

G. lineola. Fabr. Auf Gestråuch nicht selten.

G. Calmariensis. L. Auf Gesträuch nicht häufig.

G. tenella. L. Auf Gestränch nicht häufig.

Agelastica. Redt.

A. Alni. L. Auf Gesträuch häufig.

Phyllobratica. Redt.

Ph.4-maculata. L. Auf Gesträuch selten.

Luperus. Geoff.

L. circumfusus. Marsh. L. Auf Gestränch nicht selten.

L. pinicola. Duft. Auf Nadelbäumen häufig.

L. rufipes. Fabr. Auf Gesträuch häufig.

L. flavipes. $L$. Wie der Vorige.

L. vividipennis. Germ. Auf Gesträuch in uördlichen Stenermark häufig.

\section{Haltica. Geoflr.}

H. Erucue. Duft. Auf Pflanzen häufig.

H. oleracea. L. Auf Gemiise häufig.

H. Mercurialis, Fabr. Auf Mercurialis annua (Gat. Gro)

H. rufipes. L. Auf Gras und anderen Pflanzen selten.

H. nitidula. L. Auf trockenen Grasplätzen selten (Gr. Koll.)

H. versicolor. Kutsch. Auf Grasplätzen selten.

H. Helxines. L. Anf Gras mur anderen Pflanzen hänfig.

H. pubescens. Ent. Heft. Unter Laub selten (Br.)

H. Atropae. All. Auf Atropa Belladonna oft in grosser Anzahl $(\mathrm{Br}$.

H. tronsversa. Marsh. Um St. Leonhard auf Wiesen (Sp.)

H. ferruginea. Scop. Auf Wiesen sehr häufig.

H. femorata. Gyll. Auf Wiesen nicht selten.

H. Peirolevii. Kutsch. Um St. Leonhard selten (Sp.)

H. melanostoma. Redt. Auf Gräsern selten (Stbl. Kahr).

H. cyanescens. Duft. Im Gebirge häufig.

H. nigritula. Gyll. Auf Wiesen selten (Gat. Kahr.)

H. simplicipes. Kutsch. Auf PHanzen selten (Kahr).

H. Modeeri. L. Anf Pflanzen nicht selten.

H. Salicariae. Payk. Auf Pflanzen selten (Gat. Kod.)

H. ventralis. Il. Auf Pflanzen selten (Sp. Br.)

H. alpina. Germ. Unter Steinen und Moos auf Alpen, besonders häufig am Schöckl bei Graz.

H. Malvae. Ill. Auf Pflanzen nicht häufig (Gr. Gat.)

H. fuscicornis. L. Auf Wiesen nicht häufig (Gat.)

H. Armoraciae. E. $H$. Auf Pflanzen selten (Gr.)

H. Hexuosa. Ill. Auf Pflanzen häufig.

H. Brassicae. Fabr. Auf Pflanzen nicht selten. 
H. ochripes. C'urt. Auf Pflanzen selten (Kahr).

H. simuata. Redt. Auf Pflanzen (Sp.)

H. nemorum. I. Auf Pflanzen und Gebüsch häufig.

H. vitula. Redt. Auf Aeckern um St. Lambrecht (Kod.)

H. atro. Ent. Hft. Auf Pllanzen selten (Gr。. Kod.)

H. Lepidii. Ent. Hft. Auf Lepidium häufig.

H. antemnata. Ent. Hft. Auf Wiesen selten.

H. Rrbi. Payk. Auf Himbeeren nicht selten.

H. cyparissiae. Ent. Heft. Auf Euphorbia Cyparissiae häutig.

H. coerulea. Payl. Auf Pflanzen häufig.

H. cyanella. Redt. Auf Scrophularia häufig.

H. pygmaea. Kutsch. Auf Pflanzen (Gr.)?

H. Enpleorbiae. Fabr. Auf Euphorbia und Verbascum lı̊ufig.

H. Campanulae. Redt. Auf Wiesen läufig (Kod. Gat.)

H. lacertosa. Rosh. Auf trockenen Grasplätzen ( $\mathrm{Bl}^{\circ}$.)

H. msticu. I. Auf Grasplätzen (Gat. Stbl.)

H. obtusata. Gyll. Auf Gras und Bliithen (Gr. Sp.)

\section{Longitarsus. Latr.}

L. Lirucuei. Duft. Auf Pflanzen selten (Gat. Sp.)

L. Echii. Eut. Hft. Auf Pflanzen häufig.

L. parvuius. Payk. Anf Pflanzen nicht selter.

L. upicalis. Beck. Auf Pflanzen (Gat. Gr.)

L. Holsaticus. L. Anf Wiesen selten (Stbl. Kod.)

I. Cynoglossi. Marsh. Auf Pflanzèn selten (Br.)

L. luvidus. Scop. Anf Wiesen häufig.

L. Brunneus. Redt. Auf Gräsern (Gat.)

L. Nastmeri. Fubr. Auf feuchten Wiesen (Gr. Gat.)

I. Terbasci. Pan:. Auf Verbascum häufig.

L. melanoceplealus. Redt. Auf Gartenreseda häufig (Kod.)

L. Sisymbrii. Fabr. Auf Wiesen (Gr.)

L. pratensis. All. Auf Wiesen (Gl. Gat.)

L. tabirtus. Fabr. Auf Wiesen häufig.

L. ochrolencus. Marsh. Auf Wiesen um St. Leonhard (Sp.)

\section{Plectroscelis. Redt.}

P. semicoerulea. Ent. Hy't. Auf Wiesen nicht selten.

P. concinna. Marsh. Auf Wiesen nicht selten.

P. meridionalis. Fondr. Auf Wiesen um St. Leonhard (Sp.)

P. rividellu. Payk. Anf Wiesen häufig.

P. Salubergii. Gyll. Auf Wiesen (Gat.)

P. aridula. Gyll. Anf Wiesen (Gat.)

\section{Psylliodes. Latr.}

P. Dulcanearce. Ent. Hft. Auf Wiesen selten (Gat.)

P. chalcomerus. Ill. Um St. Leonhard auf Wiesen (Sp.)

P. Hyoscyrmi. L. An Gemiise häufig (Kod.)

$P$. chrysocephalus. I. Auf Wiesen häufig.

P. instabilis. Foudr. Auf Wiesen selten (Gat.)

I'. attemiatus. Ent. Hft. Auf Wiesen (Br. Kod.)

P. Trapi. Ent. Hft. Aut Pflanzen (Br. Sp.)

P. glaber. Duft. Auf Alpenwiesen nicht häufig (Gat.). 


\section{Dibolia. Latr.}

D. femoralis. Redt. Auf Salvia pratensis um Graz nicht selten. D. Cynoglossi. Ent. Hft. Auf Grasplätzen (Gr.)

\section{Apteropeda. Redt.}

A. globosa. Ill. Auf Alpenwiesen selten (Sp, Gat.)

A. graminis, Ent. Hft. Auf Grasplätzen selten.

Hypnophila. Foudr.

H. obesa. Waltl. Auf Alpen unter Moos häufig.

H. impuncticollis. All. Mit der Vorigen.

\section{Miniophila. Steph.}

M. muscorum. Ent. Hft. Auf Alpen unter Moos sehr häufig.

\section{Sphaeroderma. Steph.}

Sph. testaceum. Fabr. In Gärten um St. Lambrecht selten (Kod.) Sph. Cardui. Gyll. Auf Disteln selten (Gat.)

\section{Argopus. Fisch.}

A. hemisphaericus. Duft. Auf trockenen Grasplätzen selten (Gat. Sp.)

\section{Hispa. Linn.}

H. atra. L. Auf sandigen Grasplätzen nicht selten. v. aptera. L. (Gr.)

\section{Cassida. Limn.}

C. murraca. $L$. Auf Pflanzen (Gro)

C. denticollis. Suffr. Auf Wiesen selten (Br. Kod.)

C. vubiginosa. Ill. Auf Disteln nicht selten.

C. thoracica. Kug. Auf Wiesen selten bei Graz (Drnbk.), hälfiger bei Fiirstenfeld (Kahr.)

C. vibex. I. Auf Wiesen nicht selten.

C. stigmatica. Suffr.? Un St. Lambrecht 1 Ex. (Kod.)

C. sanguinolenta. Fabr. Auf Wiesen nicht selten.

C. lucida. Suff. Auf Wiesen um St. Leonhard selten (Sp.)

C. oblonga. Ill. Auf Wiesen (Gat.)

C. nobilis. $L$, Auf Wiesen nicht selten.

C. nargaritacea. Schall. C. Auf Wiesen nicht selten.

C. subreticulata. Suffr. Auf Wiesen selten (Stbl. Gat.)

C. lineola. Creutz. Auf Wiesen $11 \mathrm{~m}$ St. Leonhard selten (Sp.), häufiger um Cilli (Ltgb.)

C. nebulosa. L. Auf Disteln häufig.

C. ferruginea. Fabr. Auf Fflanzen häufig.

C. obsoleta. Ill. Auf Wiesen selten (Sp. Gat.)

C. atrata. Fabr. Auf Wiesen selten und einzeln.

C. equestris. Fabr. Auf Disteln, auf Wiesen.

C. haemisphaerica. Hobst. Auf Wiesen nicht selten. 


\section{$-111-$ \\ Erotylidae.}

Engis. Fabr.

E. sanguinicollis. Fabr. Unter morscher Rinde selten (Kod.)

E. humeralis. Fubr. Unter Rinden, an Bamnschwämmen.

E. rufifrons. Fabr. Wie die Vorige, seltener.

E. bipustuiata. Fabr. An Baumschwämmen selten.

Triplax. Payk.

T. Russica. L. Unter morscher Rinde, an Baumschwämmen.

T. aenea. Payk. Wie die Vorige.

T. collaris. Schall. Wie die Vorigen, selten (Sp. Gat.)

T. bicolor. Marsh. An faulen Zäunen um St. Leonhard (Sp.)

T. rufipes. Fabr. An Baumschwämmen selten (Gat. Sp.)

T. styriaca. $K r$. Von Spitzy um St. Leonhard auf morschen Zäunen entdeckt.

Tritoma. Fabr.

T. bipustulata. Fabr. Unter morscher Rinde, an Baumschwämmen.

\section{End om y c hidae.}

Dopsa. Latr.

D. trimaculata. Motsch. Unter Laub bei St. Leonhard 1 Ex. (Sp.)

Lycoperdina. Latr.

L. succincta. L. In Bovisten häufig.

Mycetina. Huls.

M. cruciata. Schall. Unter morscher Rinde nicht häufig.

Eudomychus. Panz.

$E$. coccineus. L. Unter morscher Rinde nicht häufig.

Leiestes. Redt.

L. seminigra. Gyll. Unter morscher Rinde um St. Leonhard sehr selten (Sp.)

\section{Symbiotes. Redt.}

S. pygmaeus. Hampe. Unter Moos in der Nähe von Ameisen selten (Br.)

Mycetaea. Steph.

M. hirta. Marsh. In Kellern, unter dumpfen Moose. 


\section{Coccinellidae.}

Hippodamia. Muls.

H. 1:-punctuta. L. Auf Gesträuch lıäufig.

H. T-maculata. de Geer. Wie die Vorig'e.

\section{Coccinella. Liin.}

C. 19-punctata. L. Auf Gesträuch häufig.

C. mutabilis. Scrib. Auf Gesträuch nicht selten.

C. obiiterata. L. Auf Gesträuch nicht selten.

c. Bothnica. Payk. Auf Geträuch selten (Gat.)

C. bipunctata. L. Auf Gesträuch häufig.

C. alpina. Muls. Auf der Laa-Alpe (Gat.), Hoch-Lautsch (Tpk.)

C. 11-notata. Schneir. Auf Gesträuch häufig.

C. marginepunctata. Schll. Auf Gesträuch selten (Br.)

C. impustulata. L. Auf Gestränch häufig.

C. 14-pustulata. L. Auf Gesträuch.

C. variabilis. Ill. Auf Gesträuch häufig.

C. 11-punctata. L. Auf Gesträuch (Gr.)

C. hieroglyphica. L. A uf Gesträuch (Gat Kud.)

C. 5-punctata. L. Auf Gesträuch häufig.

C. 7-punctata. L. Anf Gesträuch sehr häufig.

C. magnifica. Redt. Auf Gesträuch selten (Gr.)

\section{Halyzia. Muls.}

H. ocellata. L. Auf Gesträuch nicht selten.

H. oblongorzuttata. L. Auf Gesträuch nicht selten.

H. tigrina. I. Auf Gesträuch nicht selten.

v. 20-guttata. L. Auf Gestränch selten (Br.)

H. 18-guttata. L. Auf Gestråuch häufig.

H. 14-guttata. L. Auf Gestränch hänfig.

H. 10-gettata. L. Um St. Leonhard (Sp.)

H. bisseptem-guttata. Schall. Auf Gesträuch (Gr.)

H. 16-guttata. L. Auf Gesträuch nicht selten.

H. 22-punctata. L. Auf Gesträuch häufig.

H. 14-punctata. L. Auf Gesträuch (Drnbk.)

H. conglobata. L. Auf Gesträuch (Gr. Kod.)

Misraspis. Redt.

M. 12-punctata. L. Auf Gesträuch häufig.

Chilocorus. Leach.

Ch. renipustulatus. Scrib. Auf Gesträuch hänfig.

Ch. bipustulatus. L. Wie die Vorigen.

Exochomus. Redt.

E. auritus. Scrib. Auf Gesträuch nicht häıfig.

E. 4-pustulatus. L. Wie der Vorige. 


\section{Hyperaspis. Redt.}

H. 4-macrilata. Redt. Auf Gesträuch selten (Br.)

H. campestris, Hrbst. Auf Gesträuch selten (Gat. Kod.)

H. Reppensis. Hrbst. Auf Gesträuch nicht selten.

\section{Epilachna. Chev.}

E. globosa. Schneid. Auf. Gras und Gebuisch häufig.

E. impunctatc. L. A uf Wiesen nicht selten.

Platynaspis. Redt.

P. villosa. Fourc. Auf Gesträuch häufig.

Seymutus. Kug.

Sc. 4-lunvlatus. Ill. Auf Gesträuch und Blüthen nicht häufig.

Sc. Redtenbacheri. Muls. Auf Gesträuch um Admont (Stbl.

Sc. biverrucatus. Panz. Auf Gesträuch (Gr. Gat.)

Sc. nigrinus. Kug. Auf Gesträuch häufig.

Sc. pygmaeus. Foure. Auf Gesträuch (Gat.)

Sc. marginalis. Rossi. Auf Gesträuch häufig.

Sc. frontalis. Fabr. Auf Gesträuch nicht selten.

Sc. Abietis, Payk. Auf Nadelbäumen sehr häufig.

Sc, fasciatus. Fourc. Auf Gesträuch selten (Gat.)

Sc. arcuatus. Rossi. Auf Gesträuch selten (Gat.)

Sc, discoideus. Ill. Auf Gestränch nicht selten.

Sc. analis. Fabr. A uf Gesträuch nicht selten.

Sc. haemorrhoidalis. Hrbst. Auf Gestränch nicht selten.

Sc. capitatus. Fabr. Auf Gestränch nicht hänfig.

Sc. ater. Kug. Auf Gesträuch häufig.

Sc, minimus. Payk, Auf Gesträuch häufig.

星hizobins. Steph.

Rh. litura. Fabr. Auf Nadelbäumen selten (Gat. Br.)

\section{Coccidula. Kug.}

C. scutellata. Hrbst. Auf Wasserpflanzen häulig.

O. rufa. Hrbst. Wie die Vnrige.

Lithophilus. Fröh!.

L. connatus. Fabr. Auf trockenen Grasplätzen um Marburg (Sp.)

Alexia. Steph.

A. globosa. Sturm. Unter Laub häufig.

A. pilifera. Müll. Wie die Vorige.

A. pilosa. Panz. Wie die Vorigen.

\section{Corylophidae.}

Sacium. Le Conte.

S. pusillum. Gyll. Unter Lanb, auf Blïthen selten. 


\section{Arthrolips. Woll.}

A. obscurus. Sahlb. Unter Laub selten (Gr. Gat.)

Sericoderus. Steph.

S. lateralis. Gyll. Unter Laub selten (Gat. Br.)

Corylophus. Steph.

C. cassidoides. Marsh. Unter Laub selten (Br. Gat.)

Orthoperus. Steph.

O. brunnipes. Gyll. Unter Laub selten (Gat.)

Moronillus. Duvar.

M. ruficollis. Duv. Unter Laub selten (Gat.)

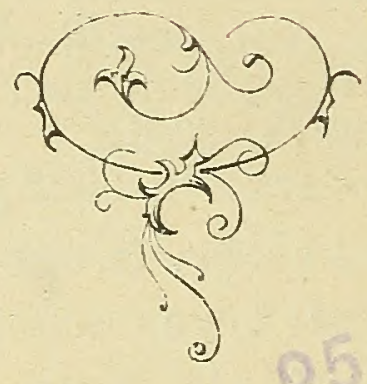



